\title{
On the use of food supplements
}

Citation for published version (APA):

Vrolijk, M. F. (2017). On the use of food supplements: potential adverse effects. [Doctoral Thesis, Maastricht University]. Maastricht University. https://doi.org/10.26481/dis.20170614mv

Document status and date:

Published: 01/01/2017

DOI:

10.26481/dis.20170614mv

Document Version:

Publisher's PDF, also known as Version of record

\section{Please check the document version of this publication:}

- A submitted manuscript is the version of the article upon submission and before peer-review. There can be important differences between the submitted version and the official published version of record.

People interested in the research are advised to contact the author for the final version of the publication, or visit the DOI to the publisher's website.

- The final author version and the galley proof are versions of the publication after peer review.

- The final published version features the final layout of the paper including the volume, issue and page numbers.

Link to publication

\footnotetext{
General rights rights.

- You may freely distribute the URL identifying the publication in the public portal. please follow below link for the End User Agreement:

www.umlib.nl/taverne-license

Take down policy

If you believe that this document breaches copyright please contact us at:

repository@maastrichtuniversity.nl

providing details and we will investigate your claim.
}

Copyright and moral rights for the publications made accessible in the public portal are retained by the authors and/or other copyright owners and it is a condition of accessing publications that users recognise and abide by the legal requirements associated with these

- Users may download and print one copy of any publication from the public portal for the purpose of private study or research.

- You may not further distribute the material or use it for any profit-making activity or commercial gain

If the publication is distributed under the terms of Article $25 \mathrm{fa}$ of the Dutch Copyright Act, indicated by the "Taverne" license above, 


\section{On the use of food supplements: Potential adverse effects}

Misha Vrolijk 
On the use of food supplements:

Potential adverse effects

Thesis, Maastricht University, Maastricht, The Netherlands

Layout: $\quad$ Misha Vrolijk

Cover design: Misha Vrolijk

Printed by: $\quad$ Gildeprint - Enschede

ISBN: $\quad$ 978-94-6233-617-9

(C) Misha F. Vrolijk, 2017

The research described in this thesis was conducted at NUTRIM School of Nutrition and Translational Research in Metabolism of Maastricht University, National Institute for Public Health and the Environment (RIVM) and the Netherlands Food and Consumer Product Safety Authority (NVWA). 


\title{
On the use of food supplements: Potential adverse effects
}

\author{
PROEFSCHRIFT \\ ter verkrijging van de graad van doctor aan de Universiteit Maastricht, \\ op gezag van de Rector Magnificus, Prof. Dr. Rianne M. Letschert \\ volgens het besluit van het College van Decanen, \\ in het openbaar te verdedigen \\ op woensdag 14 juni 2017 om 16.00 uur
} door

Misha François Vrolijk

geboren te Maastricht op 10 Oktober 1989 


\section{Promotores}

Prof. dr. A. Bast

Prof. dr. A. Opperhuizen

Prof. dr. G.R.M.M. Haenen

\section{Co-promotor}

Dr. E. H. J. M. Jansen (RIVM, Bilthoven)

\section{Beoordelingscommissie}

Prof. dr. T.M. Hackeng (voorzitter)

Prof.dr.ir. I.C.W. Arts

Prof. dr. P.W. de Leeuw

Dr. H. Deluyker (European Food Safety Authority)

Prof. dr. R. Witkamp (Universiteit Wageningen) 


\section{Contents}

$\begin{array}{lll}\text { Chapter } 1 & \text { General Introduction } & 7\end{array}$

Chapter 2 The shifting perception on antioxidants: the case of vitamin E 37 and $\beta$-carotene

Chapter 3 The supplement-drug interaction of quercetin with tamsulosin 53 on vasorelaxation

Chapter $4 \quad$ Anticholinergic accumulation: a slumbering interaction between 71 drugs and food supplements

Chapter 5 Iron supplements and magnesium peroxide: an example of a hazardous combination in self-medication

Chapter 6 The Vitamin B6 Paradox: Supplementation of high concentrations of Pyridoxine leads to decreased vitamin B6 function

Chapter 7 General Discussion

Chapter 8 Summary

Samenvatting

Valorisatie addendum

Dankwoord

153

Curriculum Vitae 159

List of publications 



\section{Chapter 1}

General introduction 


\section{Food toxicology}

Toxicology is one of the oldest practical sciences [1]. From the very beginning, animals including humans needed to recognize and avoid eating the various toxic plants and animals in their environment to survive. Evaluation of potential risks and benefits of food, such as berries, nuts and water sources, was of critical importance. The assessment of any potential risk of particular foods was carried out by trial and error. Foods were selected or rejected based on observation (if foods were avoided by other animals) in combination with trial and error (if eating a particular food component made people sick or not). Nutritional toxicology is essential for health and well-being since the dawn of man.

\section{Nutrition and Medicines}

In the past, nutrition was also used in treating diseases and staying healthy. There was no fundamental difference between nutrition and medicine. Already in 500 BC, Hippocrates stated: 'Let food be your medicine and let medicine be your food'[2]. The ancient Greek considered food as one of the three categories of medicines. Also in other traditional medicinal systems, such as Ayurveda and Traditional Chinese Medicines, food is used in healthcare $[3,4]$.

In contrast to these traditional medicinal systems, in which nutrition and medicines overlap, the two fields of nutrition and pharmacology developed separately in the Western world $[2,5]$. Nutrition developed as a 'tool' to provide sufficient energy, proteins and (micro)nutrients and to prevent deficiencies [6]. Pharmacology had developed into a field in which medicines were primarily used to cure diseases by repairing or improving body functions. This was based on the one disease-one target concept; a single natural or synthetically compound had to act on a specific target. During the last decades, the gap between the two fields of nutrition and medicines is narrowing again. The use of nutrition in optimizing a good health became more important and it became clear that diseases could not always be treated by using a single drug for only one target. It was again realized that nutrition and medicine overlap and that nutrition and pharmacology can benefit from each other.

Nutrition is not only important for providing energy and nutrients, it can also be used to improve health and treat diseases. This has resulted in the development of new bioactive compounds that can influence health or a diseased status. Different nutritional product categories have evolved which have a specific health claim beyond providing sufficient nutrients. The most prominent examples are food supplements. Currently, countless of food supplements are available on the market, all of which claim to be healthy or to improve health. The use of food supplements has enormously increased over the past years. People take food supplements often assuming that this only has benefits and is without risks. This is of course a fallacy as any compound, including water can be toxic.

The importance of accurately assessing the risks can be exemplified by the herbal supplement containing Kava Kava, an herb derived from the roots of the plant Piper methysticum. Kava Kava has been used for many years as a recreational and ceremonial 
drink in Oceania. More recently it is used in concentrated forms in herbal supplements to treat anxiety and insomnia[7, 8]. However, in assessing the safety of these kava products, it appeared that in the applied dose Kava Kava may induce liver injury that even can be lethal [9-11]. For this reason, the use of Kava Kava has been banned or restricted in many countries of the world such as the Netherlands, Germany, Switzerland, France, Canada, and Great Britain. Apparently, food toxicology is still mandatory in order to protect consumers, as it was during the dawn of man.

\section{Ageing population}

The world population is rapidly ageing [12]. In the first five decades of the $21^{\text {st }}$ century, the world population over 60 years is estimated to be doubled to $22 \%$ of all people [13]. The absolute number of elderly is expected to increase to 2 billion. Also in the Netherlands, the population is rapidly ageing [14]. This is attributable to a decreased birth rate, but more importantly to an increased life expectancy. The average life expectancy of a 65-year old person in 2010 was 17.6 years for males and 20.8 years for females [15]. In 2050 this expectancy will increase to 21.1 years for males and to 23.6 years for females. Approximately $75 \%$ of all deaths among men and $85 \%$ of all deaths among women take place after the age of 65 [15]. This is mainly due to improved hygiene, the progress in health care and the increase in economic welfare. Consequently, the age composition of the Dutch population has changed over the years, as shown in figure 1. In 2000, 24.000 men and 42.000 women had an age of 80 years. The prognosis is that these numbers will increase to 94.000 men and 99.000 women in 2050. The total number of people over the age of 65 in 2050 will be approximately 4.5 million, which will be $25 \%$ of the total Dutch population. Other European countries even have higher percentages of elderly people. In 2010, the percentage of elderly people in Germany and Italy were already approximately $20 \%$. A main consequence of an ageing population is that the need for medical and social care increases.

\section{Free radical theory of ageing}

'Ageing' can be defined as 'processes in an organism that increase the mortality risk as a function of time'[16]. In the early 90s, it was proposed that the longevity of an organism was inversely correlated to its metabolic rate: increasing an organism's metabolic rate would decrease longevity. However, it was observed that birds, which have a much higher metabolic rate than mammals, lived much longer. Despite their high rate of oxygen consumption, birds appeared to have a much lower rate of reactive oxygen species (ROS) production. It was concluded that the rate of ROS production was more important than the metabolic rate regarding longevity. The mechanistic basis of ageing was then proposed in the 'free radical theory of ageing'[17]. Ageing and ageing-related diseases are assumed to be the consequence of free radical-induced damage to cellular molecules and the failure to counterbalance these effects by endogenous antioxidant systems [18]. Free radicals are molecules which possess an unpaired electron, and are therefore highly reactive and can react with and damage other molecules such as proteins [19]. In aerobic life forms, many free radicals are oxygen radicals, and the term ROS is often used in combination with the 
term free radical, although they do not completely overlap. For example, the ROS hydrogen peroxide is not a radical, but it can give rise to radical formation via the Fenton reaction.

Besides hydrogen peroxide, superoxide radical and hydroxyl radical are the most wellknown ROS [20]. ROS are either generated exogenously or produced intracellularly from several sources [21]. The family of NADPH oxidases is one of such intracellular source of ROS. However, the majority of intracellular ROS is produced by the mitochondria, mainly via complex I (NADH dehydrogenase) and complex III (ubiquinone-cytochrome c reductase) of the electron transport chain [22]. ROS are furthermore generated by xanthine oxidase, cytochrome P450, nitric oxide synthase and myeloperoxidase. Additionally, a number of exogenous agents can stimulate ROS production, such as ultraviolet light, ionizing radiation and chemotherapeutics. ROS-mediated damage of nucleic acids, proteins, and lipids, and has been implicated in carcinogenesis, neurodegeneration, atherosclerosis, diabetes, and as previously described, ageing [23].

\section{Antioxidant protection}

Regarding the harmful effects of ROS, one important protective mechanism that counteracts ROS production exists. This is the antioxidant system that includes the enzymatic scavengers (SOD, catalase and glutathione peroxidase) and the non-enzymatic antioxidants (such as $\beta$-carotene, vitamin C, vitamin E, uric acid, flavonoids and glutathione)[24, 25]. The balance between ROS and antioxidants determines the level of oxidative stress [26]. Several studies have shown an increased level of ROS and oxidative damage in ageing cells and organisms [27]. Apparently, increased ROS levels accelerate ageing and age-related diseases. Understandably, the public interest for developing antiageing therapies is tremendous. Based on its role in ageing, the ability to prevent or battle oxidative damage is considered to be a key determinant in stimulating longevity. Enforcing the antioxidant systems via dietary supplementation would provide a good approach to decrease oxidative stress. Although many in vitro experiments and experiments in mammalian models support this, antioxidant therapy has had only little or no effect in enhancing longevity in man yet $[28,29]$. In order to optimize such approaches, a better understanding of the pharmacological properties of anti-oxidative agents is required. Further research is needed to unravel the process of ageing to come up with anti-ageing approaches that are effective in humans. 

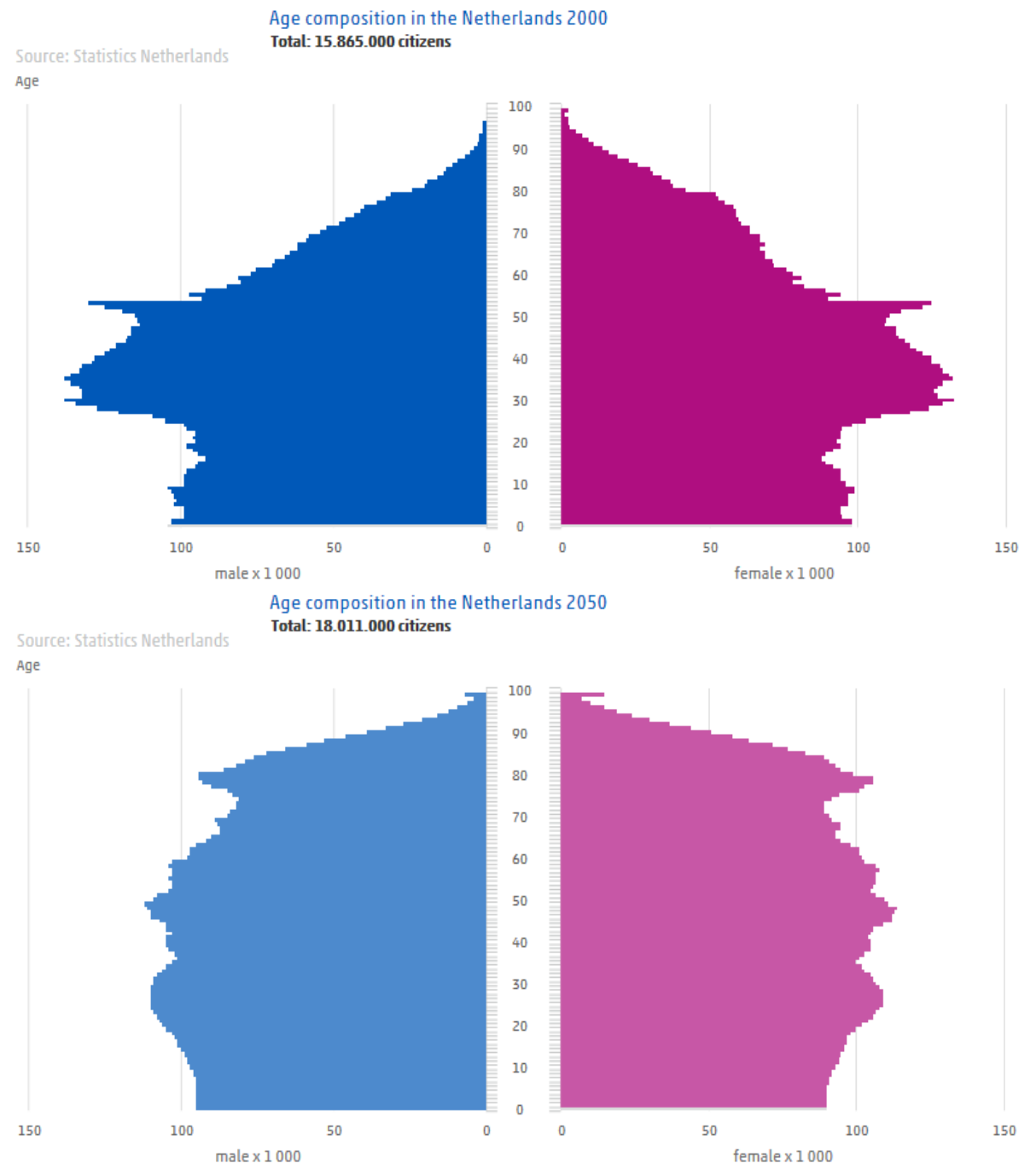

Figure 1| Age composition of the Dutch population in 2000 and the estimated age composition in 2050.

\section{Age-related physiological changes}

'Elderly' is the term for people having an age of 65 or more [30]. Because the physiological reserves of adults decline over the years, the impact of events that have a negative impact on the quality of life is higher in elderly. In general, the impact of ageing affects all physiological processes [16]. Progressive damage accumulates during life, ultimately leading to a decrease in function of organ systems, including the cardiovascular system, gastrointestinal system and neuroendocrine system. The decrease in function and the 
accompanying changes in pharmacokinetics and pharmacodynamics due to ageing increase the chance to develop diseases. Some important age-related changes are discussed.

\section{Cardiovascular system}

Ageing is associated with cardiovascular changes, such as a reduced elasticity of the great arteries [31]. These changes lead to a higher systolic arterial pressure, a decreased rate of myocardial relaxation and subsequently left ventricular hypertrophy. The left ventricle also becomes stiffer, leading to a decreased cardiac output [32]. Ageing is furthermore associated with a reduction in heart rate and an increased sinoatrial node conduction time [33]. Moreover, elderly people have a different response to postural changes compared to young people. The cardiac output is more efficiently maintained by increasing the heart rate in the young in contrast to elderly [16]. This may lead to orthostatic hypotension in elderly.

Furthermore, the prevalence of hypertension, which is the most important risk factor for vascular disease and death, is higher in older age groups [34]. Especially, the systolic blood pressure is elevated at old age. Approximately $50 \%$ of the people older than 65 is diagnosed with hypertension.

\section{Gastrointestinal system}

Ageing affects all organs of the gastrointestinal system. The main change is a decrease in the secretion of hydrochloric acid and pepsin in the stomach [35]. Moreover, heartburn is highly prevalent in the elderly population, since the band of muscle tissue which is essential for maintaining a pressure barrier against backflow of contents from the stomach weakens [36]. In the small intestine, ageing is accompanied by reduced absorption of nutrients such as sugars, calcium and iron [37]. This may contribute to the relatively high prevalence of malnutrition and iron deficiency in elderly.

\section{Central nervous system}

The central nervous system (CNS) is also influenced by ageing. In particular, the hypothalamic-pituitary-adrenal (HPA) axis is changed, which lead to changes in responses to psychological or physical stress [16]. The HPA axis is excessively activated, which together with hypersecretion of glucocorticoids, can lead to dendritic atrophy in neurons, for instance in the hippocampus. This results in learning and memory impairment in elderly.

More importantly, the Blood-Brain-Barrier (BBB) is deteriorated during ageing [38]. Brain endothelial cells and perivascular mural cells form the BBB die, which reduces the barrier for entering of neurotoxic compounds, pathogens, red blood cells and leucocytes into the brain [39]. Hence, ageing affects the BBB by increasing its permeability. Additionally, drugs or food supplements more easily enter the brain. Next to the increased permeability of the $\mathrm{BBB}$, the number of cholinergic neurons and receptors in the brains of elderly also decreases. This increases the chance of adverse side effects in the brains, such as anticholinergic side effects including cognitive impairment [40]. Many drugs display 
anticholinergic effects by blocking muscarinic receptors in our brain. Consequently, cholinergic neurotransmission is blocked. The anticholinergic side effect of a single compound is usually relatively mild. However, when several compounds are taken simultaneously, more receptors will be blocked, aggravating the impact. This is known as anticholinergic accumulation [41]. Anticholinergic accumulation results in complaints as confusion, delirium, dry mouth, headache, pain, anxiety and blurred vision.

\section{Urinary tract}

Ageing is accompanied by an enlargement of the prostate gland. Some of the prostate tissue is replaced by scar tissue. Enlargement of the prostate gland is also known also benign prostatic hyperplasia (BPH) [42]. BPH affects approximately $50 \%$ of the elderly men. $\mathrm{BPH}$ interferes with urination, by partly blocking the tube that drains the bladder. Elderly men that suffer from BPH therefore often have problems with urinating and ejaculation. Also urinary tract infections are common in elderly men.

\section{Pharmacokinetics and pharmacodynamics}

Ageing is accompanied by changes in body composition, exemplified by the reduction of total body water and lean body mass [43]. It is furthermore known to influence the pharmacokinetics (absorption, distribution, metabolism and elimination) of drugs [16]. Pharmacokinetic studies have shown that ageing is associated with a reduced absorption of nutrients such as vitamin $B_{12}$, iron and calcium [35]. The first-pass metabolism is also reduced by ageing, due to a reduction in liver mass and blood flow. Consequently, the bioavailability of drugs undergoing first-pass metabolism is significantly increased. For this reason, the activity of drugs that actually need to be converted into active metabolites in the liver might be reduced. As a result of the changes in total body water, water-soluble drugs have a smaller volume of distribution resulting in higher serum levels in older people [44]. Since ageing reduces renal function, the clearance of drugs and metabolites can be affected. As a consequence, drugs are more likely to accumulate, which gives more adverse effects [45].

Besides pharmacokinetic changes, also pharmacodynamic changes occur during ageing [30]. Pharmacodynamics refers to the pharmacological effect of a drug on the body, including adverse effects. Changes in pharmacodynamics during ageing will make elderly people more sensitive to the effects of drugs compared to younger patients. These add on the pharmacokinetic changes during ageing. The pharmacodynamic effects of drugs depend on several factors, such as the concentration of a particular drug at its receptor, the response it elicits on the receptor, post-receptor events and homeostatic mechanisms [38]. All these factors may be affected by ageing. An example of a pharmacodynamic change in elderly is the decreased effect of $\beta$-adrenergic agonists, which results in a decreased effectiveness of beta-blockers on heart rate and stroke volume [46]. Another adverse effect of drugs that has a greater chance to occur in elderly is orthostatic hypotension. Orthostatic hypotension is a sudden temporary decrease in blood pressure after standing up or stretching. The increased risk for orthostatic hypotension in elderly is due to decreased arterial compliance and baroreceptor response [47]. Hence, 
pharmacodynamic changes lead to an increased likelihood of adverse effects of drugs to happen among elderly, which might have serious consequences such as falls.

\section{Medicine use in elderly}

As mentioned earlier, the ageing process is accompanied by structural and functional changes affecting all organ systems and resulting in reduced homeostatic capacity. Elderly therefore often suffer from multiple diseases. To prevent or treat diseases, elderly people often receive a multitude of medicines. Numerous studies have shown that elderly are the largest group of consumers of medicines. Polypharmacy, which is defined as the simultaneous use of at least 3 drugs, is also very common among elderly [48]. The use of multiple drugs at once not only causes a higher risk of toxic reactions and adverse effects, it may also lead to unwanted interactions between these drugs, aggravating side effects instead of improving the quality of life of the elderly. Polypharmacy is identified as one of the most important risk factors for hospitalization. In 2013, the Dutch National Institute for Health and Innovations reported that approximately $45 \%$ of the elderly population was prescribed 5 or more different medicines [49]. Moreover, $20 \%$ of the population over 75 years was taking at least 10 different prescribed medicines.

Next to prescription medicines, self-medication, i.e. the use of over-the-counter (OTC) drugs, is on the rise. OTC drugs are medicines which can be bought without a prescription. A huge number of OTC drug products are currently available on the market. These drugs are defined as products that must be safe for consumers [50]. Most individuals assume that OTC drugs are safe and free from side effects. However, the use of OTC drugs even further increases the possibility for drug-drug interactions. Since 2005, the number of elderly at risk for major drug-drug interactions increased to approximately 1 in 6 older adults [51, 52].

\section{(Mal)nutrition in elderly}

Besides medication, nutrition is a major factor important for maintaining a good health, as previously highlighted. Food, including food supplements, is nowadays more and more used to treat diseases and to improve health. A main problem in elderly is malnutrition, which is defined as 'a state of nutrition in which a deficiency, or excess, of energy, protein and micronutrients causes measurable adverse effects on tissue/body form (body shape, size and composition) and function, and clinical outcome' [13]. In $24 \%$ of elderly men and $47 \%$ of elderly women, malnutrition or an inadequate intake of one or more essential nutrients has been reported [53]. With the predicted increase in elderly people in the upcoming years, the percentage of malnourished people will also increase. In general, three main causes of malnutrition can be pointed out:

1) A low intake of nutrients, which may be caused by poor dietary habits, isolation, depression, dementia, medication or dental or chewing problems.

2) An increased demand of nutrients due to fever, infection or dementia.

3) A reduced uptake of nutrients due to an impaired absorption or diarrhea. 
Low levels of nutrients will result in a decline of functioning of the body. Malnutrition can affect every function and organ of the human body, such as bones, brains, cardiovascular system, immune function, lung function and muscle functioning. This explains the association of poor nutritional status with increased morbidity and mortality [54, 55].

An adequate nutrition is necessary for a good health. The nutritional status can be influenced by the intake of nutrients. Important aspects are the quantity and the accessibility to food, flavor and meal ambience. Additionally, the quality of nutrient intake is also important. This may be improved by dietetic advising, delivery of nutrient dense foods or nutritional supplementation. Supplementation improves the quantity and potentially also the quality of nutrient intake and can prevent or cure malnutrition. Supplementation of nutrients is commonly applied in (malnourished) elderly.

\section{Nutritional supplementation}

Dietary or nutritional supplements are intentional to provide nutrients that are not consumed in sufficient quantities. According to the United States Food and Drug Administration (FDA), a dietary supplement is defined as a product, which is not a pharmaceutical drug, a food additive, such as spices or preservatives, or conventional food, and which fulfills the following criteria [56]:

- It is intended to supplement a person's diet and not to replace a meal.

- It contains vitamins, minerals, fatty acids, fibers, herbs, amino acids or any substance that contributes to other food eaten. The product may also contain any metabolite, ingredient, extract or combination of these ingredients.

- It is labeled as a food supplement.

There are several types of dietary supplements: vitamins, minerals, herbals, amino acids, proteins, essential fatty acids and bodybuilding supplements, of which the vitamin and mineral supplements are used the most. The National Institute for Public Health and the Environment (RIVM) made an inventory on the vitamin and mineral supplements available on the Dutch market [57]. The inventory included supplements that were specifically promoted for the elderly population as well as vitamin or mineral supplements often taken by elderly. The vitamin and mineral content of these supplements were compared to the Recommend Dietary Allowance (RDA) of elderly people aged 51 to 70 years, as established by the Health Council of the Netherlands. Furthermore, the recommended daily dosages, as recommended by the manufacturer of the supplements, were calculated as a percentage of the RDA. Finally, the composition of the supplements was compared to the Tolerable Upper Intake Level (UL), which was set by the European Food Safety Authority (EFSA). Some supplements were available that exceed the RDA and sometimes even exceed the UL.

\section{Vitamins}

Vitamins are organic compounds that organisms require in a relatively low amount as essential nutrients [58]. Vitamins cannot be synthesized by man and must therefore be 
obtained from the diet. Vitamin supplementation is important in the treatment of deficiencies, but evidence is lacking for beneficial effects when used by those who are otherwise healthy [59]. The most used vitamin supplements are vitamin A, the B-vitamins, vitamin C, vitamin D and vitamin E.

Vitamin A supplements were found to have a very narrow therapeutic range, namely between a RDA of $1000 \mu \mathrm{g}$ and a UL of $3000 \mu \mathrm{g}$. Only a few vitamin A supplements are available on the market, of which the highest dose was $1557 \mu \mathrm{g} /$ day. In contrast, $\beta$ carotene, which is the precursor of vitamin A, can be found in supplements with doses up to $15 \mathrm{mg} /$ day.

The B-vitamins are often present in multi-vitamin supplements. In several (single) supplements, high dose levels of B-vitamins were found. The highest dose for the different $B$ vitamins were found to be much higher than the corresponding RDA, e.g. 55 times for vitamin $B_{1}, 67$ times for vitamin $B_{2}, 38$ times for vitamin $B_{3}, 50$ times for vitamin $B_{5}, 56$ times for vitamin $B_{6}, 16$ times for vitamin $B_{11}$ (folic acid) and even 357 times for vitamin $B_{12}$. More importantly, the UL for the B vitamins was only exceeded for vitamin $B_{6}$ (with $400 \%$ ) and folic acid (with 500\%). Most of the vitamin $B_{6}$ supplements range from 25-150 mg/day. The UL for vitamin $B_{6}$ was recently lowered by the EFSA from $100 \mathrm{mg} /$ day to $25 \mathrm{mg} /$ day. Most of the folic acid supplements were found to have a dose between 800 and 1000 $\mu \mathrm{g} /$ day. However, one supplement with a dose of $5000 \mu \mathrm{g} /$ day was found, which is five times higher than the UL of $1000 \mu \mathrm{g} /$ day. For vitamin $B_{12}$ no UL was set by the EFSA.

Vitamin $\mathrm{C}$ was found in high doses in several supplements. The highest dose was found to be $1500 \mathrm{mg} /$ day. No UL is established for vitamin C by the EFSA, since there were insufficient data available. However, even at concentrations of $1500 \mathrm{mg} / \mathrm{day}$, no adverse effects have been reported for humans.

An UL of $50 \mu \mathrm{g} /$ day was proposed by EFSA for vitamin D. Most of the vitamin D supplements had doses between $20-25 \mu \mathrm{g} /$ day. The highest dose was found to be 1000 $\mu \mathrm{g} / \mathrm{day}$.

Several vitamin E supplements have high doses, varying from 268 to $671 \mathrm{mg} /$ day. This is about 25-63 times the RDA for elderly people aged 50-71 years. The UL of vitamin E was set at $300 \mathrm{mg} /$ day. The highest dose found for vitamin E was $224 \%$ of its UL.

\section{Minerals}

Minerals comprise chemical elements required by humans, other than carbon, hydrogen, nitrogen and oxygen. Iron, zinc and selenium are the most common mineral supplements.

Iron was found in relatively high doses with the highest dose being 50 and $100 \mathrm{mg} / \mathrm{day}$. Most of the supplements contained 14-30 mg iron/day. No UL was set by the EFSA because of insufficient data, but supplemental intake of (non-heme) iron at $30 \mathrm{mg} /$ day or more was associated with high saturation of the iron storage, which is a risk factor for several chronic diseases. 
The UL of zinc is set at $25 \mathrm{mg} /$ day. This dose is exceeded by a number of supplements. The highest dose was found to be $400 \mathrm{mg} /$ day, which is 16 times higher than the UL.

Selenium has a narrow range between the RDA (150 $\mu \mathrm{g} /$ day) and the UL (300 $\mu \mathrm{g} /$ day). Only one supplement was found to exceed the UL, having a dose of $400 \mu \mathrm{g} / \mathrm{day}$.

\section{Herbals}

Herbal supplements contain plant-derived ingredients or components, which were used as medicine through human history before the development of synthetic drugs. Herbal supplements are still used in traditional medicinal systems. The World Health Organization (WHO) estimated that approximately $80 \%$ of the Asian and African population presently uses herbal products for primary health care [60]. In contrast to pharmaceuticals, which are often too expensive for these populations, herbal products are grown from seeds or gathered from nature for little cost.

The use of herbal products, which should be developed and tested according to the strict guidelines that are used in the Western science, is not strictly based on scientific evidence. Therefore herbal supplements are categorized in the Western society as a form of alternative medicine. Remarkably, according to the WHO $25 \%$ of the Western medicines contain compounds also found in herbs, such as opium, aspirin and quinine. Moreover, there is a revival of the use of herbal dietary supplements and they are increasingly used in the Western world. The use of these products is more prevalent in people suffering from chronic diseases, such as cancer, diabetes and asthma. Females and elderly tend to use herbal products relatively frequently.

Herbs can be processed in several ways. Traditionally, the herbs were mixed with boiling water and the resulting 'tea' was drunk. Nowadays, more and more herbals are produced in tablets or capsules. The most well-known herbal supplements in the Netherlands are Ginkgo Biloba and St. John's wort. Herbal supplements are most commonly used as selfmedication to promote heath. These supplements are widely available at many pharmacies, health food stores, and doctors' offices. However, there currently is a lack of conclusive scientific evidence for the beneficial health effects of herbal supplements. This does not necessarily mean that these supplements are unsafe, but that precise scientific investigation of these supplements has not been performed. Most herbal preparations have prominent effects on biochemical pathways. However, any substance in a large enough concentration will have a biochemical effect. Carefulness is necessary in testing these agents since essential details regarding extract type, concentration, and formulation are frequently not adhered to, thereby impeding safe and accurate application of the scientific method. Moreover, herbal supplements are often used in combination with prescribed medication, which may lead to unwanted interactions, affecting the effects of these drugs leading to potentially adverse health effects. In order to profit from herbal supplement use, more research is needed to make an accurate benefit-risk assessment. 


\section{Amino acids}

Amino acids are biologically important organic compounds containing an amine, carboxylic acid group and a side group that is specific for a particular amino acid. Three subclasses of amino acids are known: essential amino acids, non-essential amino acids and conditional amino acids. Essential amino acids cannot be produced by the human body and must be obtained via food. In contrast, non-essential amino acids can be produced by the human body. Conditional amino acids are only essential during illness or stress. Commonly used amino acid supplements are L-arginine and glutamine, both conditional amino acids.

\section{Essential fatty acids}

Essential fatty acids are fatty acids that humans cannot synthesize by themselves, but which are essential for a good health. Essential fatty acids must therefore also be obtained via food. Most used fatty acid supplements are omega-3 fish oil supplements

\section{Bodybuilding supplements}

These supplements are commonly used by athletics and bodybuilders. Bodybuilding supplements are often used to replace meals in order to enhance weight gain, improve performance or to promote weight loss. Most well-known body building supplements are creatine, branched-chain amino acids (BCAA) and glutamine. Bodybuilding supplement are often used in high doses with a high frequency. This could lead to adverse health effects. Accurate benefit-risk assessment is necessary to optimally benefit from bodybuilding supplements.

\section{Regulation of food supplements}

Current legislation on food supplements in the Netherlands is based on European legislation. The European directive 2002/46/EG on food supplements has recently been amended by Directive 1170/2009. This directive is included in the Dutch regulation on food supplements. These regulations mainly concern food supplements containing vitamins and minerals.

Food supplements containing vitamins and minerals can be put into the market without any permission, under the condition that the supplements only contain the vitamins and minerals that are present on appendices of the Food and Drug Act. Quantities of these vitamins and minerals not only have to be complementary to the normal diet, but they also have to be safe. The European Commission sets minimum and safe maximum levels. Maximum levels have to be set based on ULS.

In Europe, EFSA advices the European Commission on the different aspects of food safety. Specifically, EFSA gives advice on the ULs and Dietary Reference Values for vitamins and minerals. 
With respect to herbal supplements, there is no European regulation. In the Netherlands, herbal supplements can be put into market without any permission, as long as they do not contain harmful compounds. In general, the Netherlands Food and Consumer Product Safety Authority (NVWA) investigates and monitors the safety of food and consumer products, such as food supplements.

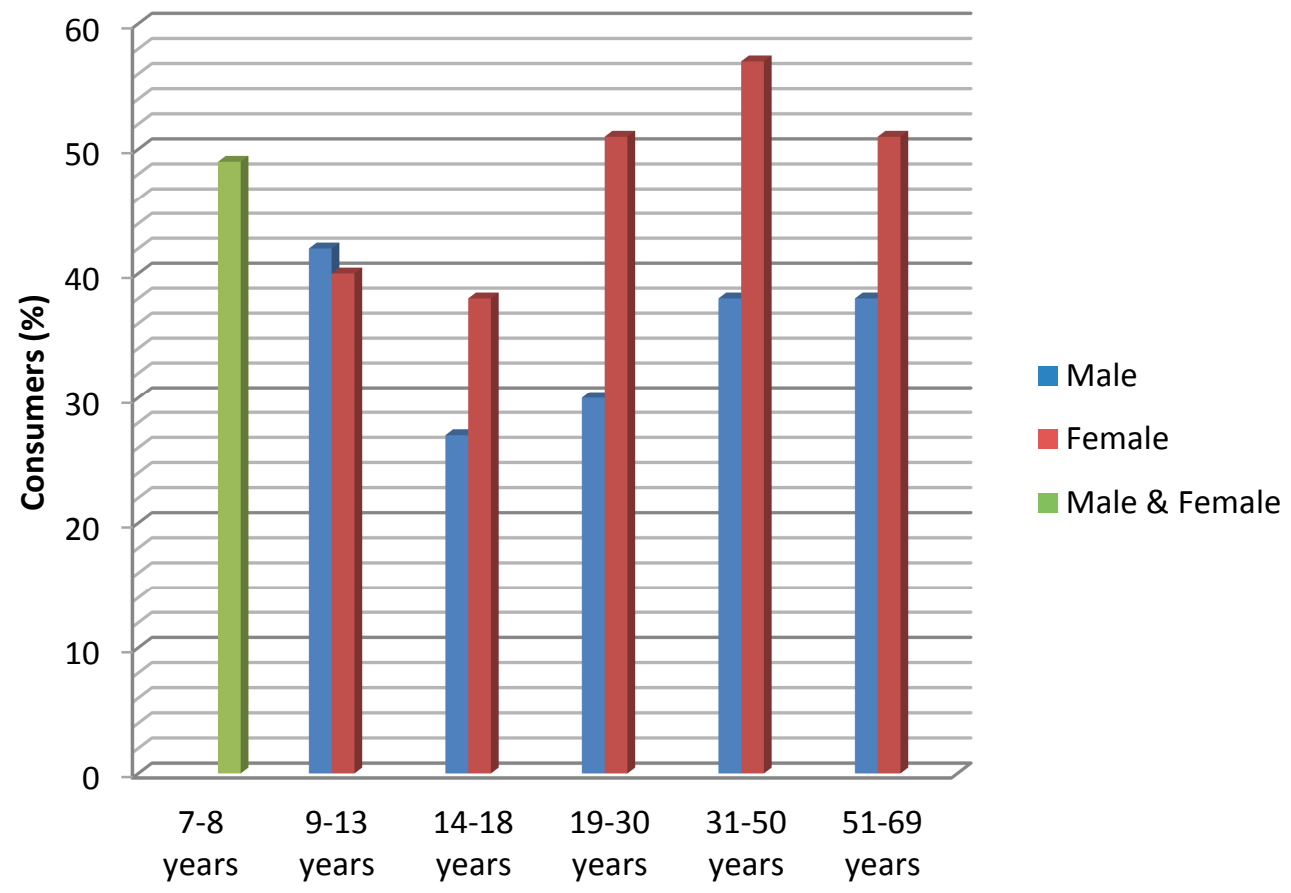

Figure 2 | Percentage dietary supplement users in the Dutch population aged 7 to 69 years (DNFCS 2007-2010), weighted for socio-demographic factors, season and day of the week ( $n=3,819)$. 


\section{Use of food supplements}

Over the past years, the use of food supplements is increasing. As part of the Dutch dietary monitoring system, the RIVM collected data on the food consumption of children and adults in the Netherlands between 2007 and 2010 [61]. 27-56\% of the Dutch population reported using one or more dietary supplements (figure 2). Supplement use was the highest during the winter compared to the rest of the year. The most frequently used supplements in all age groups were (multi)vitamins and minerals. Other often used food supplements were fish oil and the different vitamins. An inventory of the most used food supplements among the population is shown in figures 3 and 4 .

The European Prospective Investigation into Cancer and Nutrition (EPIC) study studied the use of dietary supplements in different countries in Europe [62]. The use of dietary supplements varied in frequency and type across countries. The mean frequency of supplement use was higher in the older age groups compared to the younger groups. It was furthermore shown that the use of supplements was the highest in those reporting moderate or poor health. These two findings could be linked to each other, since ageing is associated with a reduced health status.

Also in the USA, the use of food supplements is increasing [63]. Half of all adults (53\%) reported to use at least one food supplement, primarily in the form of multivitamins and minerals. A major part reported to use supplements on a daily basis. Moreover, $10 \%$ of the Americans were using more than 5 supplements daily. The use of supplements increased with advancing age. Approximately $70 \%$ of the adults over the age of 71 years reported to use dietary supplements. Remarkably, recent studies show that Americans are increasingly replacing prescription medication with dietary supplements.

Despite the increased use of dietary supplements, physicians are generally unaware of the use of these supplements. Additionally, patients do not inform their doctor on the use of supplements. This leads to incomplete information for a physician. Being unaware of the use of any food supplement, physicians may prescribe drugs that might have (adverse) interactions with these food supplements. 

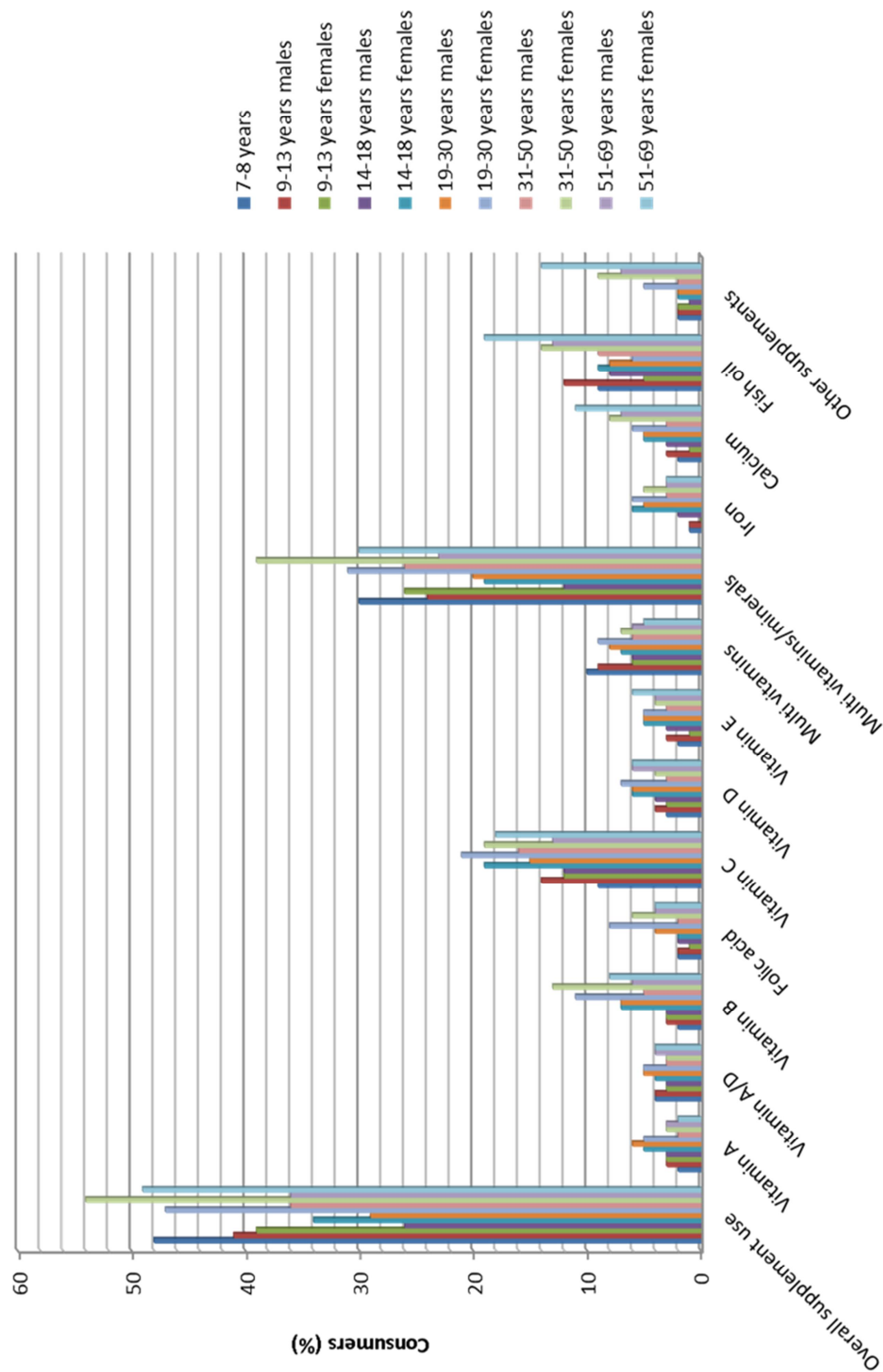

Figure 3 | Intake of the most used dietary supplements during the winter by the Dutch population aged from 7 to 69 years. Data are obtained from DNFCS 2007-2010 performed by the RIVM. 

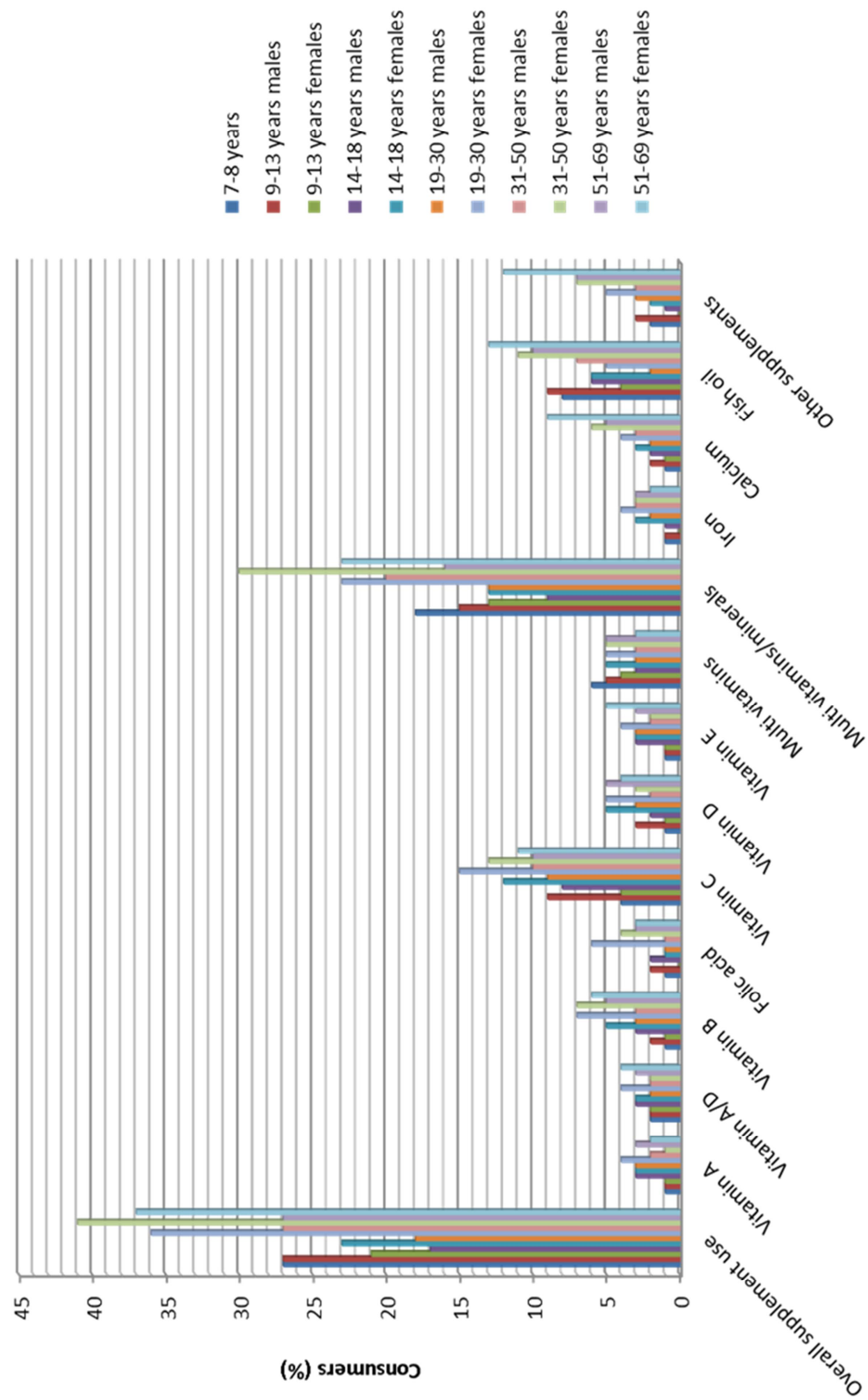

Figure 4 | Intake of the most used dietary supplements during the rest of the year by the Dutch population aged from 7 to 69 years. Data are obtained from DNFCS 2007-2010 performed by the RIVM 


\section{Perception on food supplements}

From 2007 to 2010, the National Health and Nutrition Examination Survey (NHANES) investigated the motivations for the use of dietary supplements in the USA [64]. Most common reasons for using these supplements were to improve overall health, to maintain health and to compensate for an unhealthy lifestyle. Other reasons were for a good bone health, organ-specific health reasons, getting more energy and a better mental health. Remarkably, only $22 \%$ of the users really used food supplements as a supplement to their diet. The enormous increase in food supplement use is based on the widespread believe that the products are healthy and that products of natural origin are safe [65]. Consumers assume that the quality of prescription and over-the-counter supplements is high. Generally, the consistency, purity and potency of these products are accepted without questioning. In 2007, a study among Americans of 60 years and older showed that approximately $66 \%$ of the responders mistakenly believed that herbal and dietary supplements are per se safe and pose no risk to the general public. Moreover, $70 \%$ falsely believed that these products were tested by the FDA and $60 \%$ incorrectly believed that these products were regulated by the FDA [65]. Additionally, 22\% of the responders stated that they believed it is not important to disclose the use of any supplement to their physicians.

Also in the Netherlands, the frequent use of food supplements is based on the presumption that they provide health benefits. In a survey, $61 \%$ of the responders assumed that the efficacy of these food supplements was proven sufficiently, and $48 \%$ regarded vitamin and mineral supplements as an easy tool to stay healthy [66].

\section{Adverse effects of supplements}

Although the general perception is that food supplements support (general) health, they may also induce harm. In conjunction with the increased use of food supplements, the number of adverse events, drug interactions and deaths involving these supplements is on the rise. Mostly, over-consumption, particularly of minerals and vitamins which accumulate in the body, is causing damage. Dietary supplements were implicated in approximately 23.000 emergency department visits and 2000 hospitalizations annually in the USA from 2004 to 2013 [67]. More than 12\% of these cases concerned older adults. Importantly, this reported number of emergency department visits related to food supplements induced adverse events is probably an underestimation. Supplement use by patients is often not reported and physicians do not associate adverse events with supplement use, in contrast to drugs. Next to over-consumption, interactions between supplements and drugs can also cause adverse events. Drug-food interactions give variability to effects and adverse effects of food supplements and drugs. For instance, a high intake of vitamin $K$ is known to counteract the effect of the drug warfarin [68]. Furthermore, grape juice has been shown to inhibit the metabolism of cyclosporine and non-selective monoamine oxidase inhibitors [69].

Physicians often lack knowledge about interactions of food supplements with other food supplements and medications. In the Netherlands, such data have not been recorded yet. 
Nowadays, The Netherlands Pharmacovigilance Centre Lareb collects and analyses reports of adverse reactions of food supplements, medicines and vaccines. The adverse reactions can be reported to Lareb by healthcare professionals, patients and also manufacturers. Among these adverse reactions, also potential interactions between food supplements and drugs are reported. All the reported complaints are collected into a database, which is used to write reports on adverse effects of drugs and food supplements. Lareb also sends these reports to the European Medicines Agency and the World Health Organization, helping monitoring the global food supplement and drug safety. Moreover, healthcare professionals are also informed.

\section{Types of interactions}

Two types of interactions between drugs and dietary supplements exist. Pharmacodynamic interactions occur when the activity of a drug is either augmented or inhibited by the intrinsic action of a food supplement. Pharmacokinetic interactions occur when the absorption, distribution, metabolism, or excretion of a drug is influenced by another food supplement. This leads to a change in pharmacologic activity of a drug. The most frequent pharmacokinetic interactions involve enzymes of the cytochrome P450 and Pglycoproteins. Due to the potentially harmful effects of these drug interactions, it is important to inform consumers, physicians and pharmacists of the possible risks involved. Due to the age-related changes in pharmacokinetics and pharmacodynamics, especially elderly are a vulnerable group for interactions between food supplements and drugs.

\section{Evidenced supplement-drug interactions}

Numerous interactions between food supplements and drugs are reported. The most wellknown example is the interaction between grapefruit juice and the enzyme CYP3A4, which is responsible for the metabolism of various drugs. Grapefruit juice inhibits this enzyme, resulting in changes in doses of drugs that are metabolized by this enzyme [70]. We have reviewed the literature to determine potential interactions between food supplements and drugs. Most cases of supplement-drug interactions were found for herbal supplements such as St. John's wort, Ginkgo biloba, garlic, and Ginseng. Some evidenced examples are being discussed below.

\section{St John's wort}

St. John's wort is a food supplement that is effective for depression [71]. When used in isolation, St. John's wort is relatively safe [72]. However, St. John's wort is able to effectively induce CYP enzymes and P-glycoproteins in the intestines. Therefore, numerous pharmacokinetic interactions with drugs may occur [73-76]. Many interactions of St John's wort with several drug types have been shown. The interaction between the immunosuppressant cyclosporine is the best documented [77-84]. This interaction leads to decreased plasma concentrations of cyclosporine in heart, renal and liver transplant patients when taking St John's wort. 
Numerous studies have shown that st. John's wort furthermore interacts with hormonal contraception [85-87]; cardiovascular drugs, including antiarrhythmic, antihypertensive, cardiotonic and anticoagulant drugs [88-94]; anti-cancer drugs [95-98]; drugs acting on central nervous system;[99-101]; respiratory drugs, hypoglycemic drugs, antimicrobials and drugs acting on the gastrointestinal drugs. These interactions include both pharmacokinetic and pharmacodynamic interactions. The pharmacokinetic interactions arise when St John's wort is combined with drugs that are metabolized by CYP3A4, CYP2E1 and CYP2C19 [102]. The pharmacodynamic interactions involve drugs that enhance serotonin signaling in the brain.

\section{Ginkgo Biloba}

Also for Ginkgo biloba several interactions have been identified. Ginkgo is mainly used for memory deficits and peripheral vascular disease. Ginkgo exerts its effects via antiplatelet activity, which is thought to be involved in causing bleeding after operations. The antiplatelet activity of Ginkgo increases the chance of interactions with drugs that affect platelet function and coagulation, such as warfarin and NSAIDs. Adverse events of ginkgo use have been reported with the concomitant use of aspirin, warfarin and ibuprofen, which led to spontaneous hyphemia, intracerebral hemorrhage and comatose state with intracerebral bleeding respectively [103-105]. Ginkgo is furthermore thought to affect CYP2C19 and CYP3A4 activity. It is therefore advised not to take ginkgo together with drugs that are substrates of these enzymes. One case is published on the interaction between the antidepressant trazodone and ginkgo, which led to a state of coma in an 80-year old woman [106].

\section{Garlic}

Garlic supplements are used for the treatment of hypercholesterolaemia and arteriosclerosis. Some case reports suggested that garlic supplements influence platelet function and blood coagulation [107]. Garlic supplements were furthermore reported to interact with warfarin and fluindione [108], although some trials did not find the interaction with warfarin. Other interactions are found in patients receiving the antiretroviral drugs saquinavir and ritonavir, the antidiabetic chlorpropamide and the analgesic paracetamol [109-111]. Moreover, garlic oil has been shown to inhibit CYP2E1 activity, which might lead to interactions with drugs that are metabolized by this P450 enzyme.

\section{Ginseng}

Ginseng supplements are used for a wide variety of indications, such as erectile dysfunction, cancer, and cognitive decline [112]. In elderly, the inhibition of CYP2D6 by ginseng has been reported [100]. Ginseng supplements have furthermore been shown to inhibit platelet aggregation [112]. Moreover, after taking ginseng together with the antidepressant phenelzine, one patient experienced insomnia, headaches and tremulousness [113]. Hence, also for ginseng supplements clinical evidence exists for potential adverse interactions with drugs. 


\section{Lareb: reported interactions between food supplements and drugs}

In the Netherlands, Lareb reported at least 55 reports on interactions between food supplements and drugs [114].Thirteen of these reports involved St John's wort. Furthermore, interactions with Ginkgo biloba were also reported. Inhibition of CYP3A4 by Ginkgo explains the interaction with the anti-viral agent efavirenz [115]. Next to interactions with herbal supplements, also several interactions were reported by Lareb concerning non-herbal supplements, such as glucosamine. Glucosamine was reported to have adverse interactions with vitamin $\mathrm{K}$ antagonists, antidiabetic and antiepileptic drugs [114].Also folic acid, vitamin B6 and multivitamin supplements induced adverse drug reactions to vitamin $\mathrm{K}$ antagonists. Moreover, multivitamin supplements also interacted with the anti-epileptic and anti-depressant drug levetiracetam. These are all examples of reported pharmacokinetic and pharmacodynamic interactions between food supplements and drugs. Again, the interactions that are currently reported to Lareb are expected to be an underreporting, since the use of food supplements is often unknown to a patient's health care professional. The perception of food supplements is that they are natural and safe. People therefore do not link any adverse events to the use of food supplements. However, adverse events due to interactions might have serious consequences. It is therefore important that healthcare professionals are aware of the use of food supplements and that consumers are informed about potential adverse effects of food supplements.

\section{Benefit-risk assessment}

The number as well as the use of over-the-counter and dietary supplements is greatly increasing, making it urgent to evaluate their health effect by making an accurate benefitrisk assessment [116]. It is common knowledge that a too low intake of (micro)nutrients has adverse health effects. It is not generally realized that (micro)nutrients will also have adverse health effects when the intake is too high. Therefore, strategies aimed at dietary supplementation should be carefully evaluated. The need for regulation of specific nutrients depends on the severity of their adverse health effects. In order to reduce the risk of excessive intake, ULS are set. The UL is defined as the maximum level of daily intake of a nutrient taken chronically, which is unlikely to pose a risk for adverse effects to the general population. This is not a recommended level of intake. ULs are derived for all groups of the general healthy population, including sensitive individuals. Ideally, a benefit-risk assessment should be performed for each individual. However, this is impossible. The UL is often set in such a way that even the most sensitive subjects are protected. An important factor that also needs to be considered is that the optimal intake of different population subgroups often differs. Therefore, groups that are at risk for a certain supplement as well as groups that would benefit of a certain supplement should be identified.

\section{Aims and outline of the thesis}

The use of self-medication, which includes food supplements and over-the-counter drugs, is still on the rise. Moreover, the variety in food supplements available on the market is also increasing. The general perception of food supplements is that they are safe and healthy. 
However, safety issues of food supplements are actually not well addressed yet. In this thesis we will further discuss the (health) effects of food supplements and unravel potential adverse effects of food supplements either combined with other food supplements or drugs or alone in specific population groups. Since elderly are a frail group of people vulnerable to the side effects of drugs and food supplements and the largest consumer group, we mainly focused on this population group. The research question that arose was whether food products, such as supplements, which are aimed to intervene with the process of ageing, could be damaging for this vulnerable population group?

In order to answer this research question, the following aims were set:

- Identify frequently used food supplements that may possibly have damaging effects.

- Identify potential interactions between food supplements and drugs that may have hazardous effects (in elderly).

\section{Outline of the thesis}

In chapter two we have evaluated the question if antioxidants should be considered as healthy or toxic by examining the presumed health effects of two individual antioxidants with opposite images i.e. the 'toxic' $\beta$-carotene and the 'healthy' vitamin $E$, we focused on one aspect, namely their role in inducing benzo(a)pyrene diolepoxide (BPDE)-DNA adducts.

In chapter three the pharmacodynamic interaction of quercetin with tamsulosin was investigated. The food supplement quercetin is used as self-medication for prostate disorders and is known to induce vasorelaxation. The drug tamsulosin is used in the treatment of benign prostatic hyperplasia. A major side effect of tamsulosin is orthostatic hypotension, mediated by vasorelaxation resulting from $\alpha_{1}$-adrenoceptor blockade. The vasorelaxation effects of tamsulosin and quercetin, combined and alone, were investigated in mesenteric arteries.

Many compounds display anticholinergic effects which might give rise to cognitive impairment and even delirium. These side effects are caused by their ability to bind to muscarinic receptors in our brain. Especially with combination of compounds, these effects are observed. This phenomenon, known as anticholinergic accumulation, is especially observed in elderly. In chapter four a number of food supplements have been screened for their ability to bind to muscarinic receptors.

In chapter five the effect of the combination of three different iron supplements with magnesium peroxide on reactive oxygen species formation was determined. Iron supplements and magnesium peroxide both produce adverse effects via the formation of ROS.

In chapter six the toxic effects of the different vitamers of vitamin $B_{6}$ are investigated. Since 2014, more than 50 cases of sensory neuronal pain due to vitamin $B_{6}$ supplementation were reported to Lareb. However, the mechanism of this toxicity and the contribution of 
the various $B_{6}$ vitamers to this toxicity are largely unknown. The neurotoxicity of the different forms of vitamin $B_{6}$ is tested on two different cell lines.

In chapter seven the results of the present thesis are discussed and placed in a broader scientific perspective. This is followed by a brief summary of the findings of this thesis in chapter eight. 


\section{References}

1. Hodgson, E., A Textbook o Modern Toxicology. Fourth edition ed. 2010. 672.

2. Georgiou, N.A., J. Garssen, and R.F. Witkamp, Pharma-nutrition interface: the gap is narrowing. Eur J Pharmacol, 2011. 651(1-3): p. 1-8.

3. Vaidya, A.D. and T.P. Devasagayam, Current status of herbal drugs in India: an overview. J Clin Biochem Nutr, 2007. 41(1): p. 1-11.

4. Fan, T.P., G. Deal, H.L. Koo, D. Rees, et al., Future development of global regulations of Chinese herbal products. J Ethnopharmacol, 2012. 140(3): p. 568-86.

5. Boersma, H. and L. Stolk, Innemen 2 uur voor of na een menu met spruitjes. Pharm. Weekbl, 1999(134): p. 1254-1259.

6. Afman, L. and M. Muller, Nutrigenomics: from molecular nutrition to prevention of disease. J Am Diet Assoc, 2006. 106(4): p. 569-76.

7. Boerner, R.J., H. Sommer, W. Berger, U. Kuhn, et al., Kava-Kava extract LI 150 is as effective as Opipramol and Buspirone in Generalised Anxiety Disorder--an 8-week randomized, double-blind multi-centre clinical trial in 129 out-patients. Phytomedicine, 2003. 10 Suppl 4: p. 38-49.

8. Wheatley, D., Kava and valerian in the treatment of stress-induced insomnia. Phytother Res, 2001. 15(6): p. 549-51.

9. Clouatre, D.L., Kava kava: examining new reports of toxicity. Toxicol Lett, 2004. 150(1): p. 85-96.

10. Fu, P.P., Q. Xia, L. Guo, H. Yu, et al., Toxicity of kava kava. J Environ Sci Health C Environ Carcinog Ecotoxicol Rev, 2008. 26(1): p. 89-112.

11. Wooltorton, E., Herbal kava: reports of liver toxicity. CMAJ, 2002. 166(6): p. 777.

12. Lutz, W., W. Sanderson, and S. Scherbov, The coming acceleration of global population ageing. Nature, 2008. 451(7179): p. 716-9.

13. Agarwal, E., M. Miller, A. Yaxley, and E. Isenring, Malnutrition in the elderly: a narrative review. Maturitas, 2013. 76(4): p. 296-302.

14. Zantinge, E.M., E.A. van der Wilk, S. van Wieren, and C.G. Schoemaker, Gezond ouder worden in Nederland. 2011, Rijksinstituut voor Volksgezondheid en Milieu (RIVM).

15. Van Duin, C. and J. Garssen, Bevolkingsprognose 2010-2060: sterke vergrijzing, langere levensduur. 2010, CBS: Den Haag/ Sittard.

16. Mangoni, A.A. and S.H. Jackson, Age-related changes in pharmacokinetics and pharmacodynamics: basic principles and practical applications. Br J Clin Pharmacol, 2004. 57(1): p. 6-14.

17. Harman, D., Aging: a theory based on free radical and radiation chemistry. J Gerontol, 1956. 11(3): p. 298-300.

18. Finkel, T. and N.J. Holbrook, Oxidants, oxidative stress and the biology of ageing. Nature, 2000. 408(6809): p. 239-47.

19. Boots, A.W., G.R. Haenen, and A. Bast, Health effects of quercetin: from antioxidant to nutraceutical. Eur J Pharmacol, 2008. 585(2-3): p. 325-37.

20. Papa, S. and V.P. Skulachev, Reactive oxygen species, mitochondria, apoptosis and aging. Mol Cell Biochem, 1997. 174(1-2): p. 305-19.

21. Bast, A. and G.R. Haenen, Ten misconceptions about antioxidants. Trends Pharmacol Sci, 2013. 34(8): p. 430-6.

22. Barja, G., Free radicals and aging. Trends Neurosci, 2004. 27(10): p. 595-600.

23. Wickens, A.P., Ageing and the free radical theory. Respir Physiol, 2001. 128(3): p. 379-91.

24. Vrolijk, M.F., A. Opperhuizen, E.H. Jansen, R.W. Godschalk, et al., The shifting perception on antioxidants: the case of vitamin E and beta-carotene. Redox Biol, 2015. 4: p. 272-8. 
25. Pisoschi, A.M. and A. Pop, The role of antioxidants in the chemistry of oxidative stress: A review. Eur J Med Chem, 2015. 97: p. 55-74.

26. Persson, T., B.O. Popescu, and A. Cedazo-Minguez, Oxidative stress in Alzheimer's disease: why did antioxidant therapy fail? Oxid Med Cell Longev, 2014. 2014: p. 427318.

27. Beckman, K.B. and B.N. Ames, The free radical theory of aging matures. Physiol Rev, 1998. 78(2): p. 547-81.

28. McCall, M.R. and B. Frei, Can antioxidant vitamins materially reduce oxidative damage in humans? Free Radic Biol Med, 1999. 26(7-8): p. 1034-53.

29. Yu, B.P., Approaches to anti-aging intervention: the promises and the uncertainties. Mech Ageing Dev, 1999. 111(2-3): p. 73-87.

30. Bowie, M.W. and P.W. Slattum, Pharmacodynamics in older adults: a review. Am J Geriatr Pharmacother, 2007. 5(3): p. 263-303.

31. Vaitkevicius, P.V., J.L. Fleg, J.H. Engel, F.C. O'Connor, et al., Effects of age and aerobic capacity on arterial stiffness in healthy adults. Circulation, 1993. 88(4 Pt 1): p. 1456-62.

32. Chen, C.H., M. Nakayama, E. Nevo, B.J. Fetics, et al., Coupled systolic-ventricular and vascular stiffening with age: implications for pressure regulation and cardiac reserve in the elderly. J Am Coll Cardiol, 1998. 32(5): p. 1221-7.

33. Jose, A.D. and D. Collison, The normal range and determinants of the intrinsic heart rate in man. Cardiovasc Res, 1970. 4(2): p. 160-7.

34. Vokonas, P.S., W.B. Kannel, and L.A. Cupples, Epidemiology and risk of hypertension in the elderly: the Framingham Study. J Hypertens Suppl, 1988. 6(1): p. S3-9.

35. Blechman, M.B. and A.M. Gelb, Aging and gastrointestinal physiology. Clin Geriatr Med, 1999. 15(3): p. 429-38.

36. El-Serag, H.B., S. Sweet, C.C. Winchester, and J. Dent, Update on the epidemiology of gastro-oesophageal reflux disease: a systematic review. Gut, 2014. 63(6): p. 871-80.

37. Webster, S.G. and J.T. Leeming, The appearance of the small bowel mucosa in old age. Age Ageing, 1975. 4(3): p. 168-74.

38. Midlov, P., Pharmacokinetics and pharmacodynamics in the elderly. OA Elderly Medicine, 2013. Aug(01;1(1);1).

39. Toornvliet, R., B.N. van Berckel, G. Luurtsema, M. Lubberink, et al., Effect of age on functional P-glycoprotein in the blood-brain barrier measured by use of (R)[(11)C]verapamil and positron emission tomography. Clin Pharmacol Ther, 2006. 79(6): p. 540-8.

40. Mate, K.E., K.P. Kerr, D. Pond, E.J. Williams, et al., Impact of multiple low-level anticholinergic medications on anticholinergic load of community-dwelling elderly with and without dementia. Drugs Aging, 2015. 32(2): p. 159-67.

41. Kalisch Ellett, L.M., N.L. Pratt, E.N. Ramsay, J.D. Barratt, et al., Multiple anticholinergic medication use and risk of hospital admission for confusion or dementia. J Am Geriatr Soc, 2014. 62(10): p. 1916-22.

42. Egan, K.B., The Epidemiology of Benign Prostatic Hyperplasia Associated with Lower Urinary Tract Symptoms: Prevalence and Incident Rates. Urol Clin North Am, 2016. 43(3): p. 289-97.

43. Anantharaju, A., A. Feller, and A. Chedid, Aging Liver. A review. Gerontology, 2002. 48(6): p. 343-53.

44. Graf, C.E., V.L. Karsegard, A. Spoerri, A.M. Makhlouf, et al., Body composition and all-cause mortality in subjects older than 65 y. Am J Clin Nutr, 2015. 101(4): p. 760-7.

45. Baldea, A.J., Effect of aging on renal function plus monitoring and support. Surg Clin North Am, 2015. 95(1): p. 71-83.

46. Turnheim, K., Drug dosage in the elderly. Is it rational? Drugs Aging, 1998. 13(5): p. 357-79. 
47. Phillips, P.A., G.P. Hodsman, and C.I. Johnston, Neuroendocrine mechanisms and cardiovascular homeostasis in the elderly. Cardiovasc Drugs Ther, 1991. 4 Suppl 6: p. 120913.

48. Hajjar, E.R., A.C. Cafiero, and J.T. Hanlon, Polypharmacy in elderly patients. Am J Geriatr Pharmacother, 2007. 5(4): p. 345-51.

49. Lemmens, L.W., M., Polyfarmacie bij kwetsbare ouderen : Inventarisatie van risico's en mogelijke interventiestrategieën. 2013, Rijksinstituut voor Volksgezondheid en Milieu (RIVM).

50. Rheinstein, P.H., Prescription to over-the-counter drug switches. Am Fam Physician, 1997. 56(4): p. 1211-4.

51. Budnitz, D.S., M.C. Lovegrove, N. Shehab, and C.L. Richards, Emergency hospitalizations for adverse drug events in older Americans. N Engl J Med, 2011. 365(21): p. 2002-12.

52. Qato, D.M., J. Wilder, L.P. Schumm, V. Gillet, et al., Changes in Prescription and Over-theCounter Medication and Dietary Supplement Use Among Older Adults in the United States, 2005 vs 2011. JAMA Intern Med, 2016. 176(4): p. 473-82.

53. de Groot, C.P., T. van den Broek, and W. van Staveren, Energy intake and micronutrient intake in elderly Europeans: seeking the minimum requirement in the SENECA study. Age Ageing, 1999. 28(5): p. 469-74.

54. Sullivan, D.H., G.A. Patch, R.C. Walls, and D.A. Lipschitz, Impact of nutrition status on morbidity and mortality in a select population of geriatric rehabilitation patients. Am J Clin Nutr, 1990. 51(5): p. 749-58.

55. Keller, H.H., Weight gain impacts morbidity and mortality in institutionalized older persons. J Am Geriatr Soc, 1995. 43(2): p. 165-9.

56. Committee on the Framework for Evaluating the Safety of Dietary Supplements, F.a.N.B., Board on Life Sciences, Institute of Medicine and National Research Council of the National Academies Dietary supplements a framework for evaluating safety. 2004, National Academies Press. : Washington, D.C. p. p. ES-1-ES-3. .

57. Jansen, E.H.J.M.K., A., Supplements for the elderly : An inventory of vitamins and minerals available for elderly in the Netherlands, RIVM, Editor. 2013.

58. Lieberman, S. and N. Bruning, The Real Vitamin and Mineral Book. Vol. 3. 1990, NY: Avery group.

59. Fortmann, S.P., B.U. Burda, C.A. Senger, J.S. Lin, et al., Vitamin and mineral supplements in the primary prevention of cardiovascular disease and cancer: An updated systematic evidence review for the U.S. Preventive Services Task Force. Ann Intern Med, 2013. 159(12): p. 824-34.

60. Atanasov, A.G., B. Waltenberger, E.M. Pferschy-Wenzig, T. Linder, et al., Discovery and resupply of pharmacologically active plant-derived natural products: A review. Biotechnol Adv, 2015. 33(8): p. 1582-614.

61. van Rossum, C.T.M.F., H.P.; Verkaik-Kloosterman, J.; Buurma-Rethans, E.J.M.; Ocké, M.C., Dutch National Food Consumption Survey 2007-2010, RIVM, Editor. 2011.

62. Skeie, G., T. Braaten, A. Hjartaker, M. Lentjes, et al., Use of dietary supplements in the European Prospective Investigation into Cancer and Nutrition calibration study. Eur J Clin Nutr, 2009. 63 Suppl 4: p. S226-38.

63. Bailey, R.L., J.J. Gahche, C.V. Lentino, J.T. Dwyer, et al., Dietary supplement use in the United States, 2003-2006. J Nutr, 2011. 141(2): p. 261-6.

64. Bailey, R.L., J.J. Gahche, P.E. Miller, P.R. Thomas, et al., Why US adults use dietary supplements. JAMA Intern Med, 2013. 173(5): p. 355-61.

65. Blendon, R.J., C.M. DesRoches, J.M. Benson, M. Brodie, et al., Americans' views on the use and regulation of dietary supplements. Arch Intern Med, 2001. 161(6): p. 805-10. 
66. de Jong, N., M.C. Ocke, H.A. Branderhorst, and R. Friele, Demographic and lifestyle characteristics of functional food consumers and dietary supplement users. Br J Nutr, 2003. 89(2): p. 273-81.

67. Geller, A.I., N. Shehab, N.J. Weidle, M.C. Lovegrove, et al., Emergency Department Visits for Adverse Events Related to Dietary Supplements. N Engl J Med, 2015. 373(16): p. 1531-40.

68. Wells, P.S., A.M. Holbrook, N.R. Crowther, and J. Hirsh, Interactions of warfarin with drugs and food. Ann Intern Med, 1994. 121(9): p. 676-83.

69. Amatori, F.M., V. Meucci, M. Giusiani, G. Soldani, et al., Effect of grapefruit juice on the pharmacokinetics of cyclosporine in dogs. Vet Rec, 2004. 154(6): p. 180-1.

70. Pirmohamed, M., Drug-grapefruit juice interactions: two mechanisms are clear but individual responses vary. BMJ, 2013. 346: p. f1.

71. Linde, K., M.M. Berner, and L. Kriston, St John's wort for major depression. Cochrane Database Syst Rev, 2008(4): p. CD000448.

72. Knuppel, L. and K. Linde, Adverse effects of St. John's Wort: a systematic review. J Clin Psychiatry, 2004. 65(11): p. 1470-9.

73. Di Carlo, G., F. Borrelli, E. Ernst, and A.A. Izzo, St John's wort: Prozac from the plant kingdom. Trends Pharmacol Sci, 2001. 22(6): p. 292-7.

74. Izzo, A.A., Drug interactions with St. John's Wort (Hypericum perforatum): a review of the clinical evidence. Int J Clin Pharmacol Ther, 2004. 42(3): p. 139-48.

75. Mannel, M., Drug interactions with St John's wort : mechanisms and clinical implications. Drug Saf, 2004. 27(11): p. 773-97.

76. Mills, E., V.M. Montori, P. Wu, K. Gallicano, et al., Interaction of St John's wort with conventional drugs: systematic review of clinical trials. BMJ, 2004. 329(7456): p. 27-30.

77. Breidenbach, T., M.W. Hoffmann, T. Becker, H. Schlitt, et al., Drug interaction of St John's wort with cyclosporin. Lancet, 2000. 355(9218): p. 1912.

78. Ruschitzka, F., P.J. Meier, M. Turina, T.F. Luscher, et al., Acute heart transplant rejection due to Saint John's wort. Lancet, 2000. 355(9203): p. 548-9.

79. Barone, G.W., B.J. Gurley, B.L. Ketel, M.L. Lightfoot, et al., Drug interaction between St. John's wort and cyclosporine. Ann Pharmacother, 2000. 34(9): p. 1013-6.

80. Mai, I., H. Kruger, K. Budde, A. Johne, et al., Hazardous pharmacokinetic interaction of Saint John's wort (Hypericum perforatum) with the immunosuppressant cyclosporin. Int J Clin Pharmacol Ther, 2000. 38(10): p. 500-2.

81. Karliova, M., U. Treichel, M. Malago, A. Frilling, et al., Interaction of Hypericum perforatum (St. John's wort) with cyclosporin A metabolism in a patient after liver transplantation. J Hepatol, 2000. 33(5): p. 853-5.

82. Turton-Weeks, S.M., G.W. Barone, B.J. Gurley, B.L. Ketel, et al., St John's wort: a hidden risk for transplant patients. Prog Transplant, 2001. 11(2): p. 116-20.

83. Beer, A.M. and T. Ostermann, [St. John's wort: interaction with cyclosporine increases risk of rejection for the kidney transplant and raises daily cost of medication]. Med Klin (Munich), 2001. 96(8): p. 480-3.

84. Alscher, D.M. and U. Klotz, Drug interaction of herbal tea containing St. John's wort with cyclosporine. Transpl Int, 2003. 16(7): p. 543-4.

85. Hall, S.D., Z. Wang, S.M. Huang, M.A. Hamman, et al., The interaction between St John's wort and an oral contraceptive. Clin Pharmacol Ther, 2003. 74(6): p. 525-35.

86. Pfrunder, A., M. Schiesser, S. Gerber, M. Haschke, et al., Interaction of St John's wort with low-dose oral contraceptive therapy: a randomized controlled trial. Br J Clin Pharmacol, 2003. 56(6): p. 683-90.

87. Murphy, P.A., S.E. Kern, F.Z. Stanczyk, and C.L. Westhoff, Interaction of St. John's Wort with oral contraceptives: effects on the pharmacokinetics of norethindrone and ethinyl estradiol, ovarian activity and breakthrough bleeding. Contraception, 2005. 71(6): p. 402-8. 
88. Izzo, A.A., G. Di Carlo, F. Borrelli, and E. Ernst, Cardiovascular pharmacotherapy and herbal medicines: the risk of drug interaction. Int J Cardiol, 2005. 98(1): p. 1-14.

89. Yue, Q.Y., C. Bergquist, and B. Gerden, Safety of St John's wort (Hypericum perforatum). Lancet, 2000. 355(9203): p. 576-7.

90. Jiang, X., K.M. Williams, W.S. Liauw, A.J. Ammit, et al., Effect of St John's wort and ginseng on the pharmacokinetics and pharmacodynamics of warfarin in healthy subjects. Br J Clin Pharmacol, 2004. 57(5): p. 592-9.

91. Gurley, B.J., A. Swain, D.K. Williams, G. Barone, et al., Gauging the clinical significance of Pglycoprotein-mediated herb-drug interactions: comparative effects of St. John's wort, Echinacea, clarithromycin, and rifampin on digoxin pharmacokinetics. Mol Nutr Food Res, 2008. 52(7): p. 772-9.

92. Johne, A., J. Brockmoller, S. Bauer, A. Maurer, et al., Pharmacokinetic interaction of digoxin with an herbal extract from St John's wort (Hypericum perforatum). Clin Pharmacol Ther, 1999. 66(4): p. 338-45.

93. Mueller, S.C., B. Uehleke, H. Woehling, M. Petzsch, et al., Effect of St John's wort dose and preparations on the pharmacokinetics of digoxin. Clin Pharmacol Ther, 2004. 75(6): p. 54657.

94. Portoles, A., A. Terleira, A. Calvo, I. Martinez, et al., Effects of Hypericum perforatum on ivabradine pharmacokinetics in healthy volunteers: an open-label, pharmacokinetic interaction clinical trial. J Clin Pharmacol, 2006. 46(10): p. 1188-94.

95. Meijerman, I., J.H. Beijnen, and J.H. Schellens, Herb-drug interactions in oncology: focus on mechanisms of induction. Oncologist, 2006. 11(7): p. 742-52.

96. Frye, R.F., S.M. Fitzgerald, T.F. Lagattuta, M.W. Hruska, et al., Effect of St John's wort on imatinib mesylate pharmacokinetics. Clin Pharmacol Ther, 2004. 76(4): p. 323-9.

97. Smith, P., J.M. Bullock, B.M. Booker, C.E. Haas, et al., The influence of St. John's wort on the pharmacokinetics and protein binding of imatinib mesylate. Pharmacotherapy, 2004. 24(11): p. 1508-14.

98. Mathijssen, R.H., J. Verweij, P. de Bruijn, W.J. Loos, et al., Effects of St. John's wort on irinotecan metabolism. J Natl Cancer Inst, 2002. 94(16): p. 1247-9.

99. Markowitz, J.S., C.L. DeVane, D.W. Boulton, S.W. Carson, et al., Effect of St. John's wort (Hypericum perforatum) on cytochrome P-450 2D6 and 3A4 activity in healthy volunteers. Life Sci, 2000. 66(9): p. PL133-9.

100. Gurley, B.J., S.F. Gardner, M.A. Hubbard, D.K. Williams, et al., Clinical assessment of effects of botanical supplementation on cytochrome P450 phenotypes in the elderly: St John's wort, garlic oil, Panax ginseng and Ginkgo biloba. Drugs Aging, 2005. 22(6): p. 525-39.

101. Gurley, B.J., S.F. Gardner, M.A. Hubbard, D.K. Williams, et al., Cytochrome P450 phenotypic ratios for predicting herb-drug interactions in humans. Clin Pharmacol Ther, 2002. 72(3): p. 276-87.

102. Izzo, A.A. and E. Ernst, Interactions between herbal medicines and prescribed drugs: an updated systematic review. Drugs, 2009. 69(13): p. 1777-98.

103. Rosenblatt, M. and J. Mindel, Spontaneous hyphema associated with ingestion of Ginkgo biloba extract. N Engl J Med, 1997. 336(15): p. 1108.

104. Meisel, C., A. Johne, and I. Roots, Fatal intracerebral mass bleeding associated with Ginkgo biloba and ibuprofen. Atherosclerosis, 2003. 167(2): p. 367.

105. Matthews, M.K., Jr., Association of Ginkgo biloba with intracerebral hemorrhage. Neurology, 1998. 50(6): p. 1933-4.

106. Galluzzi, S., O. Zanetti, G. Binetti, M. Trabucchi, et al., Coma in a patient with Alzheimer's disease taking low dose trazodone and gingko biloba. J Neurol Neurosurg Psychiatry, 2000. 68(5): p. 679-80. 
107. Borrelli, F., R. Capasso, and A.A. Izzo, Garlic (Allium sativum L.): adverse effects and drug interactions in humans. Mol Nutr Food Res, 2007. 51(11): p. 1386-97.

108. Pathak, A., P. Leger, H. Bagheri, J.M. Senard, et al., Garlic interaction with fluindione: a case report. Therapie, 2003. 58(4): p. 380-1.

109. Piscitelli, S.C., A.H. Burstein, N. Welden, K.D. Gallicano, et al., The effect of garlic supplements on the pharmacokinetics of saquinavir. Clin Infect Dis, 2002. 34(2): p. 234-8.

110. Aslam, M. and I.H. Stockley, Interaction between curry ingredient (karela) and drug (chlorpropamide). Lancet, 1979. 1(8116): p. 607.

111. Gwilt, P.R., C.L. Lear, M.A. Tempero, D.D. Birt, et al., The effect of garlic extract on human metabolism of acetaminophen. Cancer Epidemiol Biomarkers Prev, 1994. 3(2): p. 155-60.

112. Kiefer, D. and T. Pantuso, Panax ginseng. Am Fam Physician, 2003. 68(8): p. 1539-42.

113. Shader, R.I. and D.J. Greenblatt, Bees, ginseng and MAOIs revisited. J Clin Psychopharmacol, 1988. 8(4): p. 235.

114. de Boer, A., F. van Hunsel, and A. Bast, Adverse food-drug interactions. Regul Toxicol Pharmacol, 2015. 73(3): p. 859-65.

115. Wiegman, D.J., K. Brinkman, and E.J. Franssen, Interaction of Ginkgo biloba with efavirenz. AIDS, 2009. 23(9): p. 1184-5.

116. Qato, D.M., G.C. Alexander, R.M. Conti, M. Johnson, et al., Use of prescription and over-thecounter medications and dietary supplements among older adults in the United States. JAMA, 2008. 300(24): p. 2867-78. 




\section{Chapter 2}

\section{The shifting perception on antioxidants: the case of vitamin $E$ and $\beta$-carotene}

Misha F Vrolijk, Antoon Opperhuizen, Eugène H J M Jansen, Roger W Godschalk, Frederik J Van Schooten, Aalt Bast, Guido R M M Haenen.

Redox Biology. 2015;4:272-8 


\begin{abstract}
Antioxidants are vital for aerobic life, and for decades the expectations of antioxidants as health promoting agents were very high. However, relatively recent meta-analyses of clinical studies show that supplementation of antioxidants does not result in the presumed health benefit, but is associated with increased mortality. The dilemma that still needs to be solved is: what are antioxidants in the end, healthy or toxic? We have evaluated this dilemma by examining the presumed health effects of two individual antioxidants with opposite images i.e. the "poisonous" $\beta$-carotene and the "wholesome" vitamin $E$ and focused on one aspect, namely their role in inducing BPDE-DNA adducts. It appears that both antioxidants promote DNA adduct formation indirectly by inhibition of the protective enzyme glutathione-S-transferase $\pi$ (GST $\pi$ ). Despite their opposite image, both antioxidants display a similar type of toxicity. It is concluded that, in the appreciation of antioxidants, first their benefits should be identified and substantiated by elucidating their molecular mechanism. Subsequently, the risks should be identified including the molecular mechanism. The optimal benefit-risk ratio has to be determined for each antioxidant and each individual separately, also considering the dose.
\end{abstract}




\section{Main Text}

From a toxicological point of view, molecular oxygen and other reactive oxygen species (ROS) are among the most reactive compounds we encounter in daily life [1, 2]. Moreover, their level of exposure is relatively high and the duration of exposure is lifelong. This cumulates in the permanent threat of oxidative stress; a toxicological process implicated in the pathogenesis of virtually any disease $[3,4]$. Antioxidants, which protect against ROS, are therefore vital for aerobic life. For that reason, nutrients rich in antioxidants or antioxidants administered as supplement are applied on a large scale in an attempt to alleviate ROS induced damage [5]. The concept of oxidative stress emerged in the second half of the previous century. Consequently, at that time the expectations for the health benefits of antioxidants were very high and the use of all kinds of antioxidants in relative high quantities were recommended based on the ideas that all antioxidants are equal, and that the higher the intake, the higher the health benefits of antioxidants would be.

However, relatively recent meta-analyses of clinical studies insinuate that that the high expectations could not be met. It seems as if supplementation of antioxidants does not result in the presumed health benefit, but paradoxically a high intake of antioxidants is associated with increased mortality [6-9]. More than 68 randomized control trials were analyzed for the effects of $\beta$-carotene, vitamin $A$ and vitamin $E$ on mortality. All these compounds, given in a relatively high dose as a single compound or in different combinations, had no beneficial effects. The supplements even increased all-cause mortality. In this respect, it should be noted that vitamin A is considered not be an antioxidant, indicating that any compound (not only antioxidants) will be toxic when the dose is too high. In fact, this is the fundamental rule in toxicology coined five centuries ago by Paracelsus. As a consequence of the reports on the adverse effects of antioxidants given in a relatively high dose, the appreciation of antioxidants rigorously changed from healthy to toxic [10-12]. To date, the discussion on the health benefits of antioxidants continues.

The dilemma remains: what are antioxidants in the end, toxic or healthy? We evaluated this dilemma by examining the presumed health effects of two individual natural antioxidants in which the opposite images are materialized i.e. the "poisonous" $\beta$-carotene and the "healthy" vitamin E [13-17]. The interaction of $\beta$-carotene and vitamin $E$ with physiological systems should be evaluated at a molecular level, because at this level the biological effect of a compound arises. $\beta$-carotene and vitamin $E$ display a wide variety of effects from free radical scavenging to modulation of signal transduction [18-22]. In the present evaluation, we focused on one aspect, namely their role in inducing DNA damage by focusing on the interaction of $\beta$-carotene and vitamin $E$ with glutathione-S-transferase $\pi$ (GST $\pi$ ). However, our perception of antioxidants should not be limited to their risks; actually their benefits should be put in first place. A risk-benefit analysis is made and is based on the interaction of the antioxidants on the molecular level. It will be discussed if we should adjust our perception of both compounds. The benefits of antioxidants on a molecular level are neutralizing ROS and prevent oxidative damage. The health benefits are supported by a large body of epidemiological evidence. For instance, a low plasma level of $\beta$-carotene is associated with increased mortality [23-25]. Additionally, vitamin E is associated with a 
reduced risk of coronary heart disease and colon cancer [13, 14, 26, 27]. Our knowledge on how these compounds act has drastically increased (box 1). In the 1970's, it was believed that antioxidants only needed to scavenge free radicals which would totally absorb their reactivity. In the current concept on the molecular mechanism of action, scavenging is the first step in a series of at least three steps. The second step is that the radical is safeguarded in the antioxidant radical. Finally the radical has to be transferred safely into the antioxidant network. Although initially all antioxidants were considered to be equal, we now realize that each antioxidant has its own biochemical profile. Vitamin $E$ for instance protects membranes from lipid peroxidation by scavenging lipid peroxyl radicals, while $\beta$ carotene is one of the most potent scavengers of singlet oxygen [28, 29]. The molecular mechanism of action of the major antioxidants is already partially unraveled. Nevertheless, several important aspects such as the interaction with the endogenous antioxidant network, needs to be fully elucidated in order to completely exploit the health benefits of these antioxidants.

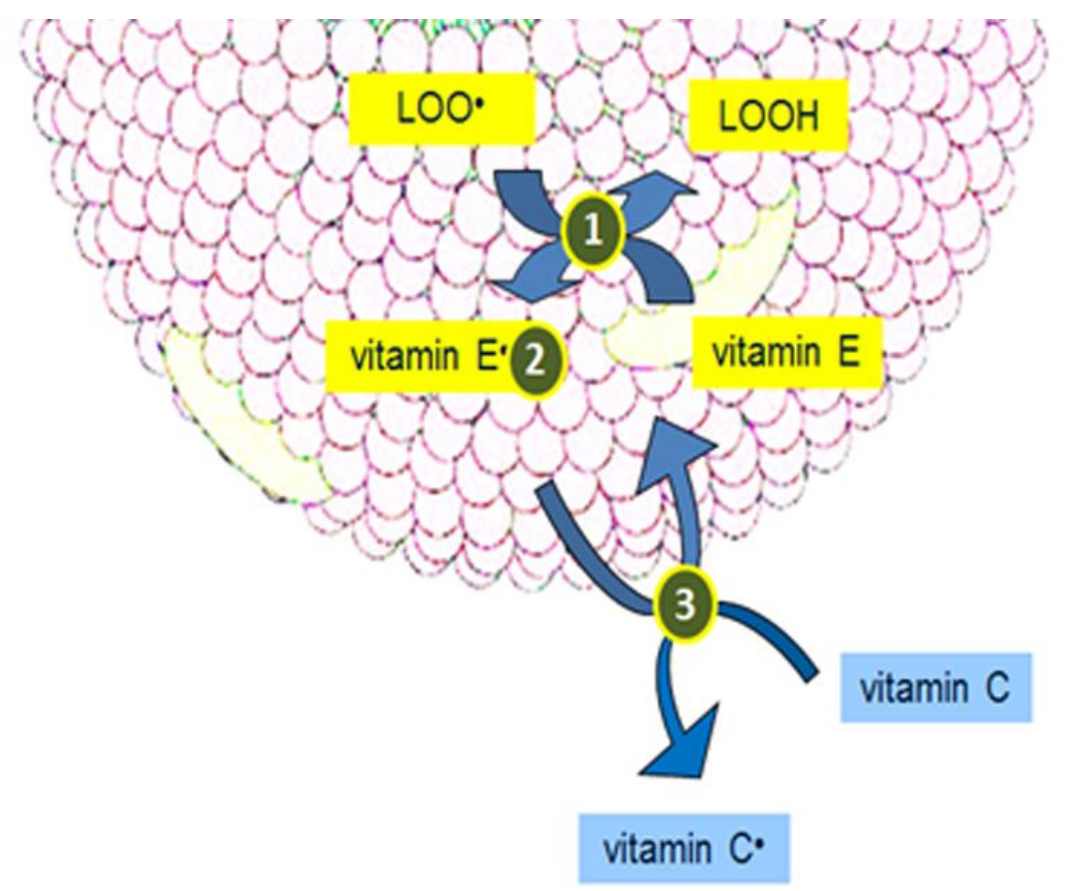

Box 1 Antioxidant protection.|For a long time, it was thought that antioxidants only needed to scavenge radicals to offer protection. Currently, our knowledge on how antioxidants functions has progressed. The mechanism of action of antioxidants consists of multiple steps, as illustrated with the protection of lipoproteins against lipid peroxidation by vitamin E. During the process of lipid peroxidation lipid peroxyl radicals (LOO') are formed. In the protection, the first step is the scavenging of $\mathrm{LOO}^{\circ}$ by the lipophilic antioxidant vitamin $\mathrm{E}$. This is a chemical reaction in which the reactive radical $\left(\mathrm{LOO}^{\circ}\right)$ is transformed into a non-radical $(\mathrm{LOOH})$ that is relatively unreactive. The second step is that the radical is safeguarded in the antioxidant radical. The vitamin E radical is relatively unreactive due to delocalization of the radical over the antioxidant molecule. In the final 
step, the radical is transferred safely into the antioxidant network. In sequential reactions, the radical is transferred from one antioxidant to another antioxidant. In the example, the radical located on vitamin $E$ in the lipoprotein is taken over by vitamin $C$ in the plasma [62]; the vitamin $C$ radical might react with $\mathrm{NADH}$ to regenerate vitamin $\mathrm{C}$, a reaction catalyzed by the ascorbate free radical reductase. In the end, the reactivity of the radical is totally absorbed in the 3 steps.

\section{$\beta$-carotene}

$\beta$-carotene belongs to the group of naturally occurring carotenoids and has a lipophilic character containing pro-vitamin activity. $\beta$-carotene is naturally occurring in dietary fruits and vegetables, but is also present as food supplements. The chemical, biological and physical properties of $\beta$-carotene are well-described [30]. Besides the proposed beneficial effects of $\beta$-carotene, several clinical trials do not support these effects and reported toxic effects of $\beta$-carotene supplementation. Regarding these risks, the ATBC study revealed in 1994 that $\beta$-carotene supplementation was associated with an increased incidence of lung cancer in smokers [31]. In the years that followed, other epidemiological studies corroborated this alarming effect [32-35]. The blame was put on $\beta$-carotene. However, the molecular mechanism for inducing lung cancer could not be evidently tied to $\beta$-carotene.

Especially in the combination with smoking, $\beta$-carotene supplementation is extra dangerous $[36,37]$. The polycyclic aromatic hydrocarbon benzyo[a]pyrene (BaP), present in tobacco smoke, has a well-known carcinogenic track record and the molecular evidence is beyond reasonable doubt [38]. $\mathrm{BaP}$ is activated into its highly mutagenic metabolite benzo(a)pyrene diol epoxide (BPDE). The electrophile BPDE attacks the nucleophilic regions of DNA, yielding BPDE-DNA adducts $[39,40]$. The carcinogenic potential of BPDE is corroborated in the present study by the presence of $153 \pm 23$ BPDE-DNA adducts $/ 10^{7}$ nucleotides (figure $1 \mathrm{~A}$ ) in lung epithelial cells (BEAS-2B) after exposure to BPDE. These DNA adducts cause chromosomal instability and eventually initiate tumor formation [41].

Protection against BPDE is provided by GSTs. This family of enzymes catalyzes the conjugation of BPDE to glutathione (GSH), which neutralizes the carcinogenic potential of BPDE [42]. These GSTs are divided into five major isoforms $(\alpha, \mu, \pi, \theta$, and $\sigma)$, of which the $\pi$ isoform is found to be the most abundant isoform in erythrocytes, lung and the human skin [43-46]. In our experiments, GST $\pi$ effectively decreased the number of BPDE-DNA adducts in the lung epithelial cells to $75 \pm 10$ BPDE-DNA adducts $/ 10^{7}$ nucleotides $(P<0.01)$ (figure 1B). The evidence on the protective role of GST $\pi$ is circumstantiated by the elevated risk for lung cancer in humans with impaired GST $\pi$ activity $[45,47,48]$.

We also observed that $\beta$-carotene attenuated the enzyme activity of GST $\pi$. Five $\mu \mathrm{M}$ and 10 $\mu \mathrm{M} \beta$-carotene inhibited the GST- $\pi$ activity with $35 \%$ and $43 \%$ respectively (figure $1 \mathrm{C}$ ). Consequently, $\beta$-carotene weakens the defense against BPDE. Indeed, in lung epithelial cells exposed to BPDE, $\beta$-carotene inhibits the protective effect of GST $\pi$, by increasing the number of BPDE-DNA adducts to $125 \pm 10 / 10^{7}$ nucleotides $(P<0.05)$ (figure $\left.1 B\right)$. This means that $\beta$-carotene indirectly increases the formation of BPDE-DNA adducts, since the conjugation of BPDE to GSH will not take place. This finding implies that inhibition of the 
protective activity of GST $\pi$ by $\beta$-carotene is involved in the tumor promoting effect in smokers (figure 3) [31].
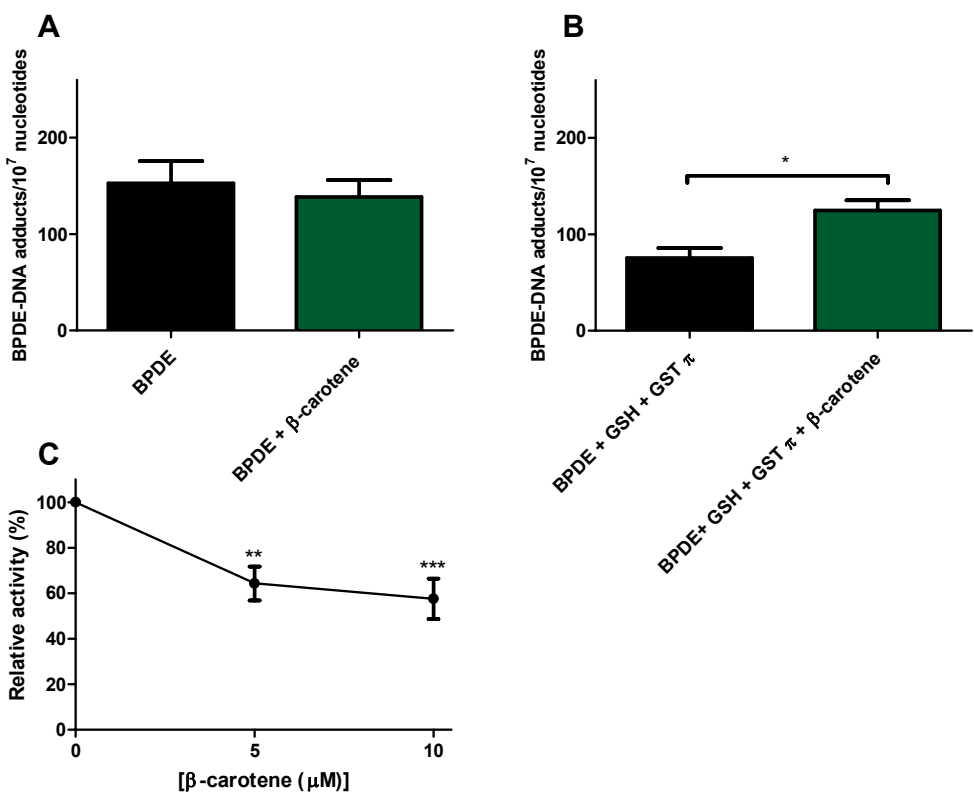

Figure 1| The effects of $\beta$-carotene $(10 \mu \mathrm{M})$ on BPDE-DNA adduct formation (A), on GST $\pi$ induced detoxification of BPDE (B) and the inhibitory effect $\beta$-carotene on the activity of GST $\pi$. The inhibitory effect of $\beta$-carotene on GST $\pi$ induced BPDE detoxification. BPDE-DNA adduct formation was measured by 32P-postlabeling assay. BEAS2B-cells were treated for 1 hour with $0.1 \mu \mathrm{M}$ BPDE in the absence or in the presence of $\beta$-carotene, the combination of GST $\pi(50 \mathrm{mU} / \mathrm{mL})$ and GSH $(1 \mathrm{mM})$ or the combination of GST $\pi(50 \mathrm{mU} / \mathrm{mL}), \mathrm{GSH}(1 \mathrm{mM})$ and $\beta$-carotene $(10 \mu \mathrm{M})$. After treatment, medium was removed and cells were collected and stored at $-20{ }^{\circ} \mathrm{C}$. DNA adduct levels were determined according to the nuclease P1 enrichment technique as described by Reddy and Randerath with minor modifications $[59,60]$. GST $\pi$ activity measurements were performed as described by Mannervik and Guthenberg with slight modifications [61]. In short, the reaction of $1 \mathrm{mM}$ CDNB with $1 \mathrm{mM}$ GSH in $100 \mathrm{mM}$ potassium phosphate buffer $\left(\mathrm{pH} 6.5 ; 37^{\circ} \mathrm{C}\right)$ was spectrophotometrically monitored by measuring the increase in absorbance at $340 \mathrm{~nm}$. The effect of $\beta$-carotene (final concentrations: $5 \mu \mathrm{M}$ and $10 \mu \mathrm{M})$ on GST enzyme activity $(0.05 \mathrm{U} / \mathrm{ml}$ in buffer) was determined. The control activity (of $127 \pm 3 \mathrm{nmol} / \mathrm{min} / \mathrm{ml}$ ) was set to $100 \%$. Data are shown as means $\pm \operatorname{SEM}(n=6)$. One way analysis of variance (ANOVA) with Bonferroni post hoc correction was used to examine differences in enzyme activities of GST $\pi$. In order to determine differences in BPDE-DNA adduct formation, Student's t-test was used. Differences were considered to be statistically significant when $P<0.05$. ${ }^{*} P<0.05, * * P<0.005, * * * P<0.001$.

The blame the ATBC study put on $\beta$-carotene supplementation fitted in the disappointment on the unrealistically high expectations of the health effect of antioxidant supplementation of that time [3]. However, by classifying it as toxic does injustice to $\beta$-carotene, and we do 
not recognize its beneficial health effects. Nevertheless, we do have to be fully aware of the hazard of $\beta$-carotene in a specific group at risk, namely smokers.

\section{Vitamin $\mathrm{E}$}

Vitamin $\mathrm{E}$ is the blanket term that covers all biological active tocopherols and tocotrienols and their derivatives. The chemical, biological and physical properties of vitamin $E$ are welldescribed [27] Vitamin $E$ is abundant in our diet and present in numerous food supplements. Also the dermal exposure has to be considered due to the inclusion of vast quantities of vitamin $\mathrm{E}$ in cosmetic products such as shampoos and skin creams. Numerous beneficial health effects have been proposed for vitamin E, which are attributed to its antioxidants activity. Despite its reputation of being healthy, vitamin $\mathrm{E}$ has a dark side that is astonishingly similar to that of $\beta$-carotene. Mitchel et al. [49] found that vitamin $E$ had tumor promoting activity of in the skin of mice exposed to 7,12-Dimethylbenz(a)anthracene (DMBA), a reference compound for inducing cancer that displays a molecular mechanism similar to that of BPDE.
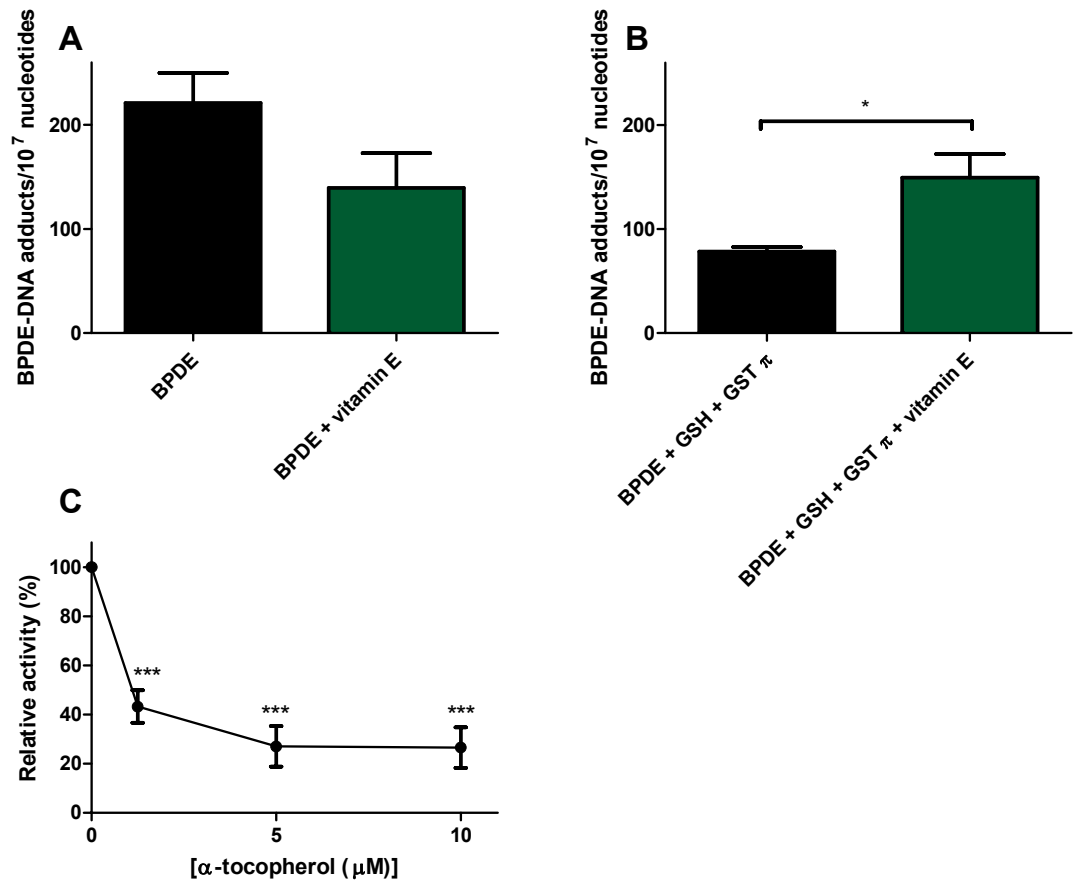

Figure 2| The effects vitamin $E(30 \mu \mathrm{M})$ on BPDE-DNA adduct formation (A), on GST $\pi$ induced detoxification of BPDE (B) and the inhibitory effect of vitamin $E$ on the activity of GST $\pi$. BPDE-DNA adduct formation was measured by 32P-postlabeling assay. HaCaT cells were treated for 1 hour with $0.1 \mu \mathrm{M}$ BPDE dissolved in DMSO in the absence or in the presence of vitamin $\mathrm{E}$, the combination of GST $\pi(50 \mathrm{mU} / \mathrm{mL})$ and GSH $(1 \mathrm{mM})$ or the combination of GST $\pi(50 \mathrm{mU} / \mathrm{mL}), \mathrm{GSH}(1 \mathrm{mM})$ and vitamin E. After treatment, medium was removed and cells were collected and stored at $-20{ }^{\circ} \mathrm{C}$. DNA 
adduct levels were determined according to the nuclease P1 enrichment technique as described by Reddy and Randerath with minor modifications $[59,60]$. The GST $\pi$ activity was determined by recording the conjugation of $1 \mathrm{mM}$ 1-chloro-2,4-dinitrobenzene (CDNB) by $1 \mathrm{mM} \mathrm{GSH}$. The reaction of $1 \mathrm{mM}$ CDNB with $1 \mathrm{mM}$ GSH in $100 \mathrm{mM}$ potassium phosphate buffer $\left(\mathrm{pH} 6.5 ; 37^{\circ} \mathrm{C}\right)$ was spectrophotometrically monitored by measuring the increase in absorbance at $340 \mathrm{~nm}$. The effect of vitamin $\mathrm{E}$ (final concentrations: $1.25 \mu \mathrm{M}, 5 \mu \mathrm{M}$ and $10 \mu \mathrm{M})$ on GST enzyme activity $(0.05 \mathrm{U} / \mathrm{ml}$ in buffer) was determined. The control activity (of $127 \pm 3 \mathrm{nmol} / \mathrm{min} / \mathrm{ml}$ ) was set to $100 \%$. Data are shown as means $\pm \operatorname{SEM}(n=6)$. One way analysis of variance (ANOVA) with Bonferroni post hoc correction was used to examine differences in enzyme activities of GST $\pi$. In order to determine differences in BPDE-DNA adduct formation, Student's t-test was used. Differences were considered to be statistically significant when $\mathrm{P}<0.05$. ${ }^{*} \mathrm{P}<0.05,{ }^{* * *} \mathrm{P}<0.001$.

In accordance to these findings, we observed that BPDE-DNA adducts were formed in skin keratinocytes (HaCaT cells) after exposure to BPDE $\left(221 \pm 28\right.$ BPDE-DNA adducts $/ 10^{7}$ nucleotides) (figure 2A). The effective protection of GST $\pi$ is corroborated in these cells, evidenced by the effective decrease in the number of BPDE-DNA adducts, which were found to be $78 \pm 4$ BPDE-DNA adducts $/ 10^{7}$ nucleotides $(P<0.01$ ) (figure $2 \mathrm{~B}$ ). Similar to inhibition of GST $\pi$ by $\beta$-carotene, we found that vitamin $E$ also inhibited this enzyme [50]. The enzyme activity of GST $\pi$ is even more potently inhibited by vitamin $E$ in a concentration dependent manner (figure 2C). In a concentration of $1.25 \mu \mathrm{M}, 5 \mu \mathrm{M}$ or 10 $\mu \mathrm{M}$ vitamin E significantly decreased the enzyme activity of GST $\pi$ with $57 \%, 73 \%$ and $74 \%$ respectively $(p<0.001)$. Conversely, in rats a diet deficient in vitamin $E$ was found to increase GST activity [51]. As a consequence of GST $\pi$ inhibition, vitamin $E$ also significantly attenuated detoxification of BPDE by GST $\pi\left(149 \pm 22\right.$ BPDE-DNA adducts $/ 10^{7}$ nucleotides; $\mathrm{P}<0.05$ ). The resulting net effect is an increase in BPDE-DNA adducts (figure 2B). This finding implies that inhibition of the protective activity of GST $\pi$ might explain the tumor promoting effect of vitamin $\mathrm{E}$ in mice (figure 3) [49].

Coal tar contains polycyclic aromatic compounds (PAH) including BP (the precursor of BPDE) and dermal exposure is associated with inducing skin cancer [52]. After being banned, coal tar is currently making a surprising comeback as ingredient in medicated shampoos, soap and ointment for the treatment of numerous skin diseases as eczematous dermatitis and psoriasis $[53,54]$. Coal tar ointments induce PAH-DNA adducts in skin [55] and in analogy with $\beta$-carotene in smokers, vitamin $\mathrm{E}$ may have an additional toxic effect on people using coal tar creams. By classifying it as wholesome we have a one-sided view on the health effect of vitamin E, and we do not recognize its toxic effect. Indeed, we do have to be fully aware of the hazard of vitamin E in a specific group at risk, namely people using coal tar creams.

\section{Conclusion and perspectives}

Apparently, the appreciation of an antioxidant is a reflection of the prevailing perception of the risks and benefits at a certain point in time, and this is subject to change (box 2). We earlier found that smokers and patients treated with coal tar ointments that are genetically deficient in GST detoxifications had higher DNA adducts in blood cells and skin [56, 57]. 


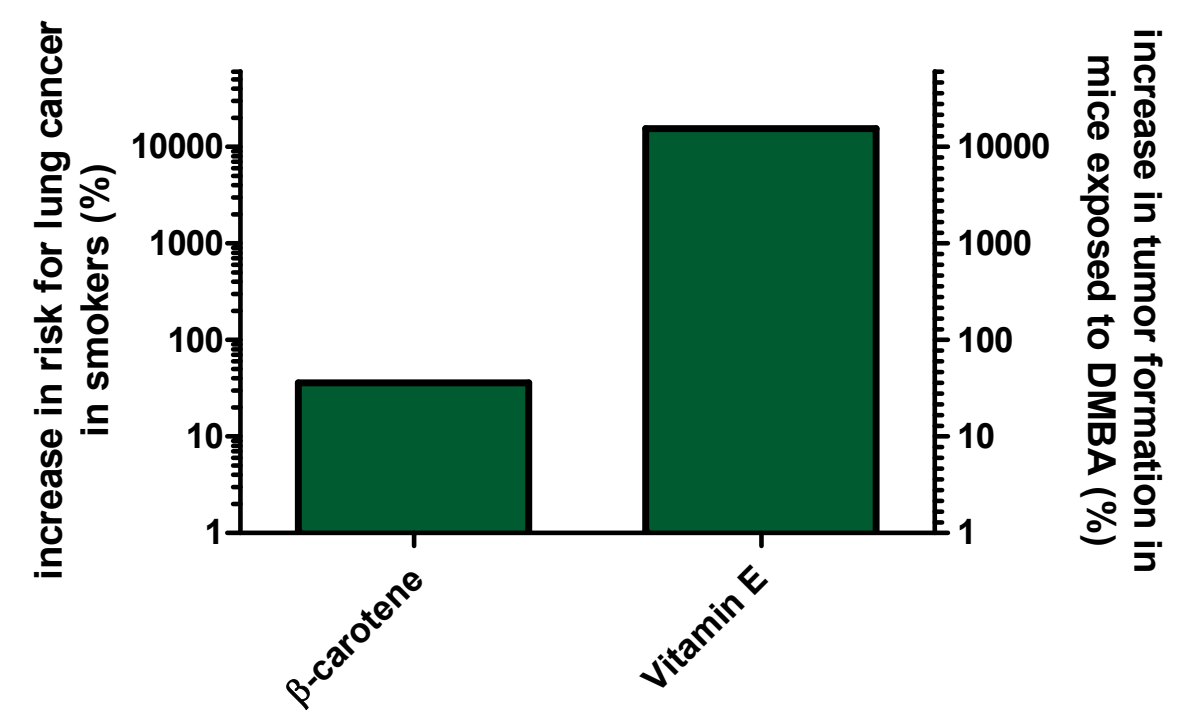

Figure $3 \mid$ Increase (\%) in risk for lung cancer in smokers induced by $\beta$-carotene (left $y$-axis) and in skin tumor formation in mice treated with DMBA induced by vitamin $E$ (right $y$-axis). $\beta$-carotene has a relative risk of lung cancer in smokers of 1.36, giving an increase of $36 \%$. Vitamin $E$ increased the number of skin tumors in mice from 1 tumor/25 animals in the control group to 154 tumors/26 animals in DMBA treated mice, giving an increase of $15400 \%$. The $\beta$-carotene data were obtained from The Alpha-Tocopherol, $\beta$-Carotene Cancer Prevention Study Group, in which male smokers were daily supplemented with $\beta$-carotene $(20 \mathrm{mg})$. Lung cancer incidence was determined during a followup of 5-8 years [32]. Vitamin E data were obtained from Mitchel et al [50]. In this study, DMBA with and without vitamin E were topically applied to the dorsal skin of female SENCAR mice from which the hair was shaved. 98 days and 153 days after DMBA initiation, skin tumor formation was determined.

So modulation of GSTs by antioxidants as $\beta$-carotene and vitamin E would certainly impose a risk in these groups of exposed persons. To come to an accurate risk-benefit analysis the following issues should be kept in mind:

1. Antioxidants are consumed to improve health and not because they are not toxic. In our appreciation on antioxidants priority is given to the risks and this needs to be corrected. The priority should be to identify groups that are likely to benefit. A challenge is that clear pharmacological endpoints still need to be defined that also includes the impact on redox signaling.

2. The molecular mechanism of the benefit is the actual fundament. Since each antioxidant has its own unique biochemical profile, antioxidants should not be treated as group. Based on the molecular pathways involved in pathology, the specific protection can be determined and the antioxidant which fits the profile best can be selected. 
3. Next to groups that benefit, also groups that are at risk should be identified. Benefits are well-defined and therefore relatively easy evaluated. In contrast, risks can in principle be anything. Therefore, finding a group at risk is often a matter of chance. For example, it could not have been foreseen that smokers are at risk for $\beta$-carotene supplementation. Probably, there are additional, not yet identified, risks in smokers or other specific groups.

4. Risks should be substantiated by elucidating the molecular mechanism. This does not have to be related to the molecular mechanism for the benefit. The toxicity of the antioxidants in the present study does not arise from their antioxidant effect or their reactive products, but from the interaction with a protein. $\beta$-carotene inhibited BPDE detoxification by GST $\pi$. This molecular mechanism puts the toxicity of $\beta$-carotene in the right perspective. BPDE is the actual culprit, whereas $\beta$-carotene is more of an accomplice to BPDE, since it inhibits the detoxifying enzyme GST. By putting the toxicity in the right perspective, an overreaction (such as a general ban on $\beta$-carotene) can be prevented. On the other hand, the molecular mechanism can be used to predict other risks, such as shown in the present study, the toxicity of vitamin E in people using coal tar.

Although the accurate appreciation of antioxidants seems straight forward to do, in practice this appears to be quite awkward. This can be exemplified by the case of $\beta$ carotene in smokers. Since smoking causes oxidative stress, it is logical to supplement smokers with antioxidants. $\beta$-carotene was selected because relatively low levels of this antioxidant were found in smokers. Unpredictably, $\beta$-carotene appeared to be toxic in this group and therefore $\beta$-carotene proved to be the wrong choice.

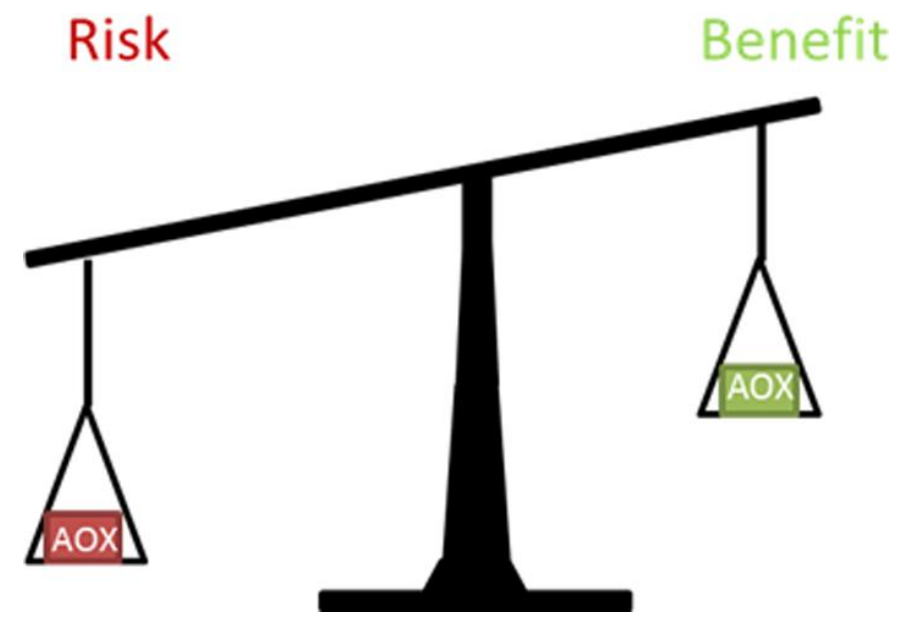

Box 2 The health effect of antioxidants. I In the perception of the health effect of an antioxidant, it is often considered that an antioxidant either only provides benefits or that it only poses risks. These opposing, one side views are the main obstacles in the accurate perception of the health effect of antioxidants. A more balanced view is mandatory as any bioactive, antioxidants included, have benefits as well as risks. In fact, the distinction between the two is not as clear-cut as generally 
assumed; as coined by Adrien Albert, the benefit is a form of selective toxicity. Critical in the riskbenefit analysis is that each individual balance is biased. In people that are expected to profit, the arm of the benefit is relatively long. Contrariwise, in vulnerable people, the arm of the risk is relatively long. The latter is seen for the risk of $\beta$-carotene in smokers. Apparently, it has to be determined for each individual separately whether the benefit outweighs the risk. The molecular mechanism is the pulling force that determines the weight of the benefit as well as the risk

Undoubtedly, oxidative stress has a substantial contribution to smoke toxicity. Therefore, smokers are expected to benefit from antioxidant supplementation. Fully elucidating the molecular mechanism is needed to identify the antioxidant that fits smokers.

In conclusion, as seen in the case of $\beta$-carotene and vitamin $E$, there is a thin line between toxic and healthy. Supplementation of antioxidants does not necessarily have to be beneficial and a natural origin is no guaranty for safety. The optimal benefit-risk ratio has to be determined for each antioxidant and each individual separately, also considering the dose. The molecular mechanism is the fundament to put the benefits as well as the risks in an accurate perspective. 


\section{References}

1. Halliwell B, Gutteridge JM. Oxygen toxicity, oxygen radicals, transition metals and disease. Biochem J. 1984;219:1-14.

2. Halliwell B. Free radicals and antioxidants - quo vadis? Trends in pharmacological sciences. 2011;32:125-30.

3. Bast A, Haenen GR. Ten misconceptions about antioxidants. Trends Pharmacol Sci. 2013;34:430-6.

4. Thomson L, Paton J. Oxygen Toxicity. Paediatr Respir Rev. 2014.

5. Seifried $\mathrm{HE}$, Anderson DE, Fisher El, Milner JA. A review of the interaction among dietary antioxidants and reactive oxygen species. J Nutr Biochem. 2007;18:567-79.

6. Lee SH, Oe T, Blair IA. Vitamin C-induced decomposition of lipid hydroperoxides to endogenous genotoxins. Science. 2001;292:2083-6.

7. Bjelakovic G, Nikolova D, Gluud LL, Simonetti RG, Gluud C. Mortality in randomized trials of antioxidant supplements for primary and secondary prevention: systematic review and meta-analysis. Jama. 2007;297:842-57.

8. Rietjens IM, Boersma MG, Haan L, Spenkelink B, Awad HM, Cnubben NH, et al. The prooxidant chemistry of the natural antioxidants vitamin $\mathrm{C}$, vitamin $\mathrm{E}$, carotenoids and flavonoids. Environ Toxicol Pharmacol. 2002;11:321-33.

9. Bjelakovic G, Nikolova D, Gluud C. Antioxidant supplements and mortality. Current opinion in clinical nutrition and metabolic care. 2014;17:40-4.

10. Bast A, Haenen GR. The toxicity of antioxidants and their metabolites. Environ Toxicol Pharmacol. 2002;11:251-8.

11. Miller ER, 3rd, Pastor-Barriuso R, Dalal D, Riemersma RA, Appel LJ, Guallar E. Meta-analysis: high-dosage vitamin $\mathrm{E}$ supplementation may increase all-cause mortality. Ann Intern Med. 2005;142:37-46.

12. Bjelakovic G, Nikolova D, Gluud C. Antioxidant supplements to prevent mortality. Jama. 2013;310:1178-9.

13. Rimm EB, Stampfer MJ, Ascherio A, Giovannucci E, Colditz GA, Willett WC. Vitamin E consumption and the risk of coronary heart disease in men. N Engl J Med. 1993;328:1450-6.

14. Bostick RM, Potter JD, McKenzie DR, Sellers TA, Kushi LH, Steinmetz KA, et al. Reduced risk of colon cancer with high intake of vitamin E: the lowa Women's Health Study. Cancer Res. 1993;53:4230-7.

15. Goralczyk R. Beta-carotene and lung cancer in smokers: review of hypotheses and status of research. Nutrition and cancer. 2009;61:767-74.

16. Hernandez ML, Wagner JG, Kala A, Mills K, Wells HB, Alexis NE, et al. Vitamin E, gammatocopherol, reduces airway neutrophil recruitment after inhaled endotoxin challenge in rats and in healthy volunteers. Free radical biology \& medicine. 2013;60:56-62.

17. Stone WL, Krishnan K, Campbell SE, Palau VE. The role of antioxidants and pro-oxidants in colon cancer. World journal of gastrointestinal oncology. 2014;6:55-66.

18. Joseph JA, Shukitt-Hale B, Denisova NA, Prior RL, Cao G, Martin A, et al. Long-term dietary strawberry, spinach, or vitamin $E$ supplementation retards the onset of age-related neuronal signaltransduction and cognitive behavioral deficits. J Neurosci. 1998;18:8047-55.

19. Zingg JM. Modulation of signal transduction by vitamin E. Mol Aspects Med. 2007;28:481506.

20. Palmer HJ, Paulson KE. Reactive oxygen species and antioxidants in signal transduction and gene expression. Nutr Rev. 1997;55:353-61.

21. Azzi A. Molecular mechanism of alpha-tocopherol action. Free radical biology \& medicine. 2007;43:16-21. 
22. Xiong RB, Li Q, Wan WR, Guo JQ, Luo BD, Gan L. Effects and mechanisms of vitamin A and vitamin $E$ on the levels of serum leptin and other related cytokines in rats with rheumatoid arthritis. Experimental and therapeutic medicine. 2014;8:499-504.

23. Mayne ST, Cartmel B, Lin H, Zheng T, Goodwin WJ, Jr. Low plasma lycopene concentration is associated with increased mortality in a cohort of patients with prior oral, pharynx or larynx cancers. J Am Coll Nutr. 2004;23:34-42.

24. De Waart FG, Schouten EG, Stalenhoef AF, Kok FJ. Serum carotenoids, alpha-tocopherol and mortality risk in a prospective study among Dutch elderly. Int J Epidemiol. 2001;30:136-43.

25. Greenberg ER, Baron JA, Karagas MR, Stukel TA, Nierenberg DW, Stevens MM, et al. Mortality associated with low plasma concentration of beta carotene and the effect of oral supplementation. Jama. 1996;275:699-703.

26. Blum S, Vardi M, Brown JB, Russell A, Milman U, Shapira C, et al. Vitamin E reduces cardiovascular disease in individuals with diabetes mellitus and the haptoglobin 2-2 genotype. Pharmacogenomics. 2010;11:675-84.

27. Traber MG, Stevens JF. Vitamins $C$ and $E$ : beneficial effects from a mechanistic perspective. Free radical biology \& medicine. 2011;51:1000-13.

28. Niki E. Role of vitamin $\mathrm{E}$ as a lipid-soluble peroxyl radical scavenger: in vitro and in vivo evidence. Free Radic Biol Med. 2014;66:3-12.

29. Stahl W, Sies H. Antioxidant activity of carotenoids. Mol Aspects Med. 2003;24:345-51.

30. Jomova K, Valko M. Health protective effects of carotenoids and their interactions with other biological antioxidants. European journal of medicinal chemistry. 2013;70:102-10.

31. The effect of vitamin $E$ and beta carotene on the incidence of lung cancer and other cancers in male smokers. The Alpha-Tocopherol, Beta Carotene Cancer Prevention Study Group. N Engl J Med. 1994;330:1029-35.

32. Baron JA, Cole BF, Mott L, Haile R, Grau M, Church TR, et al. Neoplastic and antineoplastic effects of beta-carotene on colorectal adenoma recurrence: results of a randomized trial. J Natl Cancer Inst. 2003;95:717-22.

33. Touvier M, Kesse E, Clavel-Chapelon F, Boutron-Ruault MC. Dual Association of betacarotene with risk of tobacco-related cancers in a cohort of French women. J Natl Cancer Inst. 2005;97:1338-44.

34. Lung cancer associated with beta-carotene supplementation in smokers. Prescrire international. 2010;19:121.

35. Tanvetyanon T, Bepler G. Beta-carotene in multivitamins and the possible risk of lung cancer among smokers versus former smokers: a meta-analysis and evaluation of national brands. Cancer. 2008;113:150-7.

36. van Helden YG, Keijer J, Knaapen AM, Heil SG, Briede JJ, van Schooten FJ, et al. Betacarotene metabolites enhance inflammation-induced oxidative DNA damage in lung epithelial cells. Free Radic Biol Med. 2009;46:299-304.

37. van Helden YG, Keijer J, Heil SG, Pico C, Palou A, Oliver P, et al. Beta-carotene affects oxidative stress-related DNA damage in lung epithelial cells and in ferret lung. Carcinogenesis. 2009;30:2070-6.

38. Hecht SS. Tobacco smoke carcinogens and lung cancer. J Natl Cancer Inst. 1999;91:1194-

210.

39. Szeliga J, Dipple A. DNA adduct formation by polycyclic aromatic hydrocarbon dihydrodiol epoxides. Chem Res Toxicol. 1998;11:1-11.

40. Zuo J, Brewer DS, Arlt VM, Cooper CS, Phillips DH. Benzo pyrene-induced DNA adducts and gene expression profiles in target and non-target organs for carcinogenesis in mice. BMC genomics. 2014;15:880.

41. Salinas AE, Wong MG. Glutathione S-transferases--a review. Curr Med Chem. 1999;6:279309. 
42. Swedmark S, Romert L, Morgenstern R, Jenssen D. Studies on glutathione transferases belonging to class pi in cell lines with different capacities for conjugating (+)-7 beta, 8 alphadihydroxy-9 alpha, 10 alpha-oxy-7,8,9,10-tetrahydrobenzo[a]pyrene. Carcinogenesis. 1992;13:171923.

43. Terrier P, Townsend AJ, Coindre JM, Triche TJ, Cowan KH. An immunohistochemical study of pi class glutathione S-transferase expression in normal human tissue. Am J Pathol. 1990;137:845-53.

44. Moscow JA, Fairchild CR, Madden MJ, Ransom DT, Wieand HS, O'Brien EE, et al. Expression of anionic glutathione-S-transferase and P-glycoprotein genes in human tissues and tumors. Cancer Res. 1989;49:1422-8.

45. Ou C, Zhu B, Zhao HL, Huang LS, Li PZ, Lao M, et al. Association of glutathione S-transferase $\mathrm{P} 1$ gene polymorphism with the risk of small-cell carcinoma of lung cancer. Journal of receptor and signal transduction research. 2014:1-5.

46. Campione E, Medda E, Paterno EJ, Diluvio L, Ricozzi I, Carboni I, et al. Chronically Sundamaged Melanomas Express Low Levels of Nuclear Glutathione-S-transferase-pi: An Epidemiological and Clinicopathological Study in Italy. Acta dermato-venereologica. 2014.

47. Thiele JJ, Hsieh SN, Ekanayake-Mudiyanselage S. Vitamin E: critical review of its current use in cosmetic and clinical dermatology. Dermatol Surg. 2005;31:805-13; discussion 13.

48. Henderson CJ, Smith AG, Ure J, Brown K, Bacon EJ, Wolf CR. Increased skin tumorigenesis in mice lacking pi class glutathione S-transferases. Proc Natl Acad Sci U S A. 1998;95:5275-80.

49. Mitchel RE, McCann R. Vitamin $E$ is a complete tumor promoter in mouse skin. Carcinogenesis. 1993;14:659-62.

50. van Haaften RI, Evelo CT, Haenen GR, Bast A. alpha-Tocopherol inhibits human glutathione S-transferase pi. Biochem Biophys Res Commun. 2001;280:631-3.

51. Stone WL, Dratz EA. Increased glutathione-S-transferase activity in antioxidant-deficient rats. Biochim Biophys Acta. 1980;631:503-6.

52. van Schooten FJ, Godschalk R. Coal tar therapy. Is it carcinogenic? Drug Saf. 1996;15:374-7.

53. van den Bogaard EH, Bergboer JG, Vonk-Bergers M, van Vlijmen-Willems IM, Hato SV, van der Valk PG, et al. Coal tar induces AHR-dependent skin barrier repair in atopic dermatitis. The Journal of clinical investigation. 2013;123:917-27.

54. Raut AS, Prabhu RH, Patravale VB. Psoriasis clinical implications and treatment: a review. Critical reviews in therapeutic drug carrier systems. 2013;30:183-216.

55. Godschalk RW, Ostertag JU, Moonen EJ, Neumann HA, Kleinjans JC, van Schooten FJ. Aromatic DNA adducts in human white blood cells and skin after dermal application of coal tar. Cancer Epidemiol Biomarkers Prev. 1998;7:767-73.

56. Godschalk RW, Dallinga JW, Wikman H, Risch A, Kleinjans JC, Bartsch H, et al. Modulation of DNA and protein adducts in smokers by genetic polymorphisms in GSTM1,GSTT1, NAT1 and NAT2. Pharmacogenetics. 2001;11:389-98.

57. Godschalk RW, Ostertag JU, Zandsteeg AM, Van Agen B, Neuman HA, Van Straaten H, et al. Impact of GSTM1 on aromatic-DNA adducts and p53 accumulation in human skin and lymphocytes. Pharmacogenetics. 2001;11:537-43.

58. Reddy MV, Randerath K. Nuclease P1-mediated enhancement of sensitivity of 32Ppostlabeling test for structurally diverse DNA adducts. Carcinogenesis. 1986;7:1543-51.

59. Godschalk RW, Maas LM, Van Zandwijk N, van 't Veer LJ, Breedijk A, Borm PJ, et al. Differences in aromatic-DNA adduct levels between alveolar macrophages and subpopulations of white blood cells from smokers. Carcinogenesis. 1998;19:819-25.

60. Mannervik B, Guthenberg C. Glutathione transferase (human placenta). Methods Enzymol. 1981;77:231-5.

61. Packer JE, Slater TF, Willson RL. Direct observation of a free radical interaction between

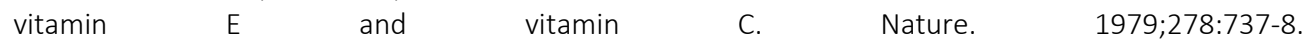






\section{Chapter 3}

\section{The supplement-drug interaction of quercetin with tamsulosin on vasorelaxation}

Misha F Vrolijk, Guido R M M Haenen, Antoon Opperhuizen, Eugène H J M Jansen, Paul M Schiffers, Aalt Bast.

European Journal of Pharmacology. 2015 Jan 5;746:132-7. 


\begin{abstract}
The food supplement quercetin is used as self-medication for prostate disorders and is known to induce vasorelaxation. The drug tamsulosin is used in the treatment of benign prostatic hyperplasia. A major side effect of tamsulosin is orthostatic hypotension, mediated by vasorelaxation resulting from $\alpha_{1}$-adrenoceptor blockade. The overlapping profile prompted us to investigate the pharmacodynamic interaction of quercetin with tamsulosin. Since quercetin is extensively metabolized in the intestines and the liver, the metabolites quercetin-3-glucuronide and 4'O-methyl-quercetin were also examined. Vasorelaxation induced by the compounds was tested in rat mesenteric arteries (average diameter: $360 \pm 8 \mu \mathrm{m})$ constricted by the $\alpha_{1}$-adrenoceptor agonist phenylephrine. Tamsulosin (0.1 nM) decreased phenylephrine sensitivity 17 -fold $(n=10)$. Quercetin $(5,10$ and $20 \mu \mathrm{M}$ ) also caused a decrease (2-, 4- and 6-fold respectively) of phenylephrine sensitivity, while $10 \mu \mathrm{M}$ of quercetin-3-glucuronide and 4'O-methyl-quercetin decreased this sensitivity (1.5- and 2-fold) only slightly $(n=6)$. The combination of tamsulosin with quercetin or quercetin metabolites proved to be far more potent than the compounds in isolation. The combination of quercetin, quercetin-3-glucuronide or 4'0-methyl-quercetin with tamsulosin decreased the phenylephrine sensitivity approximately 200-, 35- and 150fold $(n=6)$. The strong pharmacodynamic interaction between the food supplement quercetin and tamsulosin underlines the potential of the impact of supplement-drug interactions that warrant more research.
\end{abstract}




\section{Introduction}

Dietary supplements are used for all sorts of indications and have been linked to a wide variety of health benefits. Among these supplements, quercetin belongs to the best studied dietary flavonoids, a class of polyphenolic compounds that are abundantly present in vegetables and fruit [1-3]. It displays a multitude of activities, such as antioxidant, antiinflammatory and anti-atherogenic activities [3-7]. In addition, quercetin has been found to induce vasorelaxation of resistance arteries, which has been shown to potentially reduce blood pressure [2, 8-10]. The exact mechanism by which quercetin causes vasorelaxation is not fully elucidated. Quercetin is known to act as a signaling molecule by forming reactive intermediates [11-13]. These reactive intermediates may activate particular signaling cascades. One example of such intermediate is $\mathrm{H}_{2} \mathrm{O}_{2}$, which is an important regulator of signal transduction, by which it induces endothelium-dependent vasorelaxation [9]. The formation of $\mathrm{H}_{2} \mathrm{O}_{2}$ has been implicated in the vasorelaxant effect of quercetin.

Among the indications of quercetin is prostate pain and swelling, chronic pelvic pain syndrome and chronic prostatitis $[14,15]$. In contrast to the growing interest in the biological effects and the side effects of quercetin supplementation, the interaction of quercetin with drugs has gained remarkably little attention. Similar to drug-drug interactions, drug-nutrition interactions may be predicted from the overlap in their pharmacodynamic profiles. This strategy revealed the potentially hazardous interaction of quercetin with the drug tamsulosin on vasorelaxation with orthostatic hypotension as primary threat.

Tamsulosin belongs to the $\alpha_{1}$-adrenoceptor antagonists that are used to treat urine retention caused by benign prostatic hyperplasia (BPH) [16]. BPH has a prevalence of over $70 \%$ in men above the age of $60[17,18]$. Blocking $\alpha_{1}$-adrenoceptors limits constriction of smooth muscles in the urinary tract and the prostate, facilitating urinary flow [19].

Three subtypes of the $\alpha_{1}$-adrenoceptor exist: $\alpha_{1 \mathrm{~A}}, \alpha_{1 \mathrm{~B}}$ and $\alpha_{1 \mathrm{D}}$. These adrenoceptors have a contractile role in the vasculature [20]. Tamsulosin is an insurmountable antagonist for all three $\alpha_{1}$-adrenoceptor subtypes, meaning that it depresses maximal effects of $\alpha_{1}$-agonists [21]. The selectivity of tamsulosin is generally considered to be $\alpha_{1 \mathrm{~A}}>\alpha_{1 \mathrm{D}}>\alpha_{1 \mathrm{~B}}$ [22]. Blocking $\alpha_{1}$-adrenoceptors in the vasculature causes vasorelaxation, potentially reducing the vasoconstrictor response of our body to maintain normal blood pressure after standing up. This might ultimately lead to an orthostatic drop in blood pressure [23, 24]. A major side effect of tamsulosin therefore is orthostatic hypotension, i.e. a sudden fall in blood pressure when standing up [18]. Especially in elderly, orthostatic hypotension is critical, since a sudden drop in blood pressure increases the risk of falling and fainting. Fall-induced injuries are the fifth leading cause of death worldwide in the elderly population [25-27].

The common pharmacodynamic profile, the use of both compounds in a group of frail patients and the major clinical impact prompted us to assess the potential interaction between the supplement quercetin and the drug tamsulosin on vasorelaxation. The supplement-drug interaction was assessed in rat mesenteric arteries constricted by the $\alpha_{1}$ adrenoceptor agonist phenylephrine. Nourian et al (2008) have shown a strong correlation 
between the in vivo orthostatic hypotensive effects of antipsychotic drugs in an animal model of orthostatic hypotension, with the in vitro effects of these drugs on $\alpha_{1}$ adrenoceptors of mesenteric arteries in rats [28]. This corroborated the experimental strategy that $\alpha_{1}$-adrenoceptors of mesenteric resistance arteries are responsible for the orthostatic hypotensive effects. Since quercetin is extensively metabolized in the intestine and the liver, the biological effects of quercetin are mainly mediated by its metabolites, the effects of the metabolites quercetin-3-glucuronide and 4'O-methyl-quercetin were also determined [2]. Here we show that quercetin and its metabolites 4'O-methyl-quercetin and quercetin-3-glucronide strongly augment the vasorelaxing effects of tamsulosin. 


\section{Materials and Methods}

\section{Animal treatments}

16 weeks old male Wistar Kyoto (WKY) rats (Charles River, Maastricht, the Netherlands), weighing 200-300 gr, were housed in cages together and maintained at room temperature in a room with a 12-h light-dark cycle. Rats had free access to drinking water and standard chow. No adverse events were present in the study. All experiments were performed in accordance with the institutional guidelines and were approved by the Ethics Committee on Experimental Animal Welfare of the Maastricht University. A total of 30 animals was used in this study.

\section{Chemicals}

Phenylephrine (Sigma Aldrich) was dissolved in Krebs Ringer bicarbonate buffer (KRB) containing (in mM): $\mathrm{NaCl} 118.5, \mathrm{KCl} 4.7, \mathrm{CaCl}_{2} 2.5, \mathrm{MgSO}_{4} 1.2, \mathrm{KH}_{2} \mathrm{PO}_{4} 1.2, \mathrm{NaHCO}_{3} 25.0$ and glucose, 5.5. Quercetin (Sigma Aldrich), 4'O-methyl-quercetin (Extrasynthese, France), glucuronidated quercetin (Sigma Aldrich) and tamsulosin (Sigma Aldrich) were all dissolved in dimethyl sulfoxide (DMSO). Ferrous ammonium sulfate (Sigma Aldrich) and potassium thiocyanate (Sigma Aldrich) were both dissolved in miliQ.

\section{Vasorelaxation of mesenteric arteries}

WKY rats were killed by $\mathrm{CO}_{2}$-inhalation. The mesentery was excised and immediately submersed in KRB at room temperature. Second-order branches of the superior mesenteric artery were dissected and isolated, by removing fat and connective tissue around the artery. Then, the artery was cut into $2 \mathrm{~mm}$ long segments and these were mounted in wire myographs (DMT, Aarhus, Denmark), in which $5 \mathrm{ml} \mathrm{KRB}$ was maintained at $37^{\circ} \mathrm{C}$ and aerated with $95 \% \mathrm{O}_{2}$ and $5 \% \mathrm{CO}_{2}$. One holder of the myograph organ bath served as anchor, while a second holder was connected to an isometric force transducer, which was coupled to a signal amplifier. The myograph organ bath is connected to a computer to record isometric tension. Vascular functions were assessed as following: the arterial segments were stretched to the diameter at which contractile response to $10 \mu \mathrm{M}$ phenylephrine was observed to be the largest. This was done by increasing the arterial diameter in steps of $50 \mu \mathrm{m}$, which loaded the resting tension, and subsequently measuring the magnitude of the contractile response to $10 \mu \mathrm{M}$ of phenylephrine. In this study, the optimal internal diameter of the arterial averaged $360 \pm 8 \mu \mathrm{m}$ and contractile responses to $10 \mu \mathrm{M}$ phenylephrine averaged $3.4 \pm 0.1 . \mathrm{N} \mathrm{m}^{-1}$.

After the optimal arterial diameter was determined, endothelial function was tested by adding $10 \mu \mathrm{M}$ acetylcholine, which induced a complete endothelium-dependent relaxation of the arteries. Only arteries with intact endothelium have been used for our experiments. The resting tension of the arteries averaged $0.71 \pm 0.08 \mathrm{~N} \mathrm{~m}^{-1}$. Then the arterial mesentery segments were washed again and equilibrated for $30 \mathrm{~min}$, after which a first constructing cumulative concentration-response curve (CCRC) of phenylephrine $\left(10^{-7}\right.$ to $10^{-3} \mathrm{M}$ in logarithmic half-units) was constructed. The contractile response to phenylephrine is 
regarded as the control CCRC. After wash-out with KRB, the vessel segments were equilibrated again for $15 \mathrm{~min}$, after which $0.1 \mathrm{nM}$ tamsulosin was added. Nine minutes later, a second CCRC of phenylephrine was constructed to determine the effect of tamsulosin on phenylephrine-induced contraction. After wash-out, vessels were incubated for 9 min with $0.1 \mathrm{nM}$ tamsulosin in combination with 5, 10, or $20 \mu \mathrm{M}$ quercetin. Hereafter, a third CCRC of phenylephrine was constructed to determine the effect of combination of quercetin and tamsulosin on phenylephrine-induced contraction.

In order to determine the effect of quercetin metabolites on tamsulosin function, vessels were incubated with $10 \mu \mathrm{M}$ of either 4'O-methyl-quercetin or quercetin-3-glucuronide in combination with $0.1 \mathrm{nM}$ tamsulosin for $9 \mathrm{~min}$, after which the vessels were contracted by phenylephrine. The effects of quercetin, 4'O-methyl-quercetin and quercetin-3-glucuronide alone on phenylephrine-induced contractions were also determined. A possible reaction between quercetin and tamsulosin was checked spectrophotometrically. No reaction was found. Furthermore, as a control experiment, the effect of the vehicle (DMSO) was determined in the same concentration (max. $0.2 \%$ ) as used in the experiments. DMSO was found to have no significant effect on phenylephrine-induced contractions. After each wash-out and equilibration period, the arterial tension returned back to baseline independent of treatment. Finally, time-control experiments were performed by repeating a dose-response curve with phenylephrine at the end of the experiment. The sensitivity of the arteries to phenylephrine had not been changed during time and exposures.

\section{Ferrous thiocyanate assay}

To determine $\mathrm{H}_{2} \mathrm{O}_{2}$ levels, the ferrous thiocyanate assay was performed as described by Hildebrandt et al [29]. In this assay, ferrous ion is oxidized to ferric ion by $\mathrm{H}_{2} \mathrm{O}_{2}$. Subsequently, thiocyanate will couple the ferric ion under strongly acidic conditions to form a red colored ferric iron-thiocyanate complex. This complex can be quantified spectrophotometrically [29]. A calibration curve with $\mathrm{H}_{2} \mathrm{O}_{2}$ curve was produced. In the cuvettes $350 \mu \mathrm{l}$ of standards were mixed with $350 \mu \mathrm{l}$ of concentrated $\mathrm{HCl}, 200 \mu \mathrm{l}$ of potassium thiocyanate (final concentration $200 \mathrm{mM}$ ) and $100 \mu \mathrm{l}$ of ammonium iron sulfate (final concentration $5 \mathrm{mM}$ ) respectively. After $10 \mathrm{~min}$ at room temperature, absorption was measured at $483 \mathrm{~nm}$. A blank was prepared using $\mathrm{H}_{2} \mathrm{O}$. KRB and the flavonoids did not interfere with the assay. $\mathrm{H}_{2} \mathrm{O}_{2}$ levels induced by quercetin or quercetin metabolites were determined every minute during the 9 min incubations in KRB buffer.

\section{Data analysis}

Data are shown as mean \pm S.E.M. Contractile responses are expressed as percentage of the maximal contractile response to phenylephrine (Phe $\mathrm{MAX}_{\mathrm{M}}$ ) before administration of any other compound. Individual CCRC were fitted to a non-linear regression curve and $\mathrm{EC}_{50}$ was calculated using GraphPad Prism 5.02 (GraphPad Software Inc., La Jolla, CA, USA). In order to correct for any variability among the conditions, average $\mathrm{EC}_{50}$ values for each condition are summarized in table 1 . Decreases in sensitivity to phenylephrine are calculated by dividing the $\mathrm{EC}_{50}$ of the particular condition by the $\mathrm{EC}_{50}$ of the control condition one-way ANOVA tests were used to compare $\mathrm{EC}_{50}$ values between the different conditions. Data 58 
were analyzed using two-way ANOVA (comparison of CCRC). Bonferroni's post hoc t-tests were used to compare multiple groups. 
Results

Effect of tamsulosin on phenylephrine-induced vasoconstriction

Phenylephrine dose-dependently constricted isolated mesenteric arteries (figure 1). Tamsulosin decreased the maximal response with approximately 30\%. More importantly, tamsulosin (0.1 nM) produced a non-competitive rightward displacement of the concentration-response curve to phenylephrine (figure 1 and table 1 ), since it significantly decreased $(17$-fold) the sensitivity towards phenylephrine $(P<0.001)$.

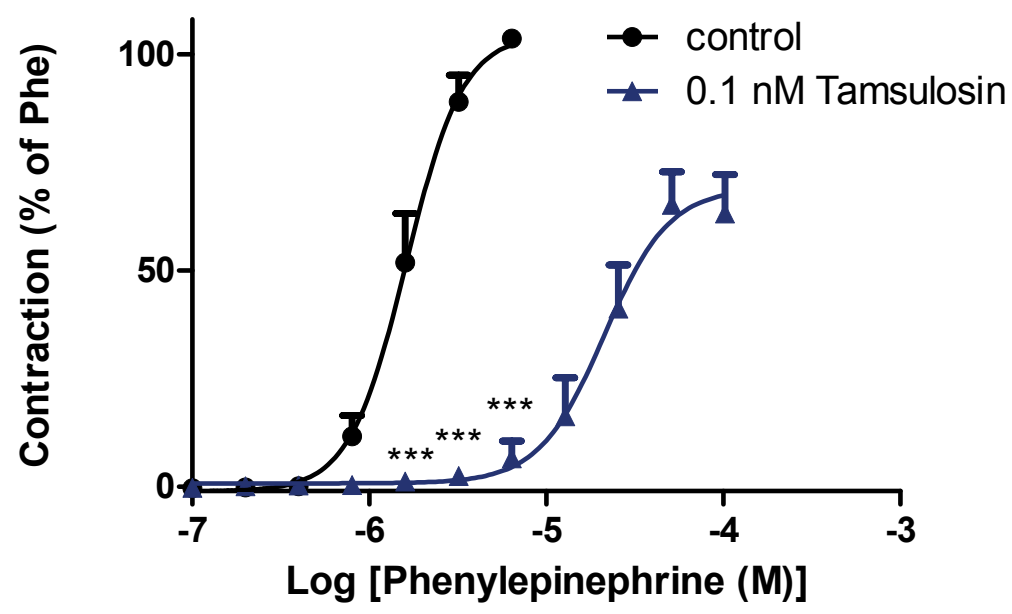

Figure 1| The effect of $0.1 \mathrm{nM}$ tamsulosin on phenylephrine-induced vasoconstriction. Phenylephrine-induced vasoconstriction is shown for control. Findings are expressed as \% $\mathrm{Phe}_{\text {MAX }}$ and are shown as means \pm S.E.M. $(n=10) .{ }^{* * *} p<0.001$.

Effect of quercetin on phenylephrine-induced vasoconstriction and tamsulosin-induced vasorelaxation

Quercetin (5, 10 and $20 \mu \mathrm{M}$ ) also shifted the concentration-response curve to phenylephrine rightward in a concentration dependent manner (with a 2-, 5-, and 6-fold decrease in phenylephrine sensitivity, respectively). Additionally, quercetin decreased the maximal response (Emax: 85\%, 75\% and 68\% respectively) (figure 2 and table 1). Although higher concentrations were used, these effects were less than that of tamsulosin. The combination of tamsulosin and quercetin $(5,10$, and $20 \mu \mathrm{M})$ was found to produce an even greater rightward shift of the CCRC to phenylephrine by decreasing the sensitivity to phenylephrine 173-, 207- and 112-fold (figure 2), without further affecting Emax. These reductions in sensitivity were greater than those observed for tamsulosin and quercetin alone. Hence, quercetin strongly increased the potency of tamsulosin $(P<0.001)$. 
Effects of quercetin metabolites on phenylephrine-induced vasoconstriction and tamsulosininduced vasorelaxation

4'O-methyl-quercetin $(10 \mu \mathrm{M})$ and quercetin-3-glucuronide $(10 \mu \mathrm{M})$ decreased the arterial sensitivity to phenylephrine slightly by 2 - and 1.5 -fold respectively $(P<0.005)$ (figure 3 and table 1). In combination with tamsulosin 4'O-methyl-quercetin and quercetin-3-glucuronide shifted the CCRC to phenylephrine markedly to the right. The sensitivity to phenylephrine was decreased 146- and 39-fold (figure 3), respectively, without further affecting Emax. As shown in table 1 , these reductions in sensitivity were greater than obtained with tamsulosin and the quercetin metabolites alone $(P<0.001)$. Thus, similary as quercetin also the metabolites 4'O-methyl-quercetin and quercetin-3-glucuronide strongly increased the tamsulosin-induced effects.

\section{$\mathrm{H}_{2} \mathrm{O}_{2}$ formation by quercetin and metabolites}

Quercetin produces $\mathrm{H}_{2} \mathrm{O}_{2}$ in a concentration-dependent manner (figure 4A). After 9 min of incubation in the organ bath, approximately $7.8 \mu \mathrm{M} \mathrm{H}_{2} \mathrm{O}_{2}$ was formed by quercetin (10 $\mu \mathrm{M})$. In contrast, 4 'O-methyl-quercetin $(10 \mu \mathrm{M})$ and quercetin-3-glucuronide (10 $\mu \mathrm{M})$ only produced minor amounts of $\mathrm{H}_{2} \mathrm{O}_{2}$ namely $1.1 \mu \mathrm{M} \mathrm{H}_{2} \mathrm{O}_{2}$ and $2.2 \mu \mathrm{M} \mathrm{H}_{2} \mathrm{O}_{2}$ respectively, which were substantially lower than the $\mathrm{H}_{2} \mathrm{O}_{2}$ levels induced by $10 \mu \mathrm{M}$ quercetin (figure 4B). 

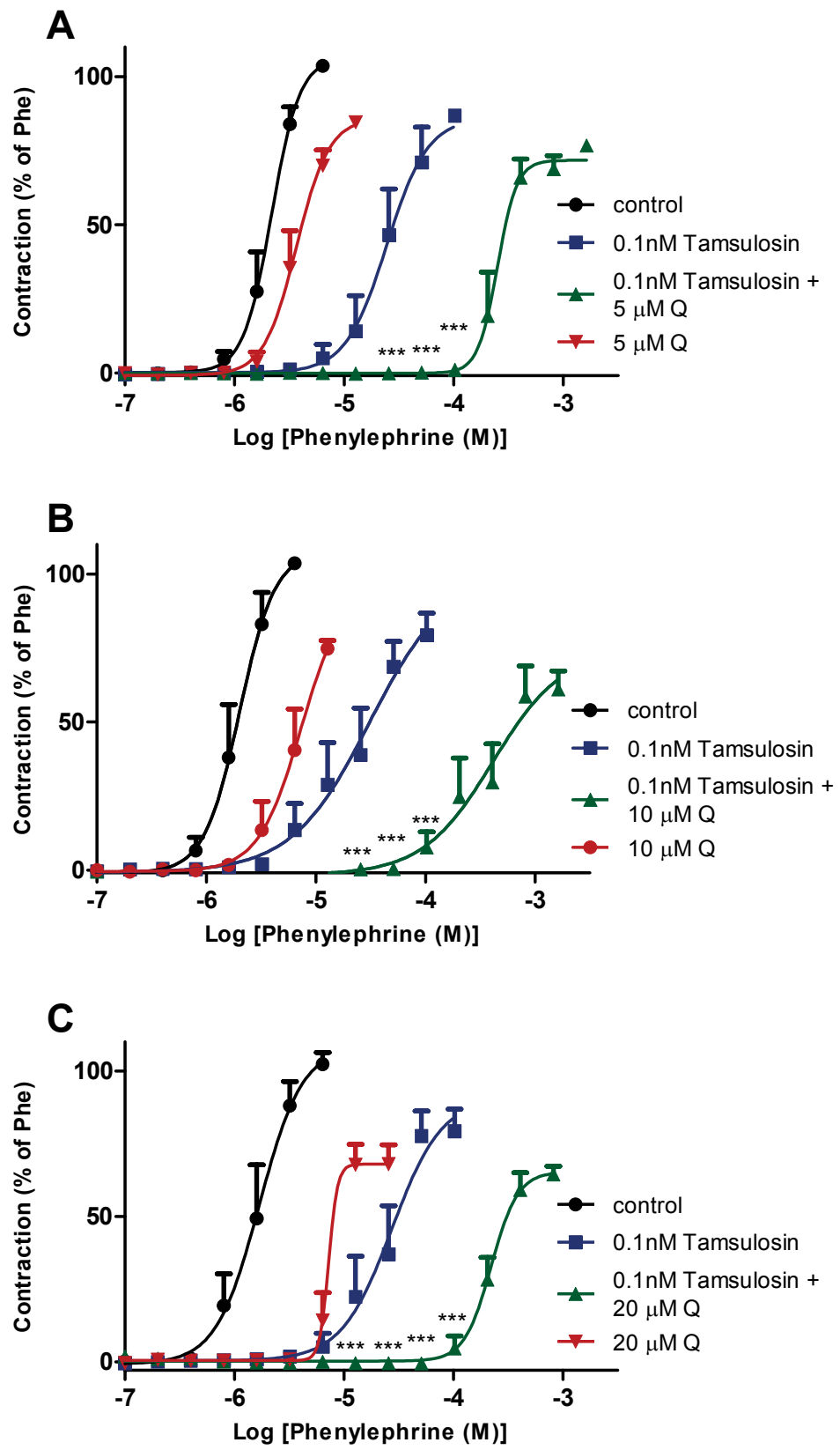

Figure 2 | The decrease in the sensitivity of the arteries towards phenylephrine and the increase in tamsulosin effects induced by different concentrations of quercetin $(5,10$ and $20 \mu \mathrm{M} ; \mathrm{A}, \mathrm{B}$ and $\mathrm{C})$. Findings are expressed as \% Phe $\mathrm{MAX}_{\mathrm{M}}$ and are shown as means \pm S.E.M. $(\mathrm{n}=6)$. ${ }^{* * *} \mathrm{P}<0.001$ (compared to tamsulosin). Q: quercetin. 

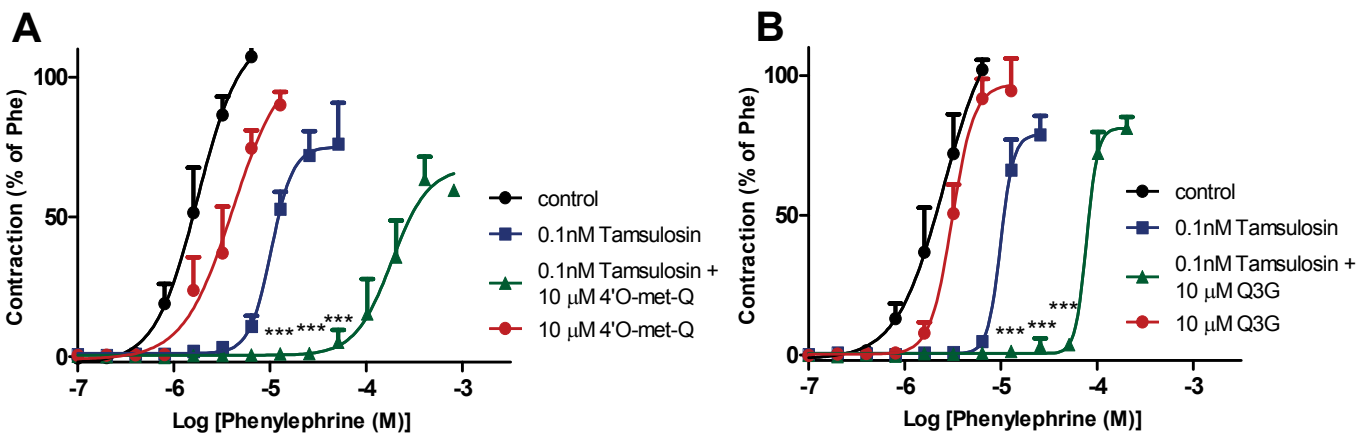

Figure $3 \mid$ The decrease in the sensitivity of the arteries towards phenylephrine and the increase in tamsulosin effects induced by $10 \mu \mathrm{M}$ 4'O-methyl-quercetin (A) or $10 \mu \mathrm{M}$ quercetin-3-glucuronide (B). Findings are expressed as \% Phe ${ }_{\text {MAX }}$ and are shown as means \pm S.E.M. $(n=6) .{ }^{*} P<0.005,{ }^{* * *} P<0.001$ (compared to tamsulosin).Q3G: quercetin-3-glucuronide, 4'O-met-Q: 4'O-methyl-quercetin.
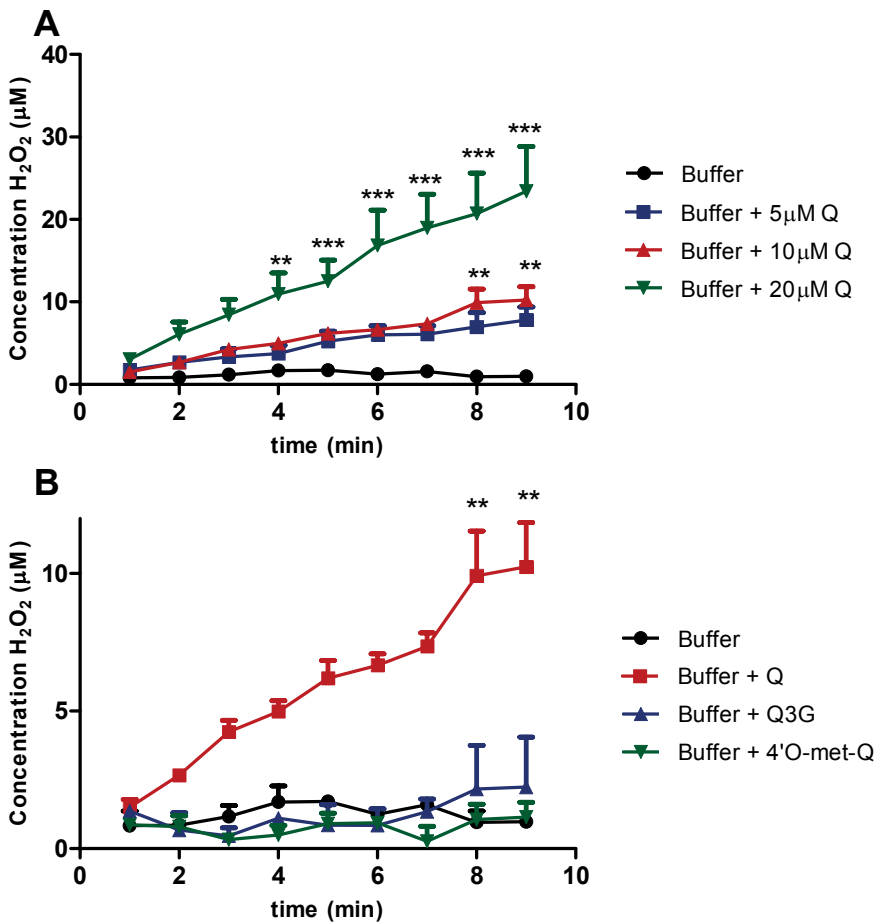

Figure 4| $\mathrm{H}_{2} \mathrm{O}_{2}$ levels after addition of different concentrations quercetin (A) or $10 \mu \mathrm{M}$ 4'O-methylquercetin and quercetin-3-glucuronide (B) during 9 min of incubation. Findings are shown as means \pm S.E.M. ( $n=4) .{ }^{* * P}<0.005,{ }^{* *} P<0.001$. Q: quercetin; Q3G; quercetin-3-glucuronide; 4'O-met-Q: 4'Omethyl-quercetin. 


\section{Discussion}

Our study reports on the pharmacodynamic supplement-drug interaction between tamsulosin and quercetin. The major finding is that the supplement quercetin strongly potentiates $\alpha_{1}$-adrenoceptor antagonizing of the drug tamsulosin.

Mesenteric arteries are involved in regulation of local blood flow and systemic blood pressure [30]. Arterial smooth muscles of mesenteric arteries are densely occupied with $\alpha_{1^{-}}$ adrenoceptors. The flavonoid quercetin has previously been shown to induce vasorelaxation by reducing the sensitivity of arteries to both the $\alpha_{1}$-adrenoceptor agonists phenylephrine and noradrenaline in arteries with and without endothelium [2, 9, 29, 3133]. Vasorelaxation induced by the $\alpha_{1}$-adrenoceptor blocker tamsulosin, as well of quercetin and its metabolites and combinations were determined on mesenteric arteries, to evaluate the interaction of the supplement quercetin with the drug tamsulosin.

In vivo, quercetin was found to decrease mean arterial pressure and blood pressure in rats and humans [34]. In rats, plasma concentrations of quercetin were found to range from 15 $\mu \mathrm{M}$ to $60 \mu \mathrm{M}$ after feeding them a meal containing quercetin [35]. In humans, plasma concentrations of quercetin range from 0.1 to $1 \mu \mathrm{M}$ [36]. However, chronic supplementation with quercetin elevates plasma concentrations up to $3 \mu \mathrm{M}$ [37]. In addition, it should be taken into account that quercetin is extensively metabolized and these metabolites are held responsible for at least part of the effects of quercetin. Based on previous studies on the vasorelaxing effect of quercetin, three different concentrations of quercetin $(5,10$ and $20 \mu \mathrm{M})$ were used in this study and compared to the effects of the metabolites quercetin-3-glucuronide and 4'O-methyl-quercetin. Our study shows that quercetin and the two quercetin metabolites 4'O-methyl-quercetin and quercetin-3glucuronide can induce vasorelaxation by reducing the sensitivity to phenylephrine.

The drug tamsulosin (0.1 nM) was able to strongly antagonize the vasoconstrictor effect of phenylephrine. This corresponds to previous research in which the vasorelaxing effects of several concentrations (ranging from $0.1 \mathrm{nM}$ to $30 \mathrm{nM}$ ) of tamsulosin on phenylephrine and (nor)adrenaline constricted arteries were determined [21]. Although tamsulosin is administered to block $\alpha_{1 A^{-}}$adrenoceptors in the prostate, it will also block $\alpha_{1 A^{-}}$and $\alpha_{1 D^{-}}$ adrenoceptors in the vasculature [21]. As a consequence of this lack of selectivity, the vasoconstrictor tone to $\alpha_{1}$-adrenoceptor agonists as phenylephrine, adrenaline and noradrenaline is blocked. This results in orthostatic hypotension, a common side effect of tamsulosin.

Orthostatic hypotension is caused by a drastic fall in blood pressure due to gravitational displacement of blood when standing up. Normally, the sympathetic system increases sympathetic outflow, heart rate, vascular resistance, constriction of the veins and cardiac output by activating $\alpha_{1 \mathrm{~A}}$-adrenoceptors in the vasculature in order to redistribute the blood and to normalize blood pressure. Blocking the $\alpha_{1}$-adrenoceptors in the arteries and veins will antagonize such a physiological vaso- and venoconstrictor reflex, which forms the molecular basis for orthostatic hypotension. Tamsulosin treatment is normally started with 0.3 or $0.6 \mathrm{mg}$ capsules. Harada et al (2000) showed showed that $0.6 \mathrm{mg}$ tamsulosin, giving a 
steady state plasma concentrations of $0.3 \mathrm{nM}$, induced orthostatic hypotension in healthy men $[38,39]$. The results found in the present study confirm the vasorelaxing ability of tamsulosin by blocking $\alpha_{1}$-adrenoceptors, which form the pharmacological fundament of orthostatic hypotension. Similar to tamsulosin, other $\alpha_{1}$-adrenoceptor antagonists as phenoxybenzamine, phentolamine and prazosin have been reported to induce orthostatic hypotensive effects by blocking these receptors [40-42]

Strikingly, the combination of quercetin, 4'O-methyl-quercetin and quercetin-3-glucuronide with tamsulosin further diminished the sensitivity to phenylephrine. The decline in sensitivity by the combination of agents was much more pronounced than that of either tamsulosin or quercetin and its metabolites in isolation. This demonstrates the potential supplement-drug interaction of quercetin and tamsulosin.

Although reports on vasorelaxing properties of quercetin are univocal, there is no consensus on the molecular mechanism. Several mechanisms have been implicated, such as an increase in intracellular $\mathrm{Ca}^{2+}$, a decreased smooth muscle calcium-sensitivity or increased nitric oxide (NO) bioavailability $[9,33] . \mathrm{H}_{2} \mathrm{O}_{2}$ is also suggested to play a role in quercetin-induced vasorelaxation as endothelium-derived hyperpolarizing factor [43, 44]. Quercetin is known to induce the formation of $\mathrm{H}_{2} \mathrm{O}_{2}[11,12] . \mathrm{H}_{2} \mathrm{O}_{2}$ is an important regulator of signal transduction. Once $\mathrm{H}_{2} \mathrm{O}_{2}$ is produced, it activates eNOS via AKT and ERK $1 / 2$ to produce NO, which causes vasorelaxation $[9,45]$.

To further unravel the mechanism, $\mathrm{H}_{2} \mathrm{O}_{2}$ production was assessed. Quercetin was found to produce significant amounts of $\mathrm{H}_{2} \mathrm{O}_{2}$ in a concentration-dependent manner, which might be involved in quercetin-induced vasorelaxation. In addition, 4'O-methyl-quercetin and quercetin-3-glucuronide hardly produced $\mathrm{H}_{2} \mathrm{O}_{2}$. Quercetin dependent production of $\mathrm{H}_{2} \mathrm{O}_{2}$ did not correlate with the potentiation of the tamsulosin effects. Moreover, the tamsulosin effects are also strongly augmented by the quercetin metabolites that hardly give rise to $\mathrm{H}_{2} \mathrm{O}_{2}$ production. These results suggest that $\mathrm{H}_{2} \mathrm{O}_{2}$ is not essential for increasing the vasorelaxation effects of tamsulosin.

The orthostatic hypotensive effect of tamsulosin is known to be aggravated by the concomitant use of sildenafil, a drug belonging to the phosphodiesterase inhibitors, which is used to treat erectile dysfunction [23]. This drug-drug interaction is well studied and documented. In the combined interaction, the side effect of tamsulosin is amplified by sildenafil. Besides drug-drug interactions, bioactive constituents from nutrition are also known to impact the response of drugs [46]. Most reported interactions are of pharmacokinetic nature, affecting the metabolism of drugs [47]. The best known is grape fruits that inhibit cytochrome P-450 3A4, a metabolic enzyme involved in the metabolism of numerous drugs $[48,49]$. As a consequence, levels of drugs such as nifedipine, nitrendipine and felodipine will rise to potential toxic levels. Besides pharmacokinetic interactions, bioactives might also modify drug effects, potentially causing adverse health effects [47]. Such pharmacodynamics interactions are scarcely investigated. Our study draws attention to a pharmacodynamic interaction between the drug tamsulosin and the supplement quercetin. Tamsulosin effects are strongly amplified by quercetin. The simultaneous use of 
these compounds may increase the potential for orthostatic hypotension and hence the risk of falling, which has serious consequences for the elderly, a group of frail patients [26]. The phamacodynamic interaction described in the present study, the frequent use of quercetin, and the potentially major clinical impact of this and probably other combinations $[50,51]$, draws attention to supplement-drug interactions that warrant more research. 


\section{References}

1. Kuhnau J. The flavonoids. A class of semi-essential food components: their role in human nutrition. World Rev Nutr Diet. 1976;24:117-91.

2. Perez-Vizcaino F, Ibarra M, Cogolludo AL, Duarte J, Zaragoza-Arnaez F, Moreno L, et al. Endothelium-independent vasodilator effects of the flavonoid quercetin and its methylated metabolites in rat conductance and resistance arteries. J Pharmacol Exp Ther. 2002;302:66-72.

3. Boots AW, Haenen GR, Bast A. Health effects of quercetin: from antioxidant to nutraceutical. Eur J Pharmacol. 2008;585:325-37.

4. Bast A, Haenen GR. Ten misconceptions about antioxidants. Trends Pharmacol Sci. 2013;34:430-6.

5. Kleemann R, Verschuren L, Morrison M, Zadelaar S, van Erk MJ, Wielinga PY, et al. Antiinflammatory, anti-proliferative and anti-atherosclerotic effects of quercetin in human in vitro and in vivo models. Atherosclerosis. 2011;218:44-52.

6. Edwards RL, Lyon T, Litwin SE, Rabovsky A, Symons JD, Jalili T. Quercetin reduces blood pressure in hypertensive subjects. J Nutr. 2007;137:2405-11.

7. Boots AW, Wilms LC, Swennen EL, Kleinjans JC, Bast A, Haenen GR. In vitro and ex vivo antiinflammatory activity of quercetin in healthy volunteers. Nutrition. 2008;24:703-10.

8. Galindo P, Rodriguez-Gomez I, Gonzalez-Manzano S, Duenas M, Jimenez R, Menendez C, et al. Glucuronidated quercetin lowers blood pressure in spontaneously hypertensive rats via deconjugation. PLoS One. 2012;7:e32673.

9. Khoo NK, White CR, Pozzo-Miller L, Zhou F, Constance C, Inoue T, et al. Dietary flavonoid quercetin stimulates vasorelaxation in aortic vessels. Free Radic Biol Med. 2010;49:339-47.

10. Larson AJ, Symons JD, Jalili T. Therapeutic potential of quercetin to decrease blood pressure: review of efficacy and mechanisms. Adv Nutr. 2012;3:39-46.

11. Williams RJ, Spencer JP, Rice-Evans C. Flavonoids: antioxidants or signalling molecules? Free Radic Biol Med. 2004;36:838-49.

12. Choi EJ, Chee KM, Lee BH. Anti- and prooxidant effects of chronic quercetin administration in rats. Eur J Pharmacol. 2003;482:281-5.

13. Boots AW, Li H, Schins RP, Duffin R, Heemskerk JW, Bast A, et al. The quercetin paradox. Toxicol Appl Pharmacol. 2007;222:89-96.

14. Ma Z, Hung Nguyen $T$, Hoa Huynh $T$, Tien Do $P$, Huynh $H$. Reduction of rat prostate weight by combined quercetin-finasteride treatment is associated with cell cycle deregulation. J Endocrinol. 2004;181:493-507.

15. Shoskes DA, Zeitlin SI, Shahed A, Rajfer J. Quercetin in men with category III chronic prostatitis: a preliminary prospective, double-blind, placebo-controlled trial. Urology. 1999;54:960-3.

16. Roehrborn CG, Schwinn DA. Alpha1-adrenergic receptors and their inhibitors in lower urinary tract symptoms and benign prostatic hyperplasia. J Urol. 2004;171:1029-35.

17. Steers WD, Zorn B. Benign prostatic hyperplasia. Dis Mon. 1995;41:437-97.

18. Djavan B, Marberger M. A meta-analysis on the efficacy and tolerability of alpha1adrenoceptor antagonists in patients with lower urinary tract symptoms suggestive of benign prostatic obstruction. Eur Urol. 1999;36:1-13.

19. Kumar D, Khan FA. Tamsulosin-induced severe hypotension during general anesthesia: a case report. J Med Case Rep. 2010;4:365.

20. Methven L, Simpson PC, McGrath JC. Alpha1A/B-knockout mice explain the native alpha1Dadrenoceptor's role in vasoconstriction and show that its location is independent of the other alpha1subtypes. Br J Pharmacol. 2009;158:1663-75.

21. Noble AJ, Chess-Williams R, Couldwell C, Furukawa K, Uchyiuma T, Korstanje C, et al. The effects of tamsulosin, a high affinity antagonist at functional alpha 1A- and alpha 1D-adrenoceptor subtypes. Br J Pharmacol. 1997;120:231-8. 
22. Taguchi K, Saitoh M, Sato S, Asano M, Michel MC. Effects of tamsulosin metabolites at alpha-1 adrenoceptor subtypes. J Pharmacol Exp Ther. 1997;280:1-5.

23. Nieminen T, Koobi T, Tammela TL, Kahonen M. Hypotensive potential of sildenafil and tamsulosin during orthostasis. Clin Drug Investig. 2006;26:667-71.

24. Piascik MT, Perez DM. Alpha1-adrenergic receptors: new insights and directions. J Pharmacol Exp Ther. 2001;298:403-10.

25. Kannus P, Parkkari J, Niemi S, Palvanen M. Fall-induced deaths among elderly people. Am J Public Health. 2005;95:422-4.

26. Tinetti ME, Williams TF, Mayewski R. Fall risk index for elderly patients based on number of chronic disabilities. Am J Med. 1986;80:429-34.

27. Kannus $\mathrm{P}$, Niemi S, Palvanen $\mathrm{M}$, Parkkari J. Continuously increasing number and incidence of fall-induced, fracture-associated, spinal cord injuries in elderly persons. Arch Intern Med. 2000;160:2145-9.

28. Nourian Z, Mow T, Muftic D, Burek S, Pedersen ML, Matz J, et al. Orthostatic hypotensive effect of antipsychotic drugs in Wistar rats by in vivo and in vitro studies of alpha1-adrenoceptor function. Psychopharmacology (Berl). 2008;199:15-27.

29. Hildebrandt AG, Roots I, Tjoe M, Heinemeyer G. Hydrogen peroxide in hepatic microsomes. Methods Enzymol. 1978;52:342-50.

30. Mulvany MJ. Structure and function of small arteries in hypertension. J Hypertens Suppl. 1990;8:S225-32.

31. Chen CK, Pace-Asciak CR. Vasorelaxing activity of resveratrol and quercetin in isolated rat aorta. Gen Pharmacol. 1996;27:363-6.

32. Rendig SV, Symons JD, Longhurst JC, Amsterdam EA. Effects of red wine, alcohol, and quercetin on coronary resistance and conductance arteries. J Cardiovasc Pharmacol. 2001;38:219-27.

33. Perez-Vizcaino F, Duarte J, Jimenez R, Santos-Buelga C, Osuna A. Antihypertensive effects of the flavonoid quercetin. Pharmacol Rep. 2009;61:67-75.

34. Larson AJ, Symons JD, Jalili T. Therapeutic potential of quercetin to decrease blood pressure: review of efficacy and mechanisms. Adv Nutr. 2012;3:39-46.

35. Manach C, Morand C, Demigne C, Texier O, Regerat F, Remesy C. Bioavailability of rutin and quercetin in rats. FEBS Lett. 1997;409:12-6.

36. Scalbert A, Williamson G. Dietary intake and bioavailability of polyphenols. I Nutr. 2000;130:2073S-85S.

37. Jin F, Nieman DC, Shanely RA, Knab AM, Austin MD, Sha W. The variable plasma quercetin response to 12-week quercetin supplementation in humans. Eur J Clin Nutr. 2010;64:692-7.

38. Harada K, Kawaguchi A, Ohmori M, Fujimura A. Antagonistic activity of tamsulosin against human vascular alpha1-adrenergic receptors. Clin Pharmacol Ther. 2000;67:405-12.

39. Korstanje C, Krauwinkel W, van Doesum-Wolters FL. Tamsulosin shows a higher unbound drug fraction in human prostate than in plasma: a basis for uroselectivity? $\mathrm{Br} J$ Clin Pharmacol. 2011;72:218-25.

40. Gabriel R, Meek D, Ghosh BC. Letter: Collapse after prazosin hydrochloride. Lancet. 1975;1:1095.

41. Ghostine SY, Comair YG, Turner DM, Kassell NF, Azar CG. Phenoxybenzamine in the treatment of causalgia. Report of 40 cases. Journal of neurosurgery. 1984;60:1263-8.

42. Humphrey SJ, McCall RB. A rat model for predicting orthostatic hypotension during acute and chronic antihypertensive drug therapy. Journal of pharmacological methods. 1982;7:25-34.

43. Cogolludo A, Frazziano G, Briones AM, Cobeno L, Moreno L, Lodi F, et al. The dietary flavonoid quercetin activates BKCa currents in coronary arteries via production of H2O2. Role in vasodilatation. Cardiovasc Res. 2007;73:424-31.

44. Shimokawa H, Matoba T. Hydrogen peroxide as an endothelium-derived hyperpolarizing factor. Pharmacol Res. 2004;49:543-9. 
45. Cai H. Hydrogen peroxide regulation of endothelial function: origins, mechanisms, and consequences. Cardiovasc Res. 2005;68:26-36.

46. Pickering G. Frail elderly, nutritional status and drugs. Arch Gerontol Geriatr. 2004;38:17480.

47. Walter-Sack I, Klotz U. Influence of diet and nutritional status on drug metabolism. Clin Pharmacokinet. 1996;31:47-64.

48. Bailey DG, Dresser G, Arnold JM. Grapefruit-medication interactions: forbidden fruit or avoidable consequences? Cmaj. 2013;185:309-16.

49. Kane GC, Lipsky JJ. Drug-grapefruit juice interactions. Mayo Clin Proc. 2000;75:933-42.

50. Akamine D, Filho MK, Peres CM. Drug-nutrient interactions in elderly people. Curr Opin Clin Nutr Metab Care. 2007;10:304-10.

51. Mallet $L$, Spinewine A, Huang A. The challenge of managing drug interactions in elderly people. Lancet. 2007;370:185-91. 



\section{Chapter 4}

\section{Anticholinergic accumulation: a slumbering interaction between drugs and food supplements}

Misha F Vrolijk, Antoon Opperhuizen, Eugène H J M Jansen, Aalt Bast, Guido R $M$ M Haenen

Basic Clinical Pharmacology and Toxicology. 2015 Dec;117(6):427-32 


\begin{abstract}
Many compounds display anticholinergic effects which might give rise to cognitive impairment and even delirium. These side effects are caused by their ability to bind to muscarinic receptors in our brain. Especially with combination of compounds, these serious effects are seen. This phenomenon, known as anticholinergic accumulation, is especially seen in elderly. A classification of drugs for anticholinergic side effects has been made based on clinical observations, the ACB score. Here, we aimed to substantiate this classification by comparing the affinity of numerous drugs for the muscarinic receptors to the ACB score. Additionally, a number of supplements are screened. The affinity of the compounds was determined by their ability to displace the radioligand $\left[{ }^{3} \mathrm{H}\right]$ pirenzepine of the muscarinic receptor induced by these compounds. Our results show that the affinity of a compound for the muscarinic receptors correlated with its ACB score. Also food supplements appeared to bind to these muscarinic receptors. Moreover, several drug-drug, supplement-supplement and supplement-drug combinations had an affinity for that is higher than the affinity of single compounds. This explains the phenomenon of anticholinergic accumulation. In conclusion, care should be taken to drug-drug and supplement-drug combinations with respect to anticholinergic accumulation.
\end{abstract}




\section{Introduction}

Many compounds display anticholinergic side effects caused by their ability to block muscarinic receptors in our brain $[1,2]$. Binding to this receptor may give rise to cognitive impairment and even delirium [3]. The anticholinergic side effect of a single compound is often relatively mild. However, when several compounds are taken simultaneously, more of the receptors will be blocked, aggravating the impact $[4,5]$. This is known as anticholinergic accumulation. Anticholinergic accumulation especially occurs in elderly as a result of polypharmacy, changes in brain neurochemistry as well as kinetics, risk factors that are all age-associated $[6,7]$.

Anticholinergic accumulation in elderly has important implications for health-care utilization and costs [8]. Delirium results in increased nursing time per patient, higher hospital costs (total nursing costs of approximately $\$ 69498$ per patient per year), and an increased duration of hospital stay (of 20.7 days compared to 8.9 days for controls) [9-11]. The resulting economic burden is substantial (which ranges from $\$ 38$ billion to $\$ 152$ billion each year in the USA) as well as the negative impact on the quality of life $[8,12]$.

In 2008 the Anticholinergic Cognitive Burden (ACB) scale was developed, which classifies drugs based on their anticholinergic effect $[13,14]$. Drugs with possible anticholinergic effects have an ACB score of 1 , drugs with established clinically relevant cognitive effects have an $A C B$ score of 2 and drugs with severe clinically relevant cognitive effects have an ACB score of 3 . The ACB list is based on clinical studies determining the anticholinergic side effects of drugs. Remarkably, in contrast to drugs, the effect of food supplements on anticholinergic accumulation has not gained any attention.

In the present study, we investigate the correlation of the affinity of drugs for the muscarinic receptor to the ACB score of that drug. Additionally, a number of supplements are screened for binding to muscarinic receptors. Since especially combinations of drugs give rise to anticholinergic accumulation with clinical relevant problems, several combinations of compounds are tested.

It was concluded that the affinity for the muscarinic receptors correlates with the clinical anticholinergic effects of the compounds tested. Not only drugs but also food supplements bind to muscarinic receptors. 


\section{Materials and Methods}

\section{Chemicals}

$\left[{ }^{3} \mathrm{H}\right]$ pirenzepine (84 $\left.\mathrm{Ci} / \mathrm{mmol}\right)\left(\left[{ }^{3} \mathrm{H}\right] \mathrm{PZ}\right)$ and Whatman filters were obtained from PerkinElmer. Amantadine, Atropine, Choline, Chondroitin, Cimetidine, Desipramine, Glucosamine, Hyoscyamine, Orphenadrine, Pirenzepine dichloride, Quercetine, Scopolamine, Theophylline, Ascorbic acid (Vitamin C), Adenosine (Vitamin B B $_{4}$, Pyridoxine (Vitamin $\mathrm{B}_{6}$ ), Cobolamine (Vitamin $\mathrm{B}_{12}$ ), Warfarin and Zinc were all obtained from Sigma Aldrich and dissolved in assay buffer (50 mM Na/K phosphate buffer; $\mathrm{pH}$ 7.4).

\section{Tissue preparation}

Male Wistar Kyoto (WKY) rats (200-250 g, Charles River, Maastricht, the Netherlands), were sacrificed by $\mathrm{CO}_{2}$-inhalation. Brains were rapidly removed and put in assay buffer. All experiments were approved by the University Animal Ethical Committee and conducted in accordance to the ethical guidelines (EEC Council directives 86 / 609) for using experimental animals ( "European Convention for the Protection of Vertebrate Animals Used for Experimental and other Scientific Purposes" (1986) and the "Guiding Principles in the Use of Animals in Toxicology", adopted by the Society of Toxicology (1989)). Brains were homogenized in assay buffer using a potter tube. Brain homogenates were first centrifuged at slow speed in order to remove unwanted pieces of tissue, which was followed by centrifuging at $20000 \times \mathrm{g}$ for 15 minutes. The precipitated material was resuspended in assay buffer and diluted in order to reach the final concentration given below.

\section{Binding assays}

For $\left[{ }^{3} \mathrm{H}\right] \mathrm{PZ}$ binding assays, $1 \mathrm{mg}$ of protein was used. Analysis of $\left[{ }^{3} \mathrm{H}\right] \mathrm{PZ}$ binding (final radioactive concentration: $100 \mu \mathrm{Ci} / \mathrm{mL}$ ) was determined as described by Michel et al (1993) [15]. For saturation binding experiments, tissues were incubated in assay buffer containing the radioligand and drugs or food supplements as indicated. The final assay volumes were $0.25 \mathrm{ml}$. Binding reactions were initiated by addition of tissues to the mixture, after which tubes were placed in the water bath for 60 minutes at $37^{\circ} \mathrm{C}$. After 1 hour binding reactions were terminated by adding $5 \mathrm{~mL}$ of ice-cold assay buffer to the reaction mixtures. This was followed by filtering the tissues over Whatman filters. Filters were washed 5 times with 5 $\mathrm{ml}$ of assay buffer, after which they were dried by suction. Finally, filters were placed into counting vials and $16 \mathrm{~mL}$ of scintillation cocktail was added to dissolve the filters. Then, filters were counted at the beta-counter. The amount of radioligand bound was less than $10 \%$ of total added ligand in all the experiments.

For saturation binding experiments, tissues were incubated for 60 minutes in a concentration-range of $\left[{ }^{3} \mathrm{H}\right] \mathrm{PZ}(0-100 \mathrm{nM})$. Non-specific binding was determined in parallel incubations using $1 \mu \mathrm{M}$ atropine. In the displacement experiments, tissues were incubated at $37^{\circ} \mathrm{C}$ for 60 minutes in the presence of $30 \mathrm{nM}$ of $\left[{ }^{3} \mathrm{H}\right] \mathrm{PZ}$ and either $100 \mathrm{nM}$ of drugs listed with an ACB score of 3,1 $\mu \mathrm{M}$ of drugs listed with an ACB score of 2 and $100 \mu \mathrm{M}$ of the 
drugs listed with an ACB score of 1 . Also, numerous food supplements (100 $\mu \mathrm{M})$ were screened for binding to muscarinic receptors. Moreover, drug-drug, supplementsupplement and drug-supplement combinations were also screened for binding to muscarinic receptors. Incubations were terminated as described above.

\section{Calculation of the affinity of the compound for the muscarinic receptor}

The affinity of the compounds for the muscarinic receptor was expressed as the $p K_{D}$ values $\left(=-\log K_{D} ; K_{D}=\right.$ dissociation constant of the compound). $p K_{D}$ values were calculated according to the modified Cheng-Prusoff equation that gives an accurate $K_{D}$ value for displacements between 20 and $80 \%$ of the labeled ligand $(0.2<\mathrm{B} / \mathrm{Bmax}<0.8)$ :

$$
p K D=-\log \left(\frac{[A] * K{ }^{* B}}{B \max ^{*}[P]-[P] * B^{*} K P-K P * B}\right)
$$

$B=\left[{ }^{3} \mathrm{H}\right] \mathrm{PZ}$ bound to receptor

$B_{\max }=$ Concentration of receptors

$[P]=$ concentration of $\left[{ }^{3} \mathrm{H}\right] \mathrm{PZ}$

$K_{P}=$ dissociation constant of $\left[{ }^{3} \mathrm{H}\right] \mathrm{PZ}$ for the receptor

$[A]=$ concentration of test compound in $\mathrm{mM}$

$K_{D}=$ Dissociation constant of $[A]$ for the receptor

$p K_{D}=-\log K_{D}$

Apparent $\mathrm{pK}_{\mathrm{D}}$ values were calculated when food supplements were combined or when two drugs were combined.

\section{Statistics}

Results are shown as mean \pm S.E.M. Saturation data were fitted to a non-linear regression curve. The kinetic parameters $K_{D}$ and $B_{\max }$ of $\left[{ }^{3} H\right] P Z$ were calculated using GraphPad Prism 5.02 (GraphPad Software Inc., La Jolla, CA, USA). Data were analyzed using a two-tailed Student's t-test to compare the (apparent) $\mathrm{PK}_{\mathrm{D}}$ values. $\mathrm{P}$ values of $<0.05$ were considered statistically significant. 


\section{Results}

In figure 1 binding of $\left.{ }^{3} \mathrm{H}\right] \mathrm{PZ}$ to the muscarinic receptors in rat brains is depicted. Nonspecific binding was determined by incubating rat brain with a fixed concentration of atropine $(1 \mu \mathrm{M})$ and various concentrations of $\left.{ }^{3} \mathrm{H}\right] \mathrm{PZ}(1-100 \mathrm{nM})$ (figure 1$)$. The $\mathrm{pK}_{\mathrm{D}}$ value (8.7) of atropine was determined after incubation of a fixed concentration of $\left[{ }^{3} \mathrm{H}\right] \mathrm{PZ}$ (30 $\mathrm{nM})$ and a variable concentration of atropine $(0.1 \mathrm{nM}-1 \mu \mathrm{M})$ (figure 1 insert). [ $\left.{ }^{3} \mathrm{H}\right] \mathrm{PZ}$ binds to the receptor with an affinitiy $\left(\mathrm{pK}_{\mathrm{D}}\right)$ of 7.9 and the concentration of muscarinic receptors $\left(B_{\max }\right)$ was $18.0 \pm 1.3 \mathrm{fmol} / \mathrm{mg}$ protein (figure 1 ).

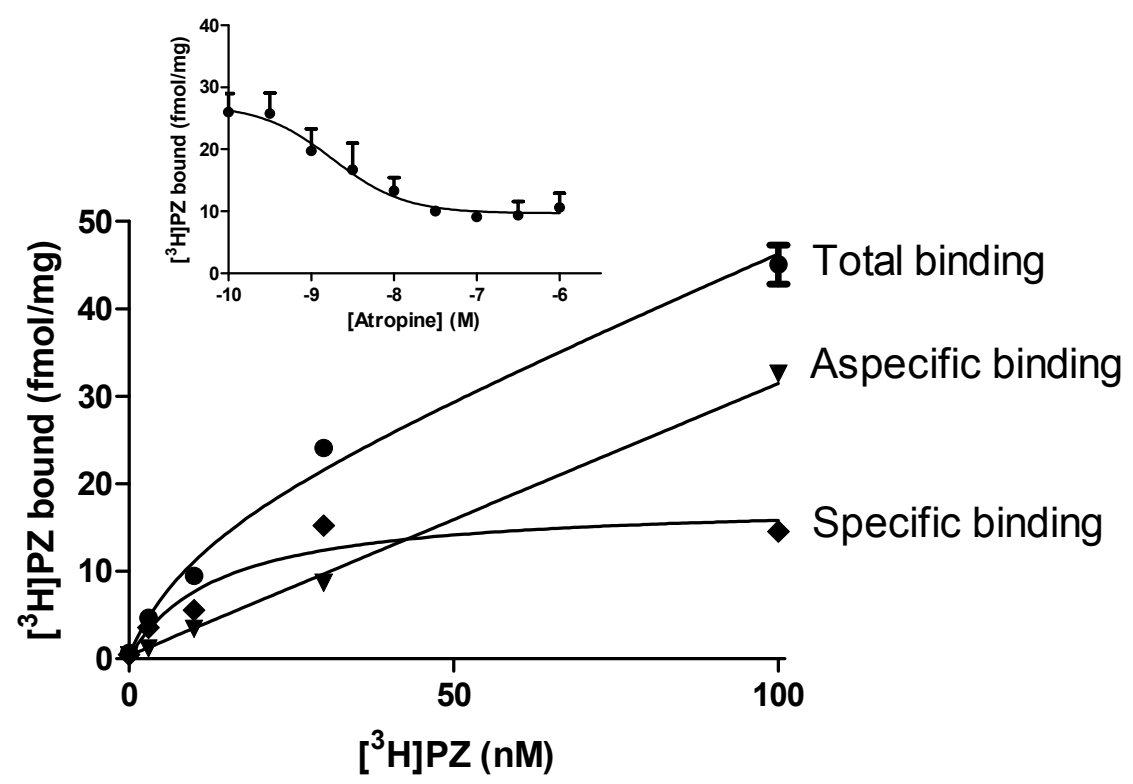

Figure 1| Binding of [3H]PZ to the muscarinic receptors in rat brains (figure) and the affinity of atropine for these receptors (insert). Analysis of total $\left[{ }^{3} \mathrm{H}\right] \mathrm{PZ}$ binding (final radioactive concentration: $100 \mu \mathrm{Ci} / \mathrm{mL}$ ) was determined as described by Michel et al (1993). Tissues were incubated for 60 minutes in a concentration-range of $\left[{ }^{3} \mathrm{H}\right] \mathrm{PZ}(0-100 \mathrm{nM})$. Non-specific binding was determined in parallel incubations using $1 \mu \mathrm{M}$ atropine. Specific binding was calculated using Prism 5.02. The affinity of atropine was determined after incubation of a fixed concentration of $\left[{ }^{3} \mathrm{H}\right] \mathrm{PZ}(30 \mathrm{nM})$ and different concentrations of atropine $(0.1 \mathrm{nM}-1 \mu \mathrm{M})$ (figure 1 insert). Data are shown as means $\pm \operatorname{SEM}(n=4)$.

In order to determine whether the ACB score of a drug could be correlated to its ability to bind to muscarinic receptors, the affinity for the receptor of a selection of drugs with different ACB scores was quantified. The drugs with an ACB score of 1 , chloretalidone, cimetidine, furosemide, haloperidol, metoprolol, risperidone, theophylline and warfarin, had a relatively low affinity for the receptors; $\mathrm{pK}_{\mathrm{D}}$-values (mM) ranged from 1.4 to 1.6 (figure 2). Amantadine, carbamazepine and oxcarbazepine, the drugs with an ACB score of 2 , had an intermediate affinity for the receptors; $\mathrm{PK}_{\mathrm{D}}$-values ranged from 3.7 to 3.8. Finally, 
atropine, desipramine, hyoscyamine, olanzapine, scopolamine and orphenadrine, the drugs with an ACB score of 3 , had a high affinity for the muscarinic receptors; $p K_{D}$-values ranged from 4.3 to5.3 (figure 2). Combination of warfarin $\left(p K_{D}: 1.7\right)$, cimetidine $\left(p K_{D}: 1.6\right)$ and theophylline $\left(p K_{D}: 1.7\right)$ resulted in an apparent $p K_{D}$ value of the combination of $2.6(P<0.05$; figure 2).

A

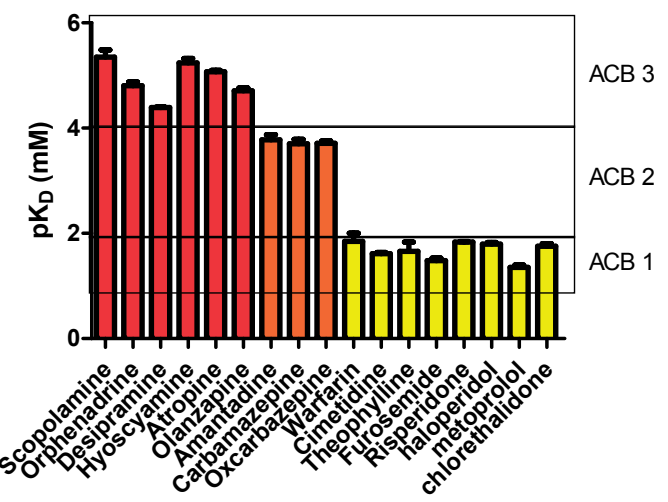

B

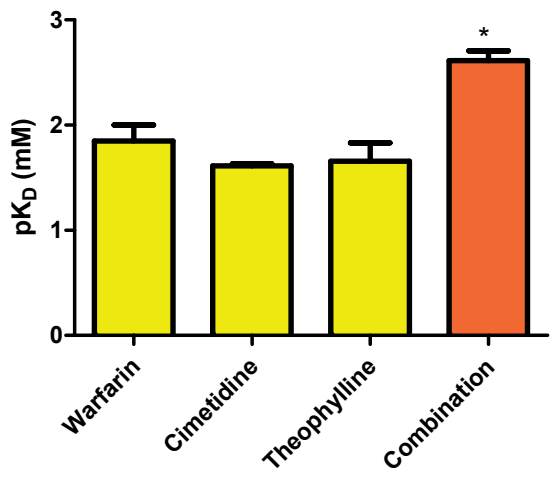

Figure 2| The affinity of numerous drugs listed on the ACB list for the muscarinic receptors (A) and the effect of combination of warfarin, cimetidine and theophylline on the apparent $\mathrm{pK}_{\mathrm{D}}(\mathrm{B})$. The affinities were calculated using a modified Cheng-Prusoff equation that gives an accurate $K_{D}$ value for displacements between 20 and $80 \%$ of the labeled ligand. In the displacement experiments, tissues were incubated at $37^{\circ} \mathrm{C}$ for 60 minutes in the presence of $30 \mathrm{nM}$ of $\left[^{3} \mathrm{H}\right] \mathrm{PZ}$ and either $100 \mathrm{nM}$ of drugs listed with an ACB score of 3 (red bars), $1 \mu \mathrm{M}$ of drugs listed with an ACB score of 2 (orange bars) and $100 \mu \mathrm{M}$ of the drugs listed with an ACB score of 1 (yellow bars). Data are shown as means \pm SEM $(n=4)$. Differences were considered to be statistically significant when $P<0.05 .{ }^{*} P<0.05$.

Numerous supplements were also screened for binding to the muscarinic receptors. Zinc and choline did not displace $\left[{ }^{3} \mathrm{H}\right] \mathrm{PZ}$ effectively. $\mathrm{pK}_{\mathrm{D}}$ values of zinc and choline were less than 0.5 indicating that both supplements did not strongly bind to the receptor. Glucosamine, quercetin and the vitamins $B_{4}, B_{6}, B_{12}$ and $C$ bound more potently with $p K_{D}$ values of 1.4 to 1.7 (figure 3).

These $\mathrm{pK}_{\mathrm{D}}$ were comparable to those of the drugs with an ACB score of 1 . Chondroitin had the highest affinity; its $p K_{D}$ value was 1.7. 

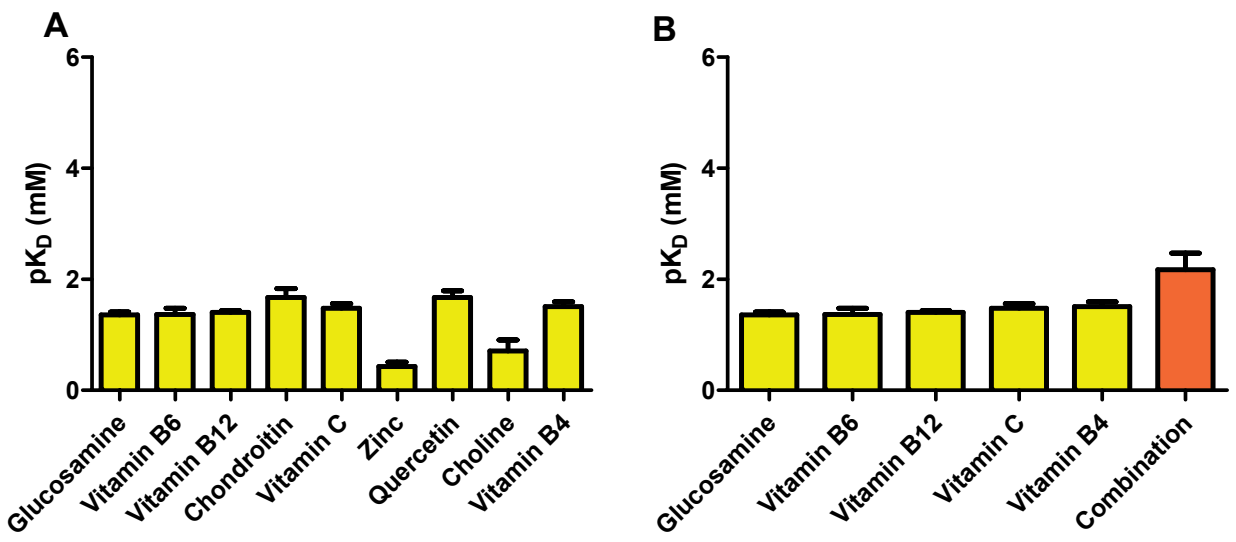

Figure 3| The affinitiy of numerous food supplements for the muscarinic receptors $(A)$ and the apparent affinity of a combination of several of these supplements (B). The affinities were calculated using a modified Cheng-Prusoff equation that gives an accurate $K_{D}$ value for displacements between 20 and $80 \%$ of the labeled ligand, after performing displacement experiments. Tissues were incubated at $37^{\circ} \mathrm{C}$ for 60 minutes in the presence of $30 \mathrm{nM}$ of $\left[{ }^{3} \mathrm{H}\right] \mathrm{PZ}$ and $100 \mathrm{nM}$ of the food supplement. Data are shown as means \pm SEM $(n=4)$.

Similar to the combination of drugs, a combination of food supplements can have a higher affinity for the receptor than that of the single compounds. This is evidenced by the combination of glucosamine $\left(p K_{D}: 1.3\right)$, vitamin $B_{6}\left(p K_{D}: 1.5\right)$, vitamin $B_{12}\left(p K_{D}: 1.5\right)$ and vitamin $C\left(p K_{D}: 1.4\right)$ (all with an affinity which would give an $A C B$ score of 1 ) had an apparent $p K_{D}$ value of 2.1. Based on this $p K_{D}$ value, the combination has an $A C B$ score of 2 (figure 3).

In addition, the combination of supplements with drugs can also result in a higher affinity for the receptor than the single compounds. This is seen with the combination of vitamin $B_{6}$, vitamin $B_{12}$ and glucosamine $\left(p K_{D}: 1.6\right)$ with either cimetidine $\left(p K_{D}: 1.6\right)$, risperidone $\left(p K_{D}: 1.8\right)$ and haloperidol $\left(p K_{D}: 1.7\right)$ (all drugs with an $A C B$ score of 1 ) all had an apparent $\mathrm{pK}_{\mathrm{D}}$ of $2.1(\mathrm{P}<0.05)$. Based on this $\mathrm{pK}_{\mathrm{D}}$ value, combinations of the supplements with the drugs have an ACB score of 2. 


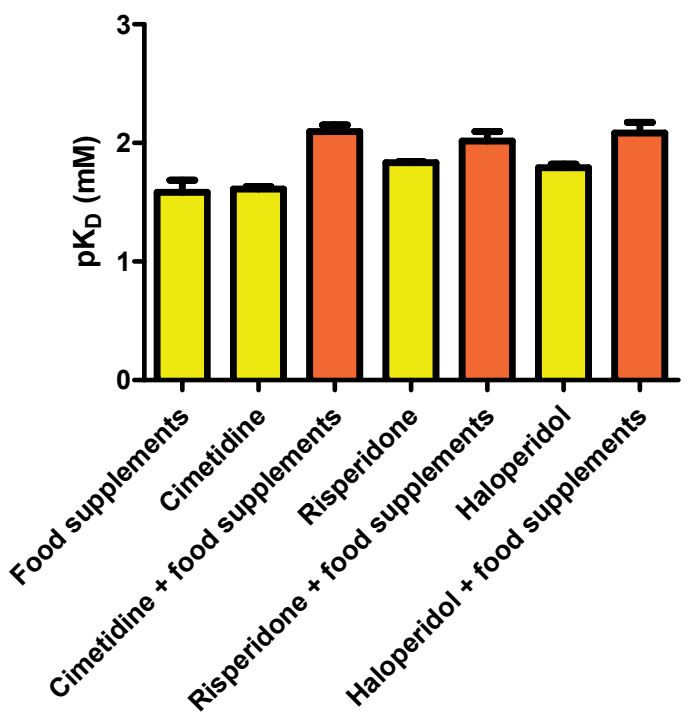

Figure 4| The effect of supplement-drug combination on the apparent affinity for muscarinic receptors. Tissues were incubated with either three food supplements (vitamin $B_{6}$, vitamin $B_{12}$ and glucosamine) or cimetidine, risperidone or haloperidol with and without a combination of food supplements (vitamin $B_{6}$, vitamin $B_{12}$ and glucosamine). The apparent affinity was calculated using a modified Cheng-Prusoff equation. Data are shown as means $\pm \operatorname{SEM}(n=4)$. Differences were considered to be statistically significant when $\mathrm{P}<0.05$. ${ }^{*} \mathrm{P}<0.05$. 


\section{Discussion}

The ACB score has been proposed as a convenient way to predict the anticholinergic side effects of drugs and combinations of drugs. The ACB score was based on the anticholinergic effect of compounds determined in clinical studies. The aim of the present study is to correlate the ACB score of compounds to their binding to muscarinic receptors, so that the anticholinergic effect of a drug can be screened in a relatively simple way by determining the affinity for the muscarinic receptor in a binding study. The ACB score of several compounds correlate well with the affinity, confirming the usefulness of the screening assay. It should be noted that it is a screening assay and positive results of new compounds need to be confirmed in a clinical setting.

Anticholinergicity refers to blockade of cholinergic neurotransmission, and especially blockade of muscarinic receptors in the brain is of relevance, since they play an important role in numerous processes, including cognition, attention, sleep, metabolism, motivation and movement. Five muscarinic receptor subtypes exist: $M_{1}, M_{2}, M_{3}, M_{4}$ and $M_{5}$, of which the $M_{1}, M_{4}$ and $M_{5}$ receptor subtypes are present in the brains [16]. Blocking of the $M_{1}$ receptor on these cholinergic neurons plays an important role in the development of both acute and chronic cognitive impairment. $P Z$ ( $p K_{D}$ of 7.9 ) has a very high affinity for $M_{1}$ receptors and therefore $\mathrm{PZ}$ was used as radioligand in our study. The affinity of $\mathrm{PZ}$ found in our study corresponds to that reported previously $\left(p K_{D}: 7.8\right)$ [17].

Over 600 medicinal products with a broad therapeutic range as well as an adverse effect profile are recognized to have anticholinergic activity [5]. These include psychoactive drugs, such as hypnotic, antipsychotic, antiparkinsonian and antidepressant drugs, and nonpsychoactive drugs, such as cardiac, corticosteroids and antibiotic drugs [7, 18]. These drugs can give cognitive impairment, especially when they are combined [19]. Thus, anticholinergic accumulation results in confusion, delirium, dry mouth, headache, pain, anxiety and blurred vision [20]. Drugs have been extensively investigated for their anticholinergic properties. In 2008, an ACB list has been developed. This list contains numerous drugs that are classified by the clinical impact of their anticholinergic effects on cognition. Drugs with an ACB score of 1 are classified as drugs with possible anticholinergic effects. Drugs with an ACB score of either 2 or 3 are classified as drugs with established clinically relevant cognitive effects and the effect of drugs with an ACB score of 3 can be quite severe.

In the present study, a correlation between muscarinic receptor affinity and clinically established symptoms of anticholinergic toxicity was found. The drugs cimetidine, theophylline, warfarin and furosemide (with an ACB score of 1) all had the lowest affinity for the muscarinic receptors in the brain with a $\mathrm{PK}_{\mathrm{D}}$ value below 2. Additionally, the drugs with established clinically anticholinergic effects (ACB score of 2) display higher affinities for muscarinic receptors ( $\mathrm{K}_{\mathrm{D}} 2-3$ ), while the drugs with the highest anticholinergic effects ( $A C B$ score of 3) had the highest affinity for these receptors $\left(\mathrm{pK}_{\mathrm{D}}>4\right)$. Hence, in the present study we have validated the anticholinergic effects of drugs using a binding study. Also, the anticholinergic effect of a drug can be screened in a relatively simple way by determining 
the affinity for the muscarinic receptor in a binding study, which is much more convenient than the epidemiological approach.

In general, anticholinergic accumulation is especially observed in people when multiple drugs are used. Polypharmacy with anticholinergic compounds is common in nursing home residents and indeed increases the risk for anticholinergic toxicity tremendously [2, 5]. Moreover, elderly are a group at risk for the anticholinergic effects of drugs. This can be explained by age-related changes in pharmacokinetics and pharmacodynamics (Moore et al., 1999). These changes include a relatively low number of cholinergic neurons and receptors in brain, a relatively low hepatic and renal clearance of drugs, the relatively high blood brain barrier permeability and the frequent use of multiple drugs (Molchan et al., 1992; Zlokovic, 2008). As a consequence, elderly are more prone to develop cognitive impairment (Tan et al., 2015; Tune et al., 1991).

That even the use of the combination of 3 drugs may lead to anticholinergic accumulation is corroborated in the present study. The combination of cimetidine, warfarin and theophylline, all drugs with an $\mathrm{ACB}$ score of 1 , increased the apparent $\mathrm{pK}_{\mathrm{D}}$ by one. The resulting $P K_{D}$ value was comparable to that of drugs having an $A C B$ score of 2 . Hence, this combination is an example of anticholinergic accumulation and the higher risk of adverse cognitive effects.

In contrast to drugs, the binding of food supplements to the muscarinic receptor binding has not been investigated yet. This is remarkable since the frequency of using dietary supplements increases with age. Over $50 \%$ of the elderly consumes at least one supplement a day. We screened the food supplements used most frequently by elderly. Among these supplements are glucosamine, vitamin $B_{6}$, vitamin $B_{12}$, vitamin $C$, chondroitin, zinc, choline, quercetin and vitamin $B_{4}$. Most of these compounds have the ability to penetrate the blood brain barrier (BBB) [21-23]. In elderly, even higher levels of these supplements in the brains might be found, since the permeability of the BBB increases with age [24]. The $\mathrm{pK}_{\mathrm{D}}$ value of these supplements for the muscarinic receptors was relatively low, which are comparable to that of the drugs with an ACB score of 1 . This indicates that food supplements may produce relatively mild adverse cognitive effects.

Combinations of food supplements are more relevant in this respect. The present study indicates that especially the use of a combination of food supplements most frequently used e.g. in a multivitamin supplement, increases the risk of anticholinergic accumulation.

The simultaneous use of food supplements and drugs is also often observed in elderly. Importantly, drug-drug, supplement-supplement and supplement-drug combinations had an affinity for the muscarinic receptor that is higher than that of the compounds in isolation. This indicates that these combinations may increase anticholinergic burden, the phenomenon known as anticholinergic accumulation. In estimating the ACB burden of a combination of drugs, it is assumed that this is equal to the sum of the ACB score of the separate drugs. It is indeed expected that the anticholinergic effect will increase when using multiple drugs; however, determining the ACB score of the combination by summing up the ACB scores of all the separate drugs probably gives an overestimation. Based on the 
affinity to bind to the receptors, the combination of three drugs with an ACB score of 1 does not give a total ACB score of 3 , but a score of 2 .

Anticholinergic accumulation may be detrimental for elderly. Even anticholinergic effects, that might be considered as relatively mild, such as a dry mouth, reduces the ability to communicate, predisposing to malnutrition, and increasing the risk of respiratory infection. Additionally, mydriasis might impair near vision, which could increase the risk of accidents, including falls that might be fatal in these elderly.

When making a risk-benefit analysis of the drugs on the ACB list and the food supplements, it is noteworthy that the benefits of the single drugs or supplements outweigh their risks. The present study provides a convenient method to screen the risks. In elderly, supplementation can also have benefits and in practice a clear risk-benefit analysis has to be made. It highlights that especially the combination of drugs and food supplements may give rise to the risks, which are increased anticholinergic effects.

In conclusion, the affinity for muscarinic receptors obtained in a simple receptor binding experiment of compounds correlates with the ACB score which is a clinical measure of anticholinergic effects. This confirms the validity of the screening assay. However, it should be noted that it is a screening assay and positive results of new compounds need to be confirmed in a clinical study. Our results draw attention to drug-drug and supplement-drug combinations that may lead to anticholinergic accumulation. Attention should be given to the use of food supplements when prescribing drugs, to prevent drug- or supplementinduced problems in elderly. More research on the anticholinergic effects of drugs and food supplements is warranted, especially in groups at risk, such as elderly. 


\section{References}

1. Alagiakrishnan K, Wiens CA. An approach to drug induced delirium in the elderly. Postgraduate medical journal. 2004;80:388-93.

2. Mate KE, Kerr KP, Pond D, Williams EJ, Marley J, Disler P, et al. Impact of Multiple Low-Level Anticholinergic Medications on Anticholinergic Load of Community-Dwelling Elderly With and Without Dementia. Drugs \& aging. 2015.

3. Myint PK, Fox C, Kwok CS, Luben RN, Wareham NJ, Khaw KT. Total anticholinergic burden and risk of mortality and cardiovascular disease over 10 years in 21,636 middle-aged and older men and women of EPIC-Norfolk prospective population study. Age and ageing. 2014.

4. Barnett SR. Polypharmacy and perioperative medications in the elderly. Anesthesiology clinics. 2009;27:377-89, table of contents.

5. Kalisch Ellett LM, Pratt NL, Ramsay EN, Barratt JD, Roughead EE. Multiple anticholinergic medication use and risk of hospital admission for confusion or dementia. Journal of the American Geriatrics Society. 2014;62:1916-22.

6. Mintzer J, Burns A. Anticholinergic side-effects of drugs in elderly people. Journal of the Royal Society of Medicine. 2000;93:457-62.

7. Sumukadas D, McMurdo ME, Mangoni AA, Guthrie B. Temporal trends in anticholinergic medication prescription in older people: repeated cross-sectional analysis of population prescribing data. Age and ageing. 2014;43:515-21.

8. Leslie DL, Marcantonio ER, Zhang Y, Leo-Summers L, Inouye SK. One-year health care costs associated with delirium in the elderly population. Archives of internal medicine. 2008;168:27-32.

9. Ely EW, Gautam S, Margolin R, Francis J, May L, Speroff T, et al. The impact of delirium in the intensive care unit on hospital length of stay. Intensive care medicine. 2001;27:1892-900.

10. Leslie DL, Zhang Y, Bogardus ST, Holford TR, Leo-Summers LS, Inouye SK. Consequences of preventing delirium in hospitalized older adults on nursing home costs. Journal of the American Geriatrics Society. 2005;53:405-9.

11. Boustani M, Baker MS, Campbell N, Munger S, Hui SL, Castelluccio P, et al. Impact and recognition of cognitive impairment among hospitalized elders. Journal of hospital medicine : an official publication of the Society of Hospital Medicine. 2010;5:69-75.

12. Kolanowski A, Fick DM, Campbell J, Litaker M, Boustani M. A preliminary study of anticholinergic burden and relationship to a quality of life indicator, engagement in activities, in nursing home residents with dementia. Journal of the American Medical Directors Association. 2009;10:252-7.

13. Campbell N, Boustani M, Limbil T, Ott C, Fox C, Maidment I, et al. The cognitive impact of anticholinergics: a clinical review. Clinical interventions in aging. 2009;4:225-33.

14. Boustani M. Impact of anticholinergics on the aging brain: a review and practical application. Aging Health. 2008;4:311-20.

15. Michel MC, Buscher R, Philipp T, Brodde OE. Alpha 1A and alpha 1B-adrenoceptors enhance inositol phosphate generation in rat renal cortex. Naunyn-Schmiedeberg's archives of pharmacology. 1993;347:180-5.

16. Caulfield MP. Muscarinic receptors--characterization, coupling and function. Pharmacology \& therapeutics. 1993;58:319-79.

17. Luthin GR, Wolfe BB. Comparison of [3H]pirenzepine and [3H]quinuclidinylbenzilate binding to muscarinic cholinergic receptors in rat brain. The Journal of pharmacology and experimental therapeutics. 1984;228:648-55.

18. Snavely SR, Hodges GR. The neurotoxicity of antibacterial agents. Annals of internal medicine. 1984;101:92-104.

19. Pasina L, Djade CD, Lucca U, Nobili A, Tettamanti M, Franchi C, et al. Association of anticholinergic burden with cognitive and functional status in a cohort of hospitalized elderly: 
comparison of the anticholinergic cognitive burden scale and anticholinergic risk scale: results from the REPOSI study. Drugs \& aging. 2013;30:103-12.

20. Campbell N, Perkins A, Hui S, Khan B, Boustani M. Association between prescribing of anticholinergic medications and incident delirium: a cohort study. Journal of the American Geriatrics Society. 2011;59 Suppl 2:S277-81.

21. Youdim KA, Qaiser MZ, Begley DJ, Rice-Evans CA, Abbott NJ. Flavonoid permeability across an in situ model of the blood-brain barrier. Free radical biology \& medicine. 2004;36:592-604.

22. Spector R. Vitamin B6 transport in the central nervous system: in vivo studies. Journal of neurochemistry. 1978;30:881-7.

23. Agus DB, Gambhir SS, Pardridge WM, Spielholz C, Baselga J, Vera JC, et al. Vitamin C crosses the blood-brain barrier in the oxidized form through the glucose transporters. The Journal of clinical investigation. 1997;100:2842-8.

24. Farrall AJ, Wardlaw JM. Blood-brain barrier: ageing and microvascular disease--systematic review and meta-analysis. Neurobiology of aging. 2009;30:337-52. 




\section{Chapter 5}

\section{Iron supplements and magnesium peroxide: an example of a hazardous combination in self-medication}

Misha F Vrolijk, Antoon Opperhuizen, Eugène H J M Jansen, Aalt Bast, Guido R $M$ M Haenen

Basic Clinical Pharmacology and Toxicology. 2016 Oct;119(4):412-7 


\begin{abstract}
The use of self-medication, which includes dietary supplements and over-the-counter drugs, is still on the rise, while safety issues are not well addressed yet. This especially holds for combinations. For example, iron supplements and magnesium peroxide both produce adverse effects via the formation of reactive oxygen species (ROS). This prompted us to investigate the effect of the combination of three different iron supplements with magnesium peroxide on ROS formation.

Hydroxyl radical formation by the three iron supplements either combined with magnesium peroxide or alone, was determined by performing a deoxyribose assay. Free iron content of iron supplements was determined using Ferrozine assay. To determine hydrogen peroxide formation by magnesium peroxide, a ferrous thiocyanate assay was performed. Finally, electron spin resonance spectroscopy (ESR) was performed to confirm the formation of hydroxyl radicals.

Our results show that magnesium peroxide induces the formation of hydrogen peroxide. All three iron supplements induced the formation of the extremely reactive hydroxyl radical, although the amount of radicals formed by the different supplements differed. It was shown that combining iron supplements with magnesium peroxide increases radical formation. The formation of hydroxyl radicals after the combination was confirmed with ESR.

All three iron supplements contained labile iron and induced the formation of hydroxyl radicals. Additionally, magnesium peroxide in water yields hydrogen peroxide, which is converted into hydroxyl radicals by iron. Hence, iron supplements and magnesium peroxide is a hazardous combination and exemplifies that more attention should be given to combinations of products used in self-medication.
\end{abstract}




\section{Introduction}

The use of self-medication, which includes dietary supplements and over-the-counter drugs (OTC's), is still on the rise. Improving or maximizing health or compensating for an unhealthy lifestyle are top reasons for using supplements. In addition, the desire for selfcare further increases the use of self-medication. Besides the beneficial health effects, the use of self-medication also has risks. For drugs, both benefits and risks are meticulously monitored and examined. Although risks of self-medication are increasingly realized, this is not well addressed yet [1]. Therefore, more attention should be given to the safety issues of dietary supplements and OTC's.

Relative to the safety issues of the use of a single supplement or OTC, the use of combinations is expected to be more hazardous. This prompted us to investigate the combination of a potential hazardous combination, i.e. the combination of iron supplements and magnesium peroxide.

Iron deficiency is the single most prevalent nutritional deficiency worldwide with elderly as a group with the highest prevalence [2]. Subsequently, iron supplements are in the top of the dietary supplements used in the older population [3].

Iron deficiency will result in anaemia, characterized by a relatively low number of red blood cells and a low haemoglobin level [3]. Symptoms of anaemia are fatigue, decreased physical endurance, decreased immune system activity and increased sensitivity to cold [3]. The human adult body normally contains approximately 45 milligram of iron per kilogram body weight. The only source of iron is nutrition. In order to maintain adequate iron levels, a daily dietary intake of 15 milligrams for adult women and 10 milligrams for adult men is required [4]. In order to restore or maintain iron levels, iron supplements are often taken [5]. Numerous iron supplements are available, each containing relatively high doses of iron ranging from $14 \mathrm{mg}$ to $695 \mathrm{mg}$.

Besides its beneficial effects, iron can also be toxic. When iron supplements are taken orally, free iron is known damage intestinal cells by generating free radicals via Fenton chemistry $[3,6]$. In the Fenton reaction, homolytic cleavage of hydrogen peroxide by ferrous iron generates the very reactive hydroxyl radical (equation 1) [7].

$$
\mathrm{Fe}^{2+}+\mathrm{H}_{2} \mathrm{O}_{2} \rightarrow \mathrm{Fe}^{3+}+\mathrm{OH}^{-}+\mathrm{HO}^{\bullet}
$$

The produced hydroxyl radical is able to cause protein modification, lipid peroxidation, or damage to RNA and DNA, especially in the intestines $[8,9]$. Hence, iron is able to exert toxic effects.

Magnesium peroxide is an antacid that is available as an OTC. It neutralises gastric acid, thereby relieving symptoms of for instance gastro-oesophageal reflux disease or gastric ulcers, which may be caused by iron supplements [10]. A major side effect of magnesium peroxide is that it causes diarrhoea [11], which is suggested to be caused by radical formation in the intestines. After ingestion of magnesium peroxide, hydrogen peroxide is 
formed. Since it may reduce the absorption of iron, it is advised not to combine magnesium peroxide with iron supplements. However, there is no literature about the toxic effects of combining both.

Due to the formed hydrogen peroxide, the combination of iron supplements and magnesium peroxide is expected to raise the production of reactive oxygen species (ROS), especially hydroxyl radicals. Remarkably, this combination has not been identified as potentially toxic. In the present study, the radical formation by the combination of three different iron supplements with magnesium peroxide was determined [12] . 


\section{Materials and Methods}

\section{Chemicals}

L-ascorbic acid, 2-deoxy-D-ribose, ferrous ammonium sulphate, magnesium hydroxide $(\mathrm{MgOH})$, magnesium peroxide $\left(\mathrm{MgO}_{2}\right)$, potassium thiocyanate $(\mathrm{KSCN})$, 2-thiobarbituric acid (TBA), trichloroacetic acid (TCA), ferrous chloride $\left(\mathrm{FeCl}_{2} \cdot 4 \mathrm{H}_{2} \mathrm{O}\right)$, ferric chloride $\left(\mathrm{FeCl}_{3} \cdot 6 \mathrm{H}_{2} \mathrm{O}\right)$, hydrogen peroxide $\left(\mathrm{H}_{2} \mathrm{O}_{2}\right), \mathrm{KH}_{2} \mathrm{PO}_{4}$ and $\mathrm{K}_{2} \mathrm{HPO}_{4} \cdot 3 \mathrm{H}_{2} \mathrm{O}$ were obtained from Sigma-Aldrich. EDTA titriplex III was obtained from Merck. The three different iron supplements contained iron lactate, iron sulfate (Fero Gradumet) and iron gluconate (Losferron) and were obtained from Kruidvat, Teofarma and Will-Pharma respectively.

\section{Deoxyribose assay}

Hydroxyl radical formation induced by the different iron supplements and $\mathrm{FeCl}_{3}$ as positive control was determined by performing the deoxyribose assay [13]. Iron mixtures of $\mathrm{FeCl}_{3}$ or each of three iron supplements with variable final concentrations, ranging from 0 to $20 \mu \mathrm{M}$, were made using deoxygenated water as solvent. Additionally, deoxyribose (2.8 $\mathrm{mM})$, ascorbic acid (0.1 mM), $\mathrm{H}_{2} \mathrm{O}_{2}(2.8 \mathrm{mM}), \mathrm{KH}_{2} \mathrm{PO}_{4} / \mathrm{KOH}$ buffer $(\mathrm{pH} 7.4 ; 10 \mathrm{mM})$, together with the $\mathrm{FeCl}_{3}$ mixtures, were added in test tubes. Stock solutions of these compounds were freshly made every day. The reaction mixtures were incubated for 1 hour at $37^{\circ} \mathrm{C}$ in a water bath. During this incubation $\mathrm{Fe}^{3+}$ was reduced to $\mathrm{Fe}^{2+}$ by ascorbic acid. Together with $\mathrm{H}_{2} \mathrm{O}_{2}$, the $\mathrm{Fe}^{2+}$ generated hydroxyl radicals, which in turn attacked deoxyribose to form fragments. In order to stop the reaction, $2 \mathrm{ml}$ stop solution $(0.5 \%(\mathrm{w} / \mathrm{v})$ TBA, $1.4 \%(\mathrm{v} / \mathrm{v})$ TCA in $\mathrm{MQ}$ ) was added to each tube after 1 hour. Then, these mixtures were heated for 20 minutes at $100{ }^{\circ} \mathrm{C}$. By adding the stop solution, fragments that were formed yielded a pink chromogen (MDA-TBA). Finally, the test tubes were cooled on ice and the absorbance of the reaction mixtures was measured at a wavelength of $532 \mathrm{~nm}$ using a spectrophotometer (Varian-Cary PCB50). The concentrations of generated hydroxyl radicals were calculated via Lambert-Beer's law, using the molar extinction coefficient of malondialdehyde (MDA) as $0.156 \mu \mathrm{M}^{-1} \mathrm{~cm}^{-1}[14]$.

In order to test the hydroxyl radical formation by $\mathrm{FeCl}_{3}$ and three different iron supplements in combination with different concentrations of $\mathrm{MgO}_{2}$, the same protocol was performed using a fixed concentration $(10 \mu \mathrm{M})$ of either $\mathrm{FeCl}_{3}$ or the iron supplements. A $1.78 \mathrm{mM} \mathrm{MgO}_{2}$ stock solution was made using a sodium phosphate buffer ( $\mathrm{pH}$ 3.8) as solvent. This stock solution was diluted to variable final concentrations of $\mathrm{MgO}_{2}(0-1.78$ $\mathrm{mM}$ ) using the $\mathrm{KH}_{2} \mathrm{PO}_{4} / \mathrm{KOH}$ buffer. In these experiments, $\mathrm{MgO}_{2}$ was used instead of $\mathrm{H}_{2} \mathrm{O}_{2}$. The reactions mixtures ultimately contained $2.8 \mathrm{mM}$ 2-deoxy-D-ribose, $0.1 \mathrm{mM}$ ascorbic acid, $10 \mu \mathrm{M}$ iron, and the variable concentrations of $\mathrm{MgO}_{2}$.

\section{FerroZine assay}

The labile iron content of $\mathrm{FeCl}_{3}$ and the three different iron supplements was determined by performing the FerroZine assay. Different concentrations of iron samples (0-20 $\mu \mathrm{M})$ were made using deoxygenated water as solvent. The iron samples were incubated at $37^{\circ} \mathrm{C}$ for a few minutes. Reagent (consisting of ascorbic acid $(0.1 \mathrm{mM})$, FerroZine $(1 \mathrm{mM})$ and 
$\mathrm{KH}_{2} \mathrm{PO}_{4} / \mathrm{KOH}$ buffer) was made and also incubated for a few minutes at $37^{\circ} \mathrm{C}$. Next, $100 \mu \mathrm{L}$ of iron samples was added to reagent. In the presence of ascorbic acid, $\mathrm{Fe}^{3+}$ was reduced into $\mathrm{Fe}^{2+}$. When $\mathrm{Fe}^{2+}$ was bound to ferozine, a colored complex was formed. The formation of this complex could spectrophotometrically be followed by measuring the absorbance at $562 \mathrm{~nm}$ and $37^{\circ} \mathrm{C}$ for 1 hour. Concentrations of the formed complexes were calculated using Lambert-Beer's law, using the molar absorbance coefficient of the purple complex $\left(=27.9 \mathrm{mM}^{-1} \mathrm{~cm}^{-1}\right)$.

\section{Ferrous thiocyanate assay}

Ferrous thiocyanate assay was performed to determine $\mathrm{H}_{2} \mathrm{O}_{2}$ levels formed after solving $\mathrm{MgO}_{2}$ in the buffer. $\mathrm{MgO}_{2}$ was used in the same concentrations as in the deoxyribose. $\mathrm{MgO}_{2}$ stock solution was dissolved and further diluted in $20 \mathrm{mM}$ potassium phosphate buffer ( $\mathrm{pH}$ 3.8). A calibration curve of $\mathrm{H}_{2} \mathrm{O}_{2}$ (final concentrations ranged from 0 to $100 \mu \mathrm{M}$ ) was prepared using Milli-Q as solvent. $\mathrm{HCl}(350 \mathrm{mM}), \mathrm{KSCN}(200 \mathrm{mM})$ and ferrous ammonium sulphate $(100 \mathrm{mM})$ were prepared in cuvettes $(1 \mathrm{~mL})$ containing the sample. In a final volume of $1 \mathrm{ml}$, the cuvettes contain: variable concentrations of $\mathrm{H}_{2} \mathrm{O}_{2}, 350 \mathrm{mM} \mathrm{HCl}$, $200 \mathrm{mM} \mathrm{KSCN}$ and $100 \mathrm{mM}$ ferrous ammonium sulphate. After 10 minutes at room temperature, the absorbance was measured at a wavelength of $483 \mathrm{~nm}$ and the concentration of $\mathrm{H}_{2} \mathrm{O}_{2}$ was calculated using the calibration curve.

\section{Electron spin resonance spectroscopy}

Electron spin resonance (ESR) spectroscopy was performed to determine hydroxyl radical formation after incubating $\mathrm{MgO}_{2}$ with $\mathrm{FeCl}_{3}$ and ascorbic acid. A sample containing $10 \mu \mathrm{M}$ $\mathrm{FeCl}_{3}, 100 \mu \mathrm{M}$ ascorbic acid and $0.89 \mathrm{mM} \mathrm{MgO}_{2}$ was prepared. Added to this sample was 5,5-dimethyl-1-pyrroline $\mathrm{N}$-oxide (DMPO), serving as a spin-trap agent. After adding all the compounds, a $100 \mu \mathrm{l}$ glass capillary was filled with the solution and sealed. ESR signals were then recorded at room temperature by X-band ESR on a Bruker EMX 1273 (Bruker BioSpin, Wormer, the Netherlands).

\section{Statistical analysis}

All results were shown as mean $\pm \operatorname{SEM}(n=3-6)$. Data were analysed compared to $\mathrm{FeCl}_{3}$ using an unpaired t-test (95\% confidence interval). Results were considered statistically significant when $\mathrm{P}<0.05$. 


\section{Results}

\section{Radical formation by the different iron supplements}

The ability of iron supplements to generate hydroxyl radicals was determined using the deoxyribose assay. Hydroxyl radical formation was measured after incubation with various concentrations of iron supplements (iron lactate, iron sulfate and iron gluconate) and $\mathrm{FeCl}_{3}$ (figure $1 \mathrm{~A}$ ).
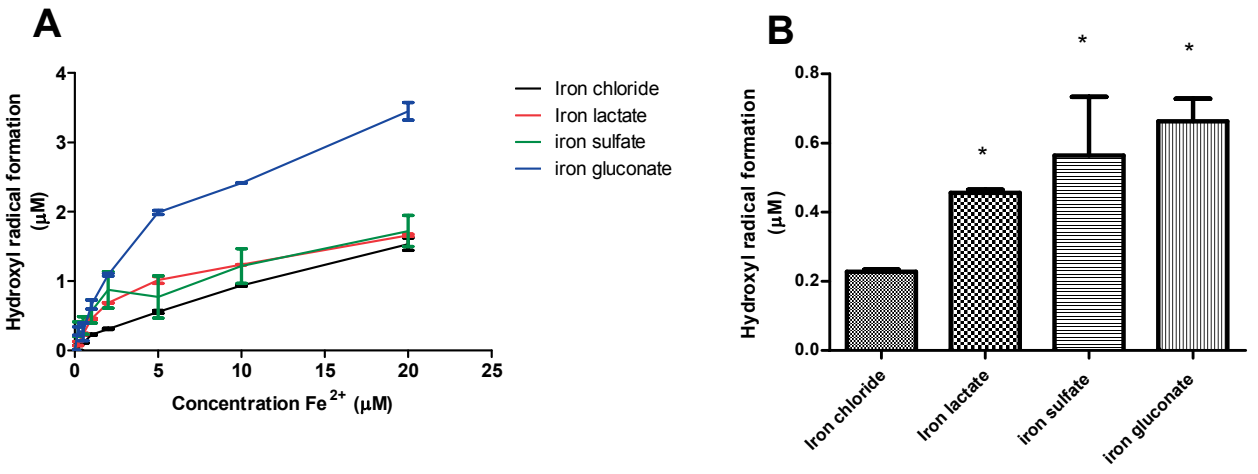

Figure 1| Hydroxyl radical formation generated by iron supplements and $\mathrm{FeCl}_{3}$ at various concentrations (A). Hydroxyl radical formation generated by iron supplements and $\mathrm{FeCl}_{3}$ at $1 \mu \mathrm{M}(\mathrm{B})$. Data are shown as mean $\pm \operatorname{SEM}(n=3)$ and considered statistically significant compared to $\mathrm{FeCl}_{3}$. $* P<0.05$

$\mathrm{FeCl}_{3}$, which was used as a positive control, promoted hydroxyl radical formation. All three supplements also induced the formation of hydroxyl radicals, but remarkably to a different extent. The iron gluconate supplement induced the most hydroxyl radicals (up to $3.4 \mu \mathrm{M}$ ), while iron sulfate and iron lactate induced a comparable amount of hydroxyl radicals as $\mathrm{FeCl}_{3}$ (figure $1 \mathrm{~A}$ ). The hydroxyl radical formation of the different iron supplements at a concentration of $1 \mu \mathrm{M}$ is shown in figure $1 \mathrm{~B}$. At this concentration, all supplements significantly generated more hydroxyl radicals than $\mathrm{FeCl}_{3}$. 
Table 1| The formation of hydroxyl radicals by $\mathrm{FeCl}_{3}(10 \mu \mathrm{M})$, either combined with $\mathrm{MgO}_{2}(1.78 \mathrm{mM})$ or $\mathrm{MgOH}(1.78 \mathrm{mM})$. Data are shown as mean $\pm \operatorname{SEM}(n=6)$ and considered statistically when $p<0.05$. $* * * \mathrm{P}<0.005$

Hydroxyl radical formation $(\mu \mathrm{M})$

\begin{tabular}{ll}
\hline $\mathrm{FeCl}_{3}$ & $1.88 \pm 0.39$ \\
$\mathrm{FeCl}_{3}+\mathrm{MgO}_{2}$ & $4.46 \pm 0.67^{* * *}$ \\
$\mathrm{FeCl}_{3}+\mathrm{MgOH}$ & $1.80 \pm 0.19$ \\
\hline
\end{tabular}

\section{Labile iron content of the different iron supplements}

In order to determine the labile iron content of the different supplements, the Ferrozine assay was performed with various concentrations of the iron supplements (0-1-2-5-10-20 $\mu \mathrm{M})$. The iron gluconate supplement had the highest amount of labile iron of all iron supplements $(4.15 \mu \mathrm{M})$, whereas the iron lactate supplement had the lowest amount of labile iron $(0.94 \mu \mathrm{M})$.Iron sulfate had an intermediate amount of labile iron. The labile iron content of the iron lactate supplement and the iron sulfate supplement differ significantly from $\mathrm{FeCl}_{3}(\mathrm{p}=0.0022$ and $\mathrm{p}=0.0490)$ (figure 2).

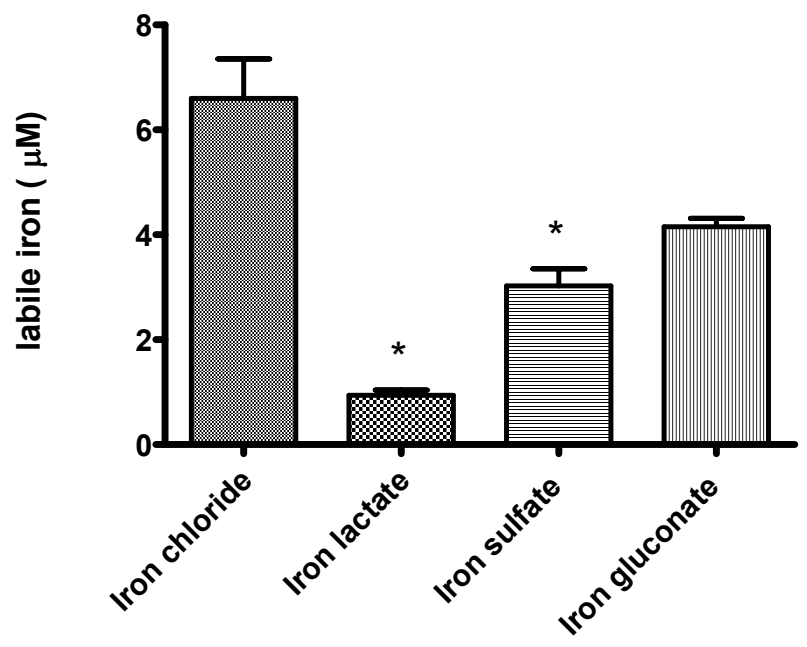

Figure 2| Labile iron content of $\mathrm{FeCl}_{3}$ and different iron supplements at a fixed concentration of $10 \mu \mathrm{M} \mathrm{Fe}^{2+}$. Data are shown as mean $\pm \operatorname{SEM}(n=3)$ and considered statistically significant compared to $\mathrm{FeCl}_{3} \cdot{ }^{*} \mathrm{P}<0.05$ 
Hydrogen peroxide formation by $\mathrm{MgO}_{2}$

Hydrogen peroxide formation formed by $\mathrm{MgO}_{2}$ was determined by performing a ferrous thiocyanate assay [15]. $\mathrm{MgO}_{2}$ induced the formation of $\mathrm{H}_{2} \mathrm{O}_{2}$ in a concentration-dependent way (figure 3). An initial concentration of $\mathrm{MgO}_{2}$ of $1.5 \mathrm{mM}$ yielded approximately $200 \mu \mathrm{M}$ of $\mathrm{H}_{2} \mathrm{O}_{2}$. The antacid function of $\mathrm{MgO}_{2}$, which is illustrated by the increase in $\mathrm{pH}$ of the acidic buffer, is furthermore shown in table 2.

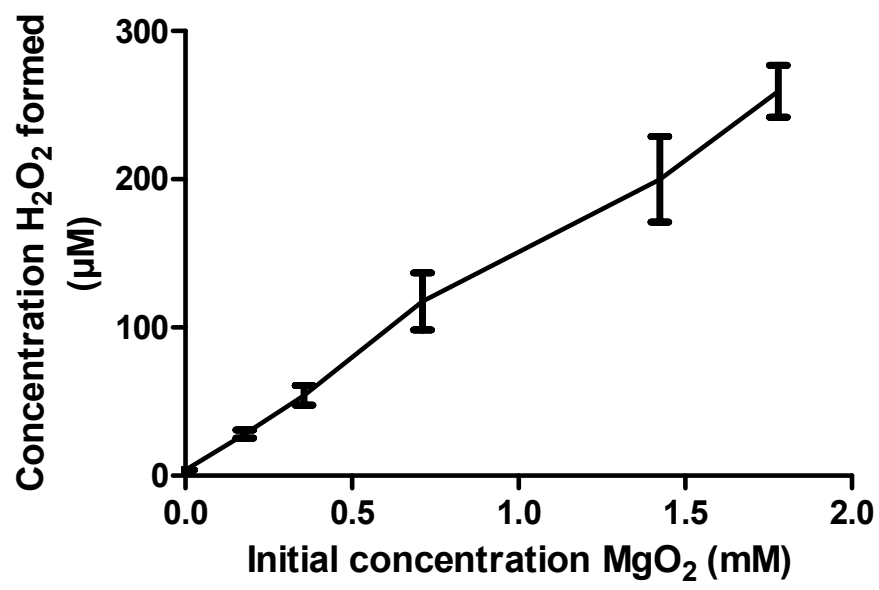

Figure 3| The formation of $\mathrm{H}_{2} \mathrm{O}_{2}$ from $\mathrm{MgO}_{2}$, which was determined using the Ferrous thiocyanate assay. Data are shown as means $\pm \operatorname{SEM}(n=3)$.

\section{Radical formation by iron supplements with $\mathrm{MgO}_{2}$}

The effects of $\mathrm{FeCl}_{3}$ and the iron supplements in combination with $\mathrm{MgO}_{2}$ on hydroxyl radical formation, determined with deoxyribose assay, are shown in figure 4A.

All three supplements again induced radical formation without $\mathrm{MgO}_{2}$. Addition of $\mathrm{MgO}_{2}$ to iron $(10 \mu \mathrm{M})$ increased the formation of hydroxyl radicals. When $\mathrm{MgO}_{2}$ was combined with an iron supplement, this promoted hydroxyl radical formation. The combination of $\mathrm{MgO}_{2}$ with the supplements (Iron lactate $7.4 \mu \mathrm{M}$, iron sulfate $8.8 \mu \mathrm{M}$, iron gluconate $13.2 \mu \mathrm{M}$ ) was higher than that with $\mathrm{MgO}_{2}$ with $\mathrm{FeCl}_{3}(4.5 \mu \mathrm{M})$ (figure 4A). Addition of $\mathrm{MgOH}$, an antacid comparable to $\mathrm{MgO}_{2}$, to $\mathrm{FeCl}_{3}$ did not increase hydroxyl radical formation (table 1 ). 

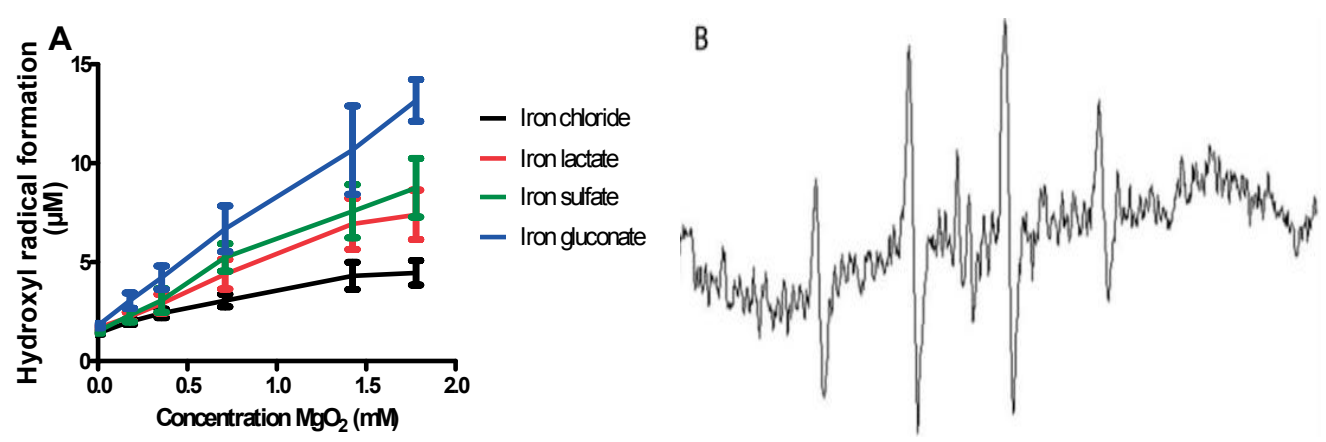

Figure 4| Hydroxyl radical formation by different concentrations $\mathrm{MgO}_{2}$ in combination with a fixed concentration of $\mathrm{FeCl}_{3}$ or iron supplements $(10 \mu \mathrm{M})(\mathrm{A})$. ESR spectrum of DMPO-OH・ adduct. ESR spectroscopy in combination with the use of the spin trapping agent DMPO was used to detect a triplet signal that is characteristic for the $\mathrm{DMPO}-\mathrm{OH}$ radical adduct in the incubation system containing Fe and $\mathrm{MgO}_{2}(\mathrm{~B})$. Data shown are means $\pm \mathrm{SEM}(n=6)$.

\section{Hydroxyl radical formation by $\mathrm{MgO}_{2}$ and $\mathrm{Fe}$}

To corroborate that $\mathrm{OH}^{\bullet}$ was formed, ESR spectroscopy was used. With the use of the spin trapping agent DMPO, a triplet signal was obtained that is characteristic for the DMPO-OH radical adduct in the incubation system containing Fe and $\mathrm{MgO}_{2}$ (figure $4 \mathrm{~B}$ ). When $\mathrm{MgO}_{2}$ was replaced by $\mathrm{MgOH}$, no radical spectrum was detected (data not shown).

Table 2| The antacid function of magnesium peroxide and magnesium hydroxide which is shown by the effect of both compounds on the $\mathrm{pH}$ of an acidic buffer.

\begin{tabular}{ll}
\hline & $\mathrm{pH}$ \\
\hline Acidic Buffer & 3.37 \\
$\mathrm{MgO}_{2}$ & 6.20 \\
$\mathrm{MgOH}$ & 6.11 \\
\hline
\end{tabular}




\section{Discussion}

The present study further examines the potential hazard of the use of self-medication, i.e. food supplements and OTC's, and highlights that especially combination increased the risks. This was exemplified by the combination of iron supplements and magnesium peroxide.

The rational for choosing the combination of iron supplements and magnesium peroxide, apart from the possible interaction, was the frequent use of these products in elderly, a frail group of people vulnerable to the side effects. Elderly often suffer from iron insufficiency, which often leads to iron deficiency anaemia. In order to maintain iron levels, iron supplements are often used. Numerous iron supplements are present, each containing relatively high dose of iron. Only a small part of the iron is absorbed in the intestine and no active excretion mechanism exists. Therefore, elderly people have a relatively high risk of iron overload when taking iron supplements, which might lead to accumulation of iron in the intestines. This may lead to side effects, which include nausea, stomach ache, diarrhoea and obstipation. In these side effects, hydroxyl radicals play a key role [16]. Our results confirm that all three iron supplements indeed stimulate the generation of hydroxyl radicals. The supplements that were used in the present study all contained $\mathrm{Fe}^{2+}$. However, both $\mathrm{Fe}^{3+}$ and $\mathrm{Fe}^{2+}$ containing iron supplements exist. Supplements containing $\mathrm{Fe}^{3+}$ are also expected to induce radical formation, since $\mathrm{Fe}^{3+}$ has to be reduced to $\mathrm{Fe}^{2+}$ in order to be absorbed. Additionally, we also included $\mathrm{FeCl}_{3}$ in our experiments, which contains $\mathrm{Fe}^{3+}$, and $\mathrm{FeCl}_{3}$ also showed a pronounced effect on radical formation.

Iron promotes hydroxyl radical formation, especially in the presence of hydrogen peroxide. High levels of free radical production will cause oxidative damage of the intestines $[6,8]$. Our results are in line with a previous study, that shows that iron supplements increase inflammation, which is linked to exacerbations in inflammatory bowel disease [17]. Hydroxyl radical formation showed an inverse correlation with the labile iron content of each supplement. This indicates that complexation increases the ability of iron to generate hydroxyl radicals.

Symptomatic gastroesophageal reflux is also a common complaint, associated to the use of iron supplements. Moreover, the incidence of heartburn is also high among elderly people [18]. Therefore, the combination of iron supplements with an antacid is of clinical relevance. The antacid magnesium peroxide is available as OTC. People are advised to take $380 \mathrm{mg}$ of magnesium peroxide four times per day. This comes down to a dose of 1.52 grams per day. The primary activity of magnesium peroxide is to neutralize gastric acid by increasing the $\mathrm{pH}$. Since the intake of magnesium peroxide may reduce the absorption of iron, it is advised not to combine magnesium peroxide and iron supplements. However, information on the toxic effects of the combination is lacking.

Our results confirmed the antacid activity of both magnesium peroxide and magnesium hydroxide (table 2). A major side effect of magnesium peroxide is irritation of the intestines, leading to diarrhoea [11]. From a chemical point of view, a synergistic toxic effect of the combination of $\mathrm{MgO}_{2}$ with iron supplements is plausible. This synergistic toxicity of the combination is based on the promotion of Fe-mediated free radical 
formation by $\mathrm{MgO}_{2}$. The following reactions are likely to occur in the presence of magnesium peroxide and iron:

$$
\begin{aligned}
& \mathrm{MgO}_{2}+2 \mathrm{H}_{2} \mathrm{O} \rightarrow \mathrm{Mg}^{2+}+2 \mathrm{OH}^{-}+\mathrm{H}_{2} \mathrm{O}_{2} \\
& \mathrm{Fe}^{2+}+\mathrm{H}_{2} \mathrm{O}_{2} \rightarrow \mathrm{Fe}^{3+}+\mathrm{OH}^{-}+\mathrm{HO}^{\bullet}
\end{aligned}
$$

In examining whether these reactions indeed occur, a step-by-step approach was used. As a first step, it was examined whether magnesium peroxide generates hydrogen peroxide (equation 3). Our results confirm that magnesium peroxide indeed gives the formation of hydrogen peroxide. The more magnesium peroxide, the more hydrogen peroxide is formed. Hence, after intake of magnesium peroxide, hydrogen peroxide will be formed (equation 3). As second step it was tested whether the combination of magnesium peroxide and the different iron supplements formed hydroxyl radicals (equation 4). The iron supplements (at a concentration of $10 \mu \mathrm{M}$ ), on their own induce the formation of hydroxyl radicals (figure 1). Probably, ferrous iron reacts with dioxygen to form hydroxyl radicals [19]. Magnesium peroxide increased the hydroxyl radical production by the iron supplements. This is explained by the reaction between the generated hydrogen peroxide with ferrous iron leading to hydroxyl radical formation (equation 4). In contrast to magnesium peroxide, magnesium hydroxide did not induce the formation of hydroxyl radicals in combination with iron (table 1). As a last step it was confirmed that indeed hydroxyl radicals were generated using, ESR. Our results show that the combination of iron supplements and magnesium peroxide gives an ESR spectrum specific for the hydroxyl radical, as shown in figure 4. Replacing $\mathrm{MgO}_{2}$ by magnesium hydroxide did not induce the formation of hydroxyl radicals. The step-by-step approach demonstrates that the combination of magnesium peroxide and iron supplements leads to the formation of hydroxyl radicals that are capable of damaging cells, proteins, enzymes and inducing gastrointestinal side effects.

In conclusion, our results provide the fundament for the interaction between magnesium peroxide and iron supplements. Iron induced intestinal damage caused by the highly reactive hydroxyl radical, which is enhanced by magnesium peroxide. This is an example of an interaction between a food supplement and an OTC. This indicates that especially combining products used in self-medication can be hazardous. Elderly are a group at risk since they are relatively frail and often combine self-medication [20].

A parallel can be drawn with prescription drugs. Much attention is given to the side effect of a drug used in isolation. In practice, however, the hazard mostly arises from the combination of drugs because side effects accumulate, especially in groups at risk such as elderly [21]. The present study highlights that also for food supplements and OTC's more attention should be given to combinations the interactions between food supplements and OTCs, which can have hazardous effects. 


\section{References}

1. Haenen GR, Bast A. The use of vitamin supplements in self-medication. Therapie. 2002;57:119-22.

2. Clark SF. Iron deficiency anemia: diagnosis and management. Current opinion in gastroenterology. 2009;25:122-8.

3. Johnson-Wimbley TD, Graham DY. Diagnosis and management of iron deficiency anemia in the 21st century. Therapeutic advances in gastroenterology. 2011;4:177-84.

4. Rubio C GÁ, Revert C, Reguera JI, Burgos A, Hardisson A. Daily dietary intake of iron, copper, zinc and magnanese in a Spanish population. Int J Food Sci Nutr. 2009;60:590-600.

5. Zhao G, Xu G, Zhou M, Jiang Y, Richards B, Clark KM, et al. Prenatal Iron Supplementation Reduces Maternal Anemia, Iron Deficiency, and Iron Deficiency Anemia in a Randomized Clinical Trial in Rural China, but Iron Deficiency Remains Widespread in Mothers and Neonates. The Journal of nutrition. 2015;145:1916-23.

6. Troost FJ, Saris WH, Haenen GR, Bast A, Brummer RJ. New method to study oxidative damage and antioxidants in the human small bowel: effects of iron application. American journal of physiology Gastrointestinal and liver physiology. 2003;285:G354-9.

7. Lemire JA, Harrison JJ, Turner RJ. Antimicrobial activity of metals: mechanisms, molecular targets and applications. Nature reviews Microbiology. 2013;11:371-84.

8. Thomas C MM, Diaz AA, Cox DP. Hydroxyl radical is produced via the Fenton reaction in submitochondrial particles under oxidative stress: implications for diseases associated with iron accumulation. Redox Rep. 2009;14:102-8.

9. $\mathrm{Xu} \mathrm{J,} \mathrm{Knutson} \mathrm{MD,} \mathrm{Carter} \mathrm{CS,} \mathrm{Leeuwenburgh} \mathrm{C.} \mathrm{Iron} \mathrm{accumulation} \mathrm{with} \mathrm{age,} \mathrm{oxidative} \mathrm{stress}$ and functional decline. PloS one. 2008;3:e2865.

10. Maton PN, Burton ME. Antacids revisited: a review of their clinical pharmacology and recommended therapeutic use. Drugs. 1999;57:855-70.

11. Ratnaike RN, Jones TE. Mechanisms of drug-induced diarrhoea in the elderly. Drugs \& aging. 1998;13:245-53.

12. Emerit J, Beaumont C, Trivin F. Iron metabolism, free radicals, and oxidative injury. Biomedicine \& pharmacotherapy = Biomedecine \& pharmacotherapie. 2001;55:333-9.

13. Halliwell B, Gutteridge JM, Aruoma OI. The deoxyribose method: a simple "test-tube" assay for determination of rate constants for reactions of hydroxyl radicals. Analytical biochemistry. 1987;165:215-9.

14. Nagababu E, Rifkind JM, Boindala S, Nakka L. Assessment of antioxidant activity of eugenol in vitro and in vivo. Methods in molecular biology. 2010;610:165-80. 
15. Vrolijk MF, Haenen GR, Opperhuizen A, Jansen EH, Schiffers PM, Bast A. The supplementdrug interaction of quercetin with tamsulosin on vasorelaxation. European journal of pharmacology. 2015;746:132-7.

16. Stein J, Dignass AU. Management of iron deficiency anemia in inflammatory bowel disease a practical approach. Annals of gastroenterology : quarterly publication of the Hellenic Society of Gastroenterology. 2013;26:104-13.

17. Carrier J, Aghdassi E, Platt I, Cullen J, Allard JP. Effect of oral iron supplementation on oxidative stress and colonic inflammation in rats with induced colitis. Alimentary pharmacology \& therapeutics. 2001;15:1989-99.

18. Nebel OT, Fornes MF, Castell DO. Symptomatic gastroesophageal reflux: incidence and precipitating factors. The American journal of digestive diseases. 1976;21:953-6.

19. Qian SY, Buettner GR. Iron and dioxygen chemistry is an important route to initiation of biological free radical oxidations: an electron paramagnetic resonance spin trapping study. Free radical biology \& medicine. 1999;26:1447-56.

20. Vrolijk MF, Opperhuizen A, Jansen EH, Godschalk RW, Van Schooten FJ, Bast A, et al. The shifting perception on antioxidants: the case of vitamin $E$ and beta-carotene. Redox biology. 2015;4:272-8.

21. Vrolijk MF, Opperhuizen A, Jansen EH, Bast A, Haenen GR. Anticholinergic Accumulation: A Slumbering Interaction between Drugs and Food Supplements. Basic \& clinical pharmacology \& toxicology. 2015;117:427-32. 




\section{Chapter $\mathbf{6}$}

\section{The Vitamin $\mathrm{B}_{6}$ Paradox: Supplementation of high concentrations of Pyridoxine leads to decreased vitamin $B_{6}$ function}

Misha F Vrolijk, Antoon Opperhuizen, Eugène H J M Jansen, G.J. Hageman, Aalt Bast, Guido R M M Haenen

(submitted) 


\begin{abstract}
Vitamin $B_{6}$ is a water-soluble vitamin that functions as a coenzyme in many reactions involved in amino acid, carbohydrates and lipid metabolism. Since 2014, more than 50 cases of sensory neuronal pain due to vitamin $B_{6}$ supplementation were reported to Lareb. Up to now, the mechanism of this toxicity is enigmatic and the contribution of the various B6 vitamers to this toxicity is largely unknown. In the present study, the neurotoxicity of the different forms of vitamin B6 is tested on SHSY5Y and CaCo-2 cells. Cells were exposed to pyridoxine, pyridoxamine, pyridoxal , pyridoxal-5'-phosphate or pyridoxamine-5'-phosphate for $24 \mathrm{~h}$, after which cell viability was measured using the MTT assay. The gene expression of Bax and caspase-8 was also measured after the 24 hours exposure. The effect of the vitamers on two pyridoxal-5-phosphate dependent enzymes was also tested. Pyridoxine induced cell death in a concentration-dependent way in SHSY5Y cells. The other vitamers did not affect cell viability. Pyridoxine furthermore significantly increased the expression of Bax and caspase-8. Moreover, both pyridoxal-5-phosphate dependent enzymes were inhibited by pyridoxine. In conclusion, the present study indicates that the neuropathy observed after taking a relatively high dose of vitamin $B_{6}$ supplements is due to pyridoxine. The inactive form pyridoxine competitively inhibits the active pyridoxal-5'-phosphate. Consequently, symptoms of vitamin $B_{6}$ supplementation are similar to those of vitamin $B_{6}$ deficiency.
\end{abstract}




\section{Introduction}

Vitamin $B_{6}$ is a water-soluble vitamin found in e.g. meat, poultry, fish, legumes, bananas, nuts and cereals [1]. Vitamin $B_{6}$ functions as a coenzyme in many reactions that are involved in amino acid, carbohydrates and lipid metabolism [2]. Additionally, vitamin $\mathrm{B}_{6}$ also plays a role in neuronal signaling through the synthesis of neurotransmitters [3]. The major forms of vitamin $B_{6}$ are: pyridoxine $(P N)$, pyridoxal $(P L)$, pyridoxamine $(P M)$ and their phosphorylated derivatives pyridoxine $5^{\prime}$-phosphate (PNP), pyridoxal-5'-phosphate (PLP) and pyridoxamine-5'-phosphate (PMP) [1].

Vitamin $\mathrm{B}_{6}$ is mainly present in our diet as PN, PL and PM. After passive absorption in the intestine, the major part of the vitamin is converted in the liver to PLP $[4,5]$. After hydrolysis to PL by alkaline phosphatases, it becomes available for every cell in our body. Within the cells, PL is phosphorylated by pyridoxal kinase to PLP [6]. Most of the PL in excess of tissue requirements is oxidized by the liver to 4-pyridoxic acid (4-PA), which is the major degradation product of vitamin $B_{6}$ in the urine. The metabolic routes of vitamin $B_{6}$ are shown in figure 1.

Vitamin $\mathrm{B}_{6}$ deficiency may arise from a too low intake, malabsorption, or due to drugs that inhibit enzymes involved in PLP metabolism. Low levels of vitamin $B_{6}$ are found in elderly, individuals with traumatic femoral fractures, and in alcoholics [7]. Deficiency has been related to increased risk of cardiovascular diseases and neuronal symptoms [8]. In these cases, vitamin $B_{6}$ supplements are advised [9-11]. In the US, about $28 \%-36 \%$ of the general population uses supplements containing vitamin B6 $[12,13]$. These supplements are most often taken by children up to 6 years and by adults over 51 years of age. Most vitamin $B_{6}$ supplements contain PN ranging from $25-100 \mathrm{mg} /$ tablet.

Recently, the European Food Safety Authority (EFSA) has established an upper limit (UL) of $25 \mathrm{mg} /$ day. This UL was based on neurological complaints observed after taking $50 \mathrm{mg}$ of PN per day. This is 4 times lower than the previous UL of $100 \mathrm{mg} /$ day of USDA and other authorities. However, since vitamin $B_{6}$ is considered to be relatively safe, doses of over 2000-fold the recommended dietary allowance of 1.4-2.1 mg/day (depending on sex and age) are used in some circumstances [14].

Already in 1987, a case of sensory neuropathy induced by a high dose of vitamin $B_{6}$ has been reported [15]. In the years that followed, more cases on vitamin $B_{6}$ toxicity were found. Recently, The Netherlands Pharmacovigilance Centre Lareb, which collects and analyses reports of adverse reactions of medicines and vaccines, published a report concerning the side effects of vitamin $B_{6}$ supplements. Since 2014, more than 50 cases of sensory neuronal pain due to vitamin $B_{6}$ were reported to Lareb [16]. The dose of vitamin $B_{6}$ differed from 1.5 - $100 \mathrm{mg}$. In these cases, high plasma levels of PLP between $183 \mathrm{nmol} / \mathrm{I}$ and $4338 \mathrm{nmol} / \mathrm{I}$ were found. Plasma levels of PN were not determined. Up to now, the mechanism of this toxicity is enigmatic and the contribution of the various $B_{6}$ vitamers to this toxicity is largely unknown. Our hypothesis is that PN is the vitamer mainly responsible for the vitamin $B_{6}$ induced toxicity. $\mathrm{PN}$, which is not the active form, is ultimately converted 
into PLP, which is the active form. High levels of PN are thought to inhibit PLP-dependent enzymes by competing with the bioactive vitamer, PLP.<smiles>Cc1ncc(CO)c(CO)c1O</smiles>

Pyridoxine
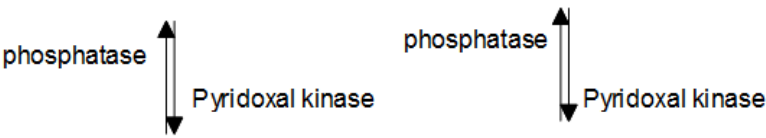<smiles>Cc1ncc(CO)c(C=O)c1O</smiles>

Pyridoxal

Pyridoxal kinase

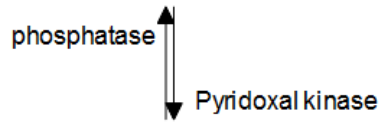

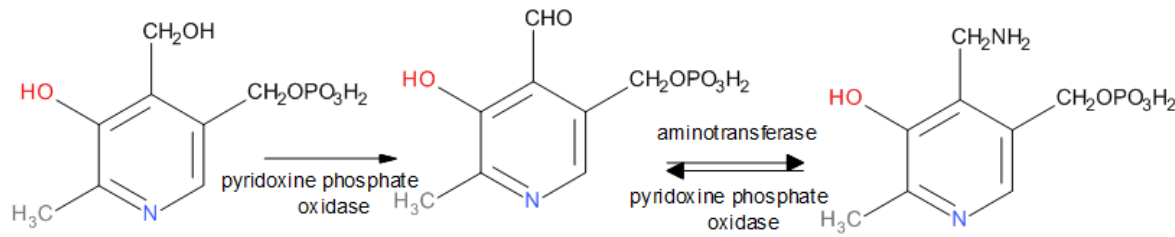

Pyridoxine phosphate

Pyridoxal phosphate

Pyridoxamine phosphate

Figure 1| Vitamin B6 metabolism.

In the present study, the neurotoxicity of the different forms of vitamin B6 is tested on neuroblastoma cells (SHSY5Y). In line with our hypothesis, PN showed the highest toxicity. The paradox that the vitamin B6 PN vitamer in high concentrations inhibits vitamin B6 dependent processes was confirmed using vitamin B6 dependent enzymes tyrosine decarboxylase and alanine transaminase. 


\section{Materials and Methods}

\section{Chemicals}

L-alanine, $\alpha$-ketoglutarate, alanine transaminase, lactate dehydrogenase (LDH),NADH, PN, PL, PM dihydrochloride, PLP hydrate, PMP, Toluene, tyrosine decarboxylase apoenzyme $(1.1 \mathrm{U} / \mathrm{mg}$ ) from Streptococcus faecalis, L-tyrosine and picrylsulfonic acid were all obtained from Sigma (St. Louis, USA).

\section{Tyrosine decarboxylase enzyme activity}

Tyrosine decarboxylase activity was measured according to the tyrosine decarboxylase enzyme activity assay. In this assay, tyrosine is converted into tyramine by the enzyme tyrosine decarboxylase and the co-enzyme PLP. At first, tyrosine (0-100 $\mu \mathrm{M})$ was added to a tube containing tyrosine decarboxylase $(1.1 \mathrm{U} / \mathrm{mL})$ with PLP and acetate buffer $(\mathrm{pH} 5.5)$. This mixture was incubated for 10 minutes at $37{ }^{\circ} \mathrm{C}$. Then, $1 \mathrm{~mL}$ of $\mathrm{K}_{2} \mathrm{CO}_{3}(1 \mathrm{M})$ was added to the tube, which was followed by the addition of $1 \mathrm{~mL}$ of TNBS $(10 \mathrm{mM})$. Finally, $2 \mathrm{~mL}$ of toluene was added, after which the tube was vortexed for $20 \mathrm{~s}$. After centrifugation for 5 min at 2000 RPM, the enzyme activity was determined by measuring the absorbance at 340 $\mathrm{nm}$ using a spectrophotometer. In order to determine the effect of the different forms of vitamin $B_{6}$, the enzyme was first incubated together with the vitamer of vitamin $B_{6}$ (at 5 $\mu \mathrm{M})$ for $2 \mathrm{~min}$. Then, the same protocol was followed as described above.

\section{Alanine transaminase activity}

Alanine transaminase activity was measured according to the alanine transaminase activity assay. In short, alanine transaminase catalyzes the transfer of an aminogroup from alanine to $\alpha$-ketoglutarate using PLP as a coenzyme. Glutamate and pyruvate are the products that are formed in this reaction. The formation of pyruvate is then spectrophotometrically followed during its conversion to lactate by $\mathrm{LDH}$ in the presence of $\mathrm{NADH}$. In this reaction, $\mathrm{NAD}$ is formed which is monitored at $340 \mathrm{~nm}$. After adding alanine transaminase $(1 \mathrm{U} / \mathrm{ml})$ to the reaction tube containing alanine $(0.5 \mathrm{mM}), \alpha$-ketoglutarate $(15 \mathrm{mM}), \mathrm{LDH}(1.25$ $\mathrm{U} / \mathrm{ml}), \mathrm{NADH}(0.18 \mathrm{mM})$ and Tris buffer $(100 \mathrm{mM}$; $\mathrm{pH} 7.5)$, the reaction was started and followed during 5 minutes. The effect of $\mathrm{PN}$ on this enzymatic reaction was tested by following the same protocol as described above including the addition of $5 \mu \mathrm{M}$ PN in the reaction tube.

\section{Cell culture}

Human neuroblastoma (SHSY5Y) cells were cultured in $75 \mathrm{~cm} 3$ cell culture flasks (Corning ${ }^{\circledR}$ Flask, Corning Incorporate, NY, USA) in DMEM:F122 (Invitrogen), supplemented with 10\% Fetal Bovine Serum (FBS; Invitrogen), 1\% I-glutamine and 1\% penicillin streptomycin (P/S; Invitrogen) at $37^{\circ} \mathrm{C}$ in a $5 \% \mathrm{CO}_{2}$ and $20 \% \mathrm{O}_{2}$ atmosphere. Media was renewed twice weekly and cultures were split when $90 \%$ confluence was reached. Cells were differentiated by exposing them to $3 \%$ medium containing $10 \mu \mathrm{M}$ retinoic acid for 5 days. After differentiation, cells were seeded 1 day prior to treatment and maintained at $37^{\circ} \mathrm{C}$ in a $5 \%$ 
$\mathrm{CO}_{2}$ atmosphere. CaCo-2 cells were cultured in $75 \mathrm{~cm} 3$ cell culture under standard conditions. Dulbecco's modified Eagle medium (DMEM) with the addition of $10 \%$ FBS, $1 \%$ of non-essential amino acids, $1 \%$ Na-pyruvate and $1 \%$ of penicillin-streptomycin.

\section{Cell treatment}

For the cell viability assays, both differentiated SHSY5Y and CaCo-2 cells were seeded in 96wells plates at a density of 25.000 cells/well. After one day, cells were exposed to PN (0 - 5 $\mu \mathrm{M}), \mathrm{PM}(0-500 \mu \mathrm{M}), \mathrm{PL}(0-500 \mu \mathrm{M})$, PLP $(0-500 \mu \mathrm{M})$ or PMP $(0-500 \mu \mathrm{M})$ for $24 \mathrm{~h}$ in normal culture medium. In order to determine if PLP could prevent PN-induced toxicity, all cells were exposed to $1 \mu \mathrm{M}$ of PN and an increasing concentration of PLP (0-100 uM). Untreated cells were used as controls in all experiments. For gene expression experiments, both SHSY5Y and CaCo-2 cells were seeded in 6-wells plate at a density of 500.000 cells/well After $24 \mathrm{~h}$, cells were exposed to PN $(0-1 \mu \mathrm{M}), \mathrm{PM}(0-50 \mu \mathrm{M}), \mathrm{PL}(0-50 \mu \mathrm{M})$, $\operatorname{PLP}(0-50 \mu \mathrm{M})$ or PMP $(0-50 \mu \mathrm{M})$ for 24 hours, after which RNA was isolated.

\section{MTT assay}

After the $24 \mathrm{~h}$ incubation, medium was removed and cells were washed with PBS. Then, $200 \mu \mathrm{l}$ of MTT solution $(0.5 \mathrm{mg} / \mathrm{ml})$ was added and cells were incubated for $1 \mathrm{~h}$ at $37 \circ \mathrm{C}$. After this incubation, the wells were washed with PBS, after which the formazan crystals were dissolved in $200 \mu \mathrm{l}$ DMSO. Cells were incubated for $30 \mathrm{~min}$ after which the absorbance at $540 \mathrm{~nm}$ was measured spectrophotometrically using a microplate reader. Relative cell viability is expressed as a percentage relative to untreated cells.

\section{RNA isolation}

After removing the medium, $500 \mu \mathrm{l}$ of Qiazol was added to each well. After incubation of 5 minutes at room temperature, the suspension was transferred into an Eppendorf tube. Next, $100 \mu \mathrm{l}$ of chloroform was added in the tube. The tube was vigorously shaken for 15 seconds. Then, samples were centrifuged for $10 \mathrm{~min}$ at $12,000 \mathrm{RPM}\left(4{ }^{\circ} \mathrm{C}\right)$. From this point, samples were held on ice. The aqueous phase was transferred to a new tube without disturbing the interphase. To this phase, $250 \mu \mathrm{l}$ of isopropanol was added and the samples were incubated for 10 minutes at room temperature. Next, samples were centrifuged for 10 minutes at 12,000 RPM at $4{ }^{\circ} \mathrm{C}$, after which the supernatant was poured out. Pellets were washed twice by adding $500 \mu$ of $70 \%$ ethanol, mixing the samples and centrifuging them for 3 minutes at 12,000 RPM at $4{ }^{\circ} \mathrm{C}$, respectively. After pouring of the supernatant, pellets were washed one last time with $500 \mu$ of $100 \%$ ethanol. Samples were centrifuged for 5 minutes and supernatant was poured out. After air drying the pellets, RNA was dissolved in $30 \mu \mathrm{l}$ RNase free water by passing through pipette tip several times. The quality and quantity of RNA was determined using the nanodrop (Thermo Scientific Nanodrop 1000 spectrophotometer, Isogen Life Science, De Meern, The Netherlands). 


\section{PCR}

One microgram of RNA was converted into complementary DNA (cDNA) by using iScript cDNA synthesis kit (Biorad, Veenendaal, The Netherlands). Sensimix SYBR \& Fluorescein kit (Bioline, Alphen aan de Rijn, The Netherlands) was used to perform quantitative RT-PCR measuring $\quad B A X$ (FW: 5'-GAGAGGTCTTTTTCCGAGTGG-3'and RV: 5'CCTTGAGCACCAGTTTGCTG-3') and caspase-8 (FW: 5'-CATCCAGTCACTTTGCCAGA-3' and RV: 5'-GCATCTGTTTCCCCATGTTT-3'). GAPDH (FW: 5'-CGCTCTCTGCTCCTCCTGTT-3' and RV: 5'CCATGGTGTCTGAGCGATGT-3') was applied as housekeeping gene. Finally, the 2- $\triangle \Delta C T$ method was used to determine relative gene expression.

\section{Statistical analysis}

All results were shown as mean \pm SEM. Data were analysed compared to (untreated) controls using an unpaired t-test. Results were considered statistically significant when $\mathrm{P}<$ 0.05 , in which ${ }^{*} P<0.05,{ }^{*} P<0.01, * * * P<0.001$. 
Results

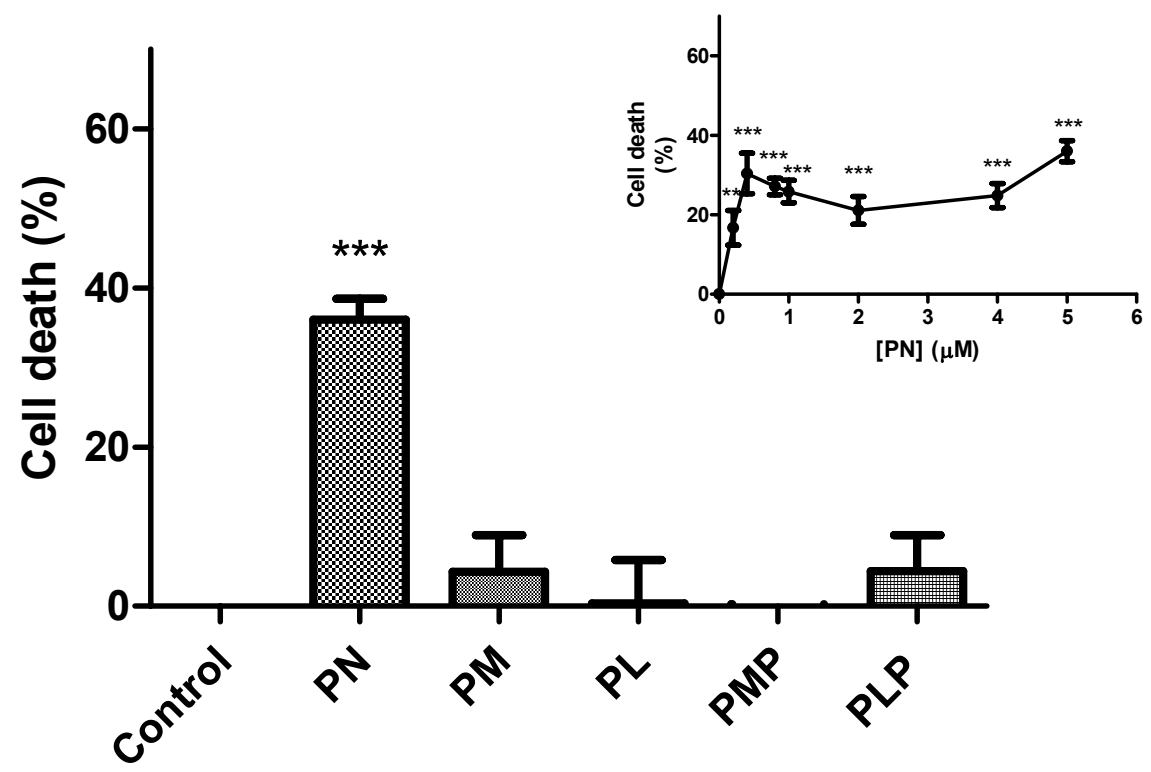

Figure 2| Cell death of SHSY5Y cells in the presence of the 5 different vitamin $B_{6}$ vitamers at a concentration of $5 \mu \mathrm{M}$ was measured with the MTT assay. Cells were exposed to these vitamers for 24 hours. Untreated cells were used as controls and results obtained with the vitamin $B_{6}$ vitamers were compared to controls (which was set at $0 \%$ ). The effect of PN was also determined in a concentration-dependent manner (0-5 $\mu \mathrm{M})$, which is shown in figure 1 insert. Data are shown as means \pm SEM $(n=4)$. Differences were considered to be statistically significant when $P<0.05$. ${ }^{* *} P<$ $0.01 ; * * * P<0.001$.

\section{Cell viability after exposure to the vitamin B6 vitamers}

MTT assays were performed to measure vitamin $B_{6}$-induced cytotoxicity in SHSY5Y cells after $24 \mathrm{~h}$ incubation. Of the vitamers, PN induced a significant amount of cell death at 5 $\mu \mathrm{M}$ (fig. 2). At this concentration, the other vitamers (PM, PL and their phosphorylated forms) did not increase cell death. PN was found to significantly increase cell death also in lower concentrations (fig 2. insert). Already at a concentration of $200 \mathrm{nM}$, cell death increased to $17 \%$. After doubling the concentration to $400 \mathrm{nM}$, cell death increased to $30 \%$. Only at very high concentrations (up to $500 \mu \mathrm{M}$ ), PLP tended to induce cell death (data not shown) although this did not reach statistical significance. In CaCo-2-cells, PN in various 
concentrations did not affect the cell viability after $24 \mathrm{~h}$ (supplementary data figure 1).
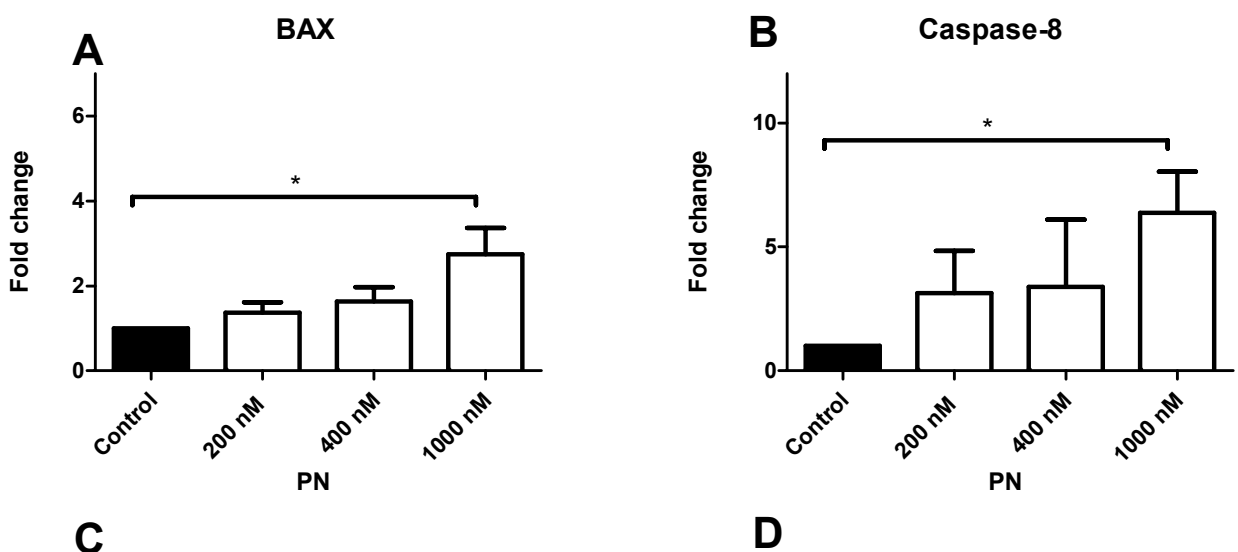

C

BAX

Caspase-8
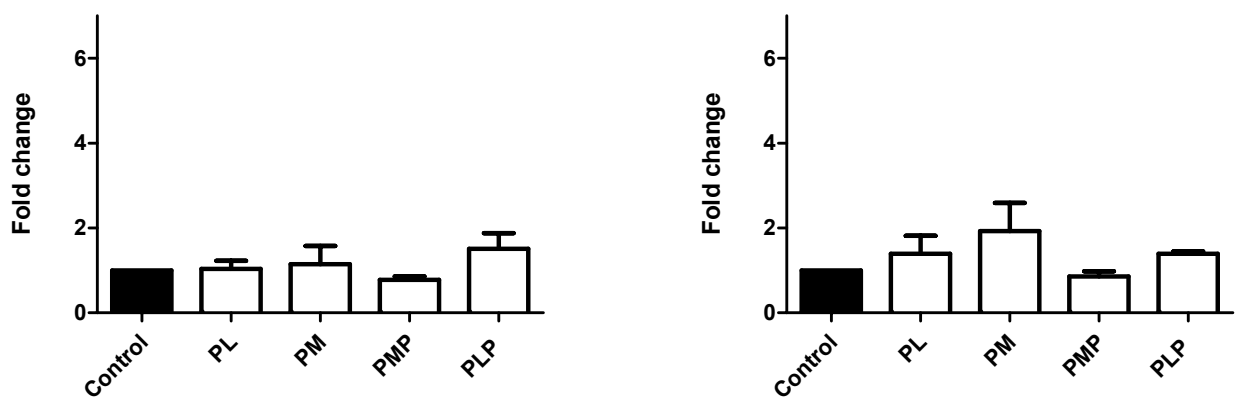

Figure 3| Gene expression data of two apoptosis genes (BAX and Caspase-8) after exposure of SHSY5Y cells to the 5 different vitamin $B_{6}$ vitamers. The effect of PN $(0-1 \mu \mathrm{M})$ on the expression of BAX and caspase- 8 is shown in panels (A) and (B). The effects of the other vitamers at a concentration of $10 \mu \mathrm{M}$ are shown in panels (C) and (D). Untreated cells were used as controls and results obtained with the vitamin $B_{6}$ vitamers were compared to controls (which was set at 1 ). Data are shown as means $\pm \operatorname{SEM}(n=3)$. Differences were considered to be statistically significant when $P<0.05 .{ }^{*} P<$ 0.05 .

\section{Expression of apoptosis genes after exposure to different vitamers of vitamin B6}

Gene expression levels of two apoptosis genes (BAX and Caspase-8) were measured in SHSY5Y and CaCo-2 cells after incubation with the different vitamers. Untreated cells were used as control condition, which was set to 1 . In SHSY5Y cells, PN increased the gene expression levels of BAX and caspase- 8 in a concentration-dependent way (fig. 3A and B). At a concentration of $1 \mu \mathrm{M}$, the increase in expression of BAX and caspase- 8 was significant. The expression of the two genes was not changed by PL, PM, PLP and PMP at a concentration of $10 \mu \mathrm{M}$ (fig. $3 \mathrm{C}$ and $\mathrm{D}$ ). Even at $50 \mu \mathrm{M}$ of PL, PM, PLP and PMP, the 
expression of the apoptosis genes remained unchanged (supplementary data figure 2).
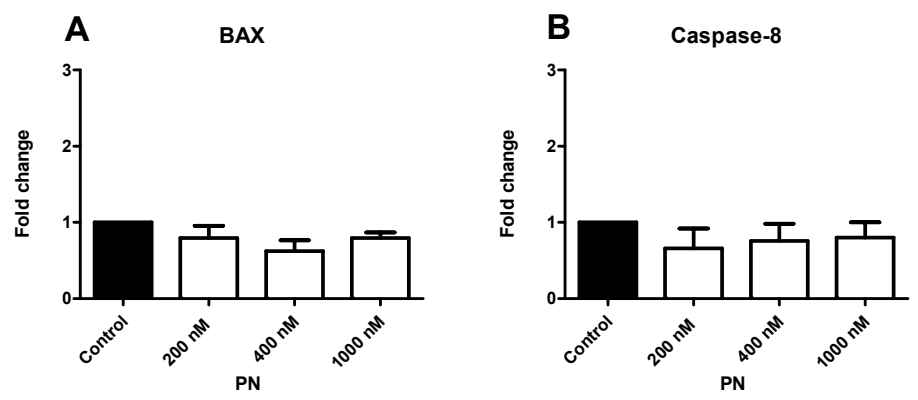

\section{C}

BAX

D
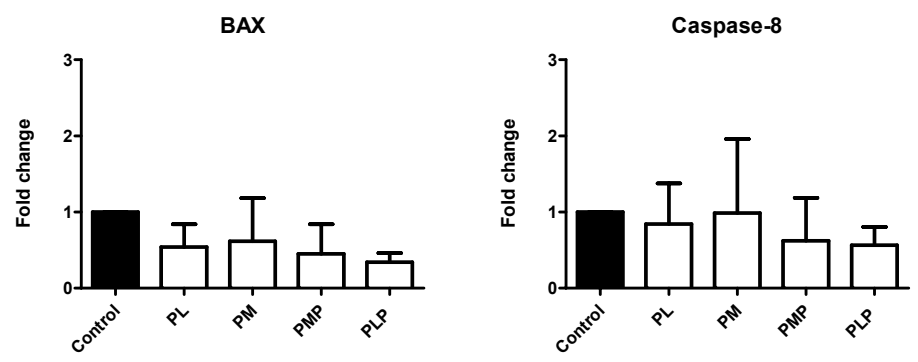

Figure 4| Gene expression data of two apoptosis genes (BAX and Caspase-8) after exposure of CaCo2 cells to the 5 different vitamin B6 vitamers. The effect of PN $(0-1 \mu \mathrm{M})$ on the expression of BAX and caspase- 8 is shown in panels (A) and (B). The effects of the other vitamers at a concentration of $10 \mu \mathrm{M}$ are shown in panels (C) and (D). Untreated cells were used as controls and results obtained with the vitamin $B_{6}$ vitamers were compared to controls (which was set at 1 ). Data are shown as means $\pm \operatorname{SEM}(n=3)$.

In contrast to SHSY5Y cells, PN did not change the expression of BAX and caspase-8 in CaCo2 cells (fig. 4). In these cells, the different vitamers of vitamin $B_{6}$ (at $10 \mu \mathrm{M}$ ) did not change the expression of BAX and caspase-8. Even at $50 \mu \mathrm{M}$, the expression of these genes was not changed (supplementary data figure 3).

\section{Protection against PN toxicity by PLP}

In order to determine whether PN toxicity might be caused by competing with the bioactive vitamer PLP, SHSY5Y cells were exposed to both PN and PLP for 24 hours and cell viability was measured using the MTT assay. PN $(1 \mu \mathrm{M})$ significantly increased cell death (fig. 5). PLP already at a concentration of $0.3 \mu \mathrm{M}$ protected against cell death induced by $1 \mu \mathrm{M}$ PN, indicating that cell death is dependent on competition of PN with PLP. 


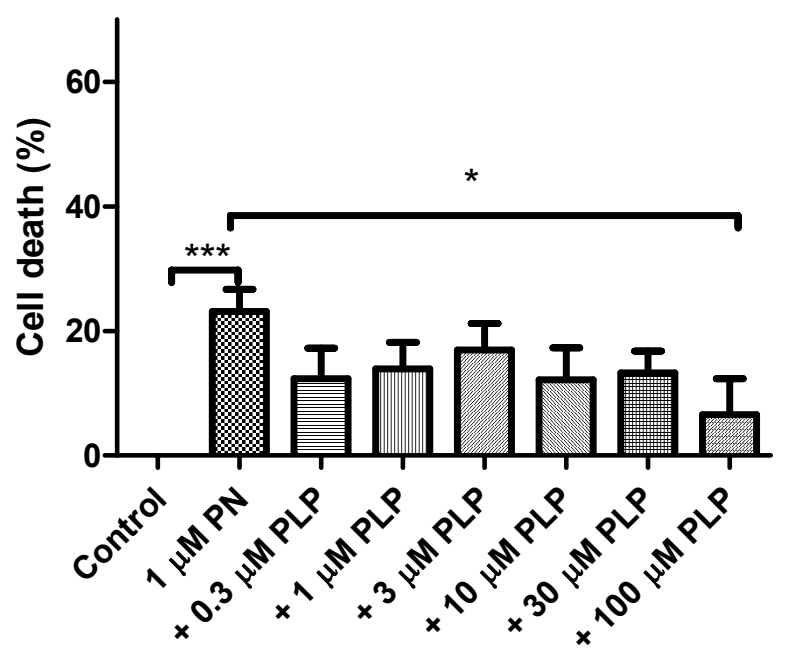

Figure $5 \mid$ Cell viability of SHSY5Y cells was measured by using the MTT assay. Cells were exposed to these $1 \mu$ of PN in the presence of increasing concentrations of PLP $(0-100 \mu \mathrm{M})$ for 24 hours. Untreated cells were used as controls and results obtained were compared to controls (which was set at $0 \%)$. Data are shown as means $\pm \operatorname{SEM}(n=4)$. Differences were considered to be statistically significant when $\mathrm{P}<0.05$. ${ }^{*} \mathrm{P}<0.05 ;{ }^{* * *} \mathrm{P}<0.001$.

\section{PLP-dependent enzyme activities}

The effect of the different vitamers (at $5 \mu \mathrm{M}$ ) on the enzyme activity of tyrosine decarboxylase was determined (fig. 6A). At a tyrosine concentration of $10 \mu \mathrm{M}$, PMP did not show any effect on the enzyme activity. PM only slightly decreased the enzyme activity, while PL and PLP even tended to increase the enzyme activity. Interestingly, PN decreased the enzyme activity with approximately 65\%. A tenfold Increase in the substrate concentration of tyrosine reduced the inhibitory effect of PN, suggesting that the inhibition by $\mathrm{PN}$ is competitive. Besides tyrosine decarboxylase, PN (at $5 \mu \mathrm{M}$ ) also inhibited the activity of alanine transaminase by $40 \%$ (fig. 6B). 
A

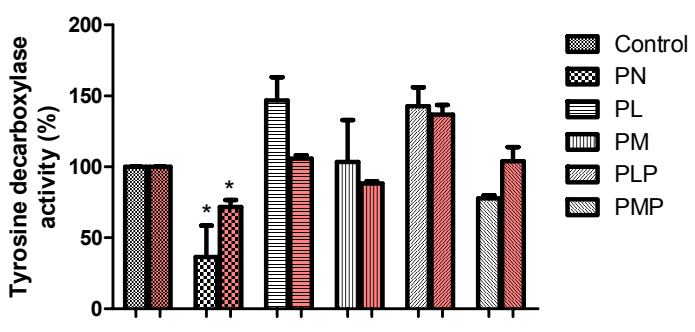

B

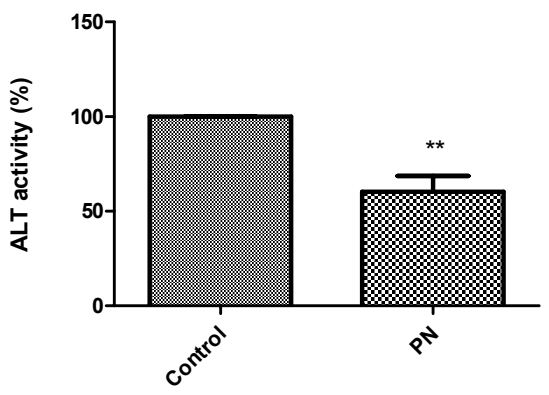

Figure 6| The effect of the different vitamin B6 vitamers $(5 \mu \mathrm{M})$ on the PLP-dependent enzyme tyrosine decarboxylase using two different substrate concentrations (10 $\mu \mathrm{M}$ (white bars) and $100 \mu \mathrm{M}$ (red bars)) is shown in (A). The effect of PN $(5 \mu \mathrm{M})$ at a second PLP-dependent enzyme (alanine aminotransferase) is shown in (B). Data are shown as means $\pm \operatorname{SEM}(n=3)$. Differences were considered to be statistically significant when $\mathrm{P}<0.05$. ${ }^{*} \mathrm{P}<0.05$; ${ }^{*} \mathrm{P}<0.01$. 


\section{Discussion}

In the last decades, various cases of vitamin $B_{6}$ induced polyneuropathy have been reported $[15,17,18]$. People chronically taking vitamin $B_{6}$ supplements reported complaints such as pain in the extremities and muscle weakness. These complaints were reversible as they faded away after stopping the supplementation. Most often, these complaints were seen when taking mega doses (>50 mg/day) of vitamin $B_{6}$ for a longer period of time. However, recently, Lareb reported cases in which lower doses ( $2 \mathrm{mg} /$ day) of vitamin $\mathrm{B} 6$ gave the same complaints [16]. Up to now, the mechanism of vitamin $B_{6}$ induced polyneuropathy is still unknown, making it difficult to give well substantiated advices.

Six different vitamers of vitamin $\mathrm{B}_{6}$ exist, namely $\mathrm{PN}, \mathrm{PL}, \mathrm{PM}$ and their phosphorylated derivatives PNP, PLP and PMP. PLP is the biological active form of vitamin $B_{6}$, being a wellknown coenzyme in a wide variety of enzymatic reactions. Of the vitamers, $P N$ is most commonly taken as a food supplement. Since vitamin $B_{6}$ is considered to be safe, supplements with high doses of PN are on the market. Once taken up, PN is converted into PLP in several steps, of which phosphorylation by pyridoxal kinase to PLP is the most critical one. All the supplements that caused adverse effects contained PN. Therefore, the focus was on PN. We hypothesized that PN is the vitamer responsible for the neurotoxic effects, by competing with the active form PLP.

Our study indeed showed that PN significantly increases cell death in the neuronal cell line SHSY5Y after a 24 hours exposure. The concentrations were selected based on plasma levels that were found in several studies [19-21]. In contrast, the other vitamers did not affect cell viability. Additionally, PLP was able to prevent PN induced cell death, indicating that PN toxicity is caused by competition with PLP, which is in line with our hypothesis. The toxic effects of PN furthermore seem to be neuronal specific, since PN did not induce cell death in the intestinal cell line CaCo-2. Neuronal cell death may result in polyneuropathy, as seen in diabetics, explaining the neuropathy observed in vitamin $B_{6}$ toxicity [22].

Remarkably, sensory neuropathy is seen in vitamin $B_{6}$ toxicity as well as vitamin $B_{6}$ deficiency. In the present study, the effect of the inactive PN on the active PLP was tested with two enzymes involving PLP as a coenzyme, namely tyrosine decarboxylase and alanine aminotransferase. Tyrosine decarboxylase catalyzes the decarboxylation of tyrosine to produce tyramine. Alanine aminotransferase catalyzes the transfer of the amino group of Lalanine to $\alpha$-ketoglutarate. The activity of both enzymes was shown to be competitively inhibited by PN. The other vitamers either increased the enzyme activities or did not affect the enzyme activities. It was concluded that PN indeed competes with the active PLP resulting in the inhibition of vitamin $B_{6}$ dependent enzymes. In vitamin $B_{6}$ deficiency, enzymes depending on PLP (the bioactive vitamer) as a cofactor will be (partially) inhibited. Vitamin $B_{6}$ supplementation mostly concerns $P N$, which is converted by pyridoxal kinase and pyridoxine phosphate oxidase into PLP. At high doses, PN saturates these enzymes. As a consequence, the inactive vitamer PN accumulates. Indeed, high levels of PN (up to 18 $\mu \mathrm{M}$ ) have been found in the cerebrospinal fluid (CSF) and (up to $200 \mathrm{nM}$ ) in plasma of two persons taking PN supplements [19-21]. 200 nM of PN already induced cell death in our 
study, furthermore underlining the relevance of our findings. At such high concentration, PN effectively competes with PLP resulting in the inhibition of PLP dependent enzymes. Hence, this explains that these effects will be paradoxically similar to that of a deficiency in vitamin $B_{6}$.

One of the pathways in which PLP is essential is the kynurenine pathway $[1,23,24]$. In this pathway, the amino acid tryptophan is metabolized to nicotinamide. Intermediate products formed are quinolinic acid, kynurenine, 3-hydroxykynurenine (3-HK) and 3hydroxyanthranilic acid (3-HAA) [1]. 3-HK is converted into xanthurenic acid and 3-HAA by two PLP-dependent enzymes. The kynurenine pathway has been linked to several central nervous system diseases, such as Huntington's disease and Alzheimer's disease $[26,27]$. Significantly increased 3-HK levels were found in brain tissues of Huntington's disease patients [25].

It has previously been shown that exposure of SHSY5Y cells to relatively high levels of 3-HK increased cell death [28]. Addition of 3-HK to striatal neuronal cell cultures caused increased cell death via apoptosis [29]. In this process, hydrogen peroxide and hydroxyl radical formation play an important role, since the antioxidant enzyme catalase reduced 3HK induced cell death. In the present study, the expression of Bax and caspase- 8 was used to monitor apoptosis in the neuronal cell line. Of the vitamers, only PN increased the expression of Bax and caspase-8. This suggests that accumulation of 3-HK, caused by inhibition of the PLP dependent metabolism of $3-\mathrm{HK}$ by PN, may play a role in the polyneuropathy observed during vitamin $B_{6}$ toxicity.

In conclusion, the present study strongly indicates that the neuropathy observed after taking a relatively high dose of vitamin $B_{6}$ supplements is due to the vitamer that is used in the supplements, namely PN. The inactive form PN competitively inhibits the active PLP. As a consequence, the paradox arises that the symptoms of vitamin $B_{6}$ supplementation are similar to those of vitamin $B_{6}$ deficiency. Vitamin $B_{6}$ supplements are used by a large number of people. The safety of vitamin $B_{6}$ is debated and recently EFSA has lowered the upper limit for vitamin $B_{6}$. The question is whether lowering the safe dose for vitamin $B_{6}$ is the solution. Remarkably, even at relatively low dose, vitamin $B_{6}$ supplementation has given rise to complaints. Our study indicates that the toxicity of vitamin $B_{6}$ is not only determined by the dose, but by the vitamer in which it is taken. Perhaps it might be better to replace PN by PL or PLP as vitamin $B_{6}$ supplements, which are much less toxic. In this way, the vitamin $B_{6}$ paradox may potentially be prevented. 


\section{References}

1. Ueland PM, Ulvik A, Rios-Avila L, Midttun O, Gregory JF. Direct and Functional Biomarkers of Vitamin B6 Status. Annual review of nutrition. 2015;35:33-70.

2. Eliot AC, Kirsch JF. Pyridoxal phosphate enzymes: mechanistic, structural, and evolutionary considerations. Annual review of biochemistry. 2004;73:383-415.

3. Percudani R, Peracchi A. The B6 database: a tool for the description and classification of vitamin B6-dependent enzymatic activities and of the corresponding protein families. BMC bioinformatics. 2009;10:273.

4. Merrill AH, Horiike K, McCormick DB. Evidence for the regulation of pyridoxal 5-phosphate formation in liver by pyridoxamine (pyridoxine) 5 -phosphate oxidase. Biochemical and biophysical research communications. 1978;83:984-90.

5. Zuo H, Ueland PM, Eussen SJ, Tell GS, Vollset SE, Nygard O, et al. Markers of vitamin B6 status and metabolism as predictors of incident cancer: the Hordaland Health Study. International journal of cancer. 2015;136:2932-9.

6. Albersen M, Bosma M, Jans JJ, Hofstede FC, van Hasselt PM, de Sain-van der Velden MG, et al. Vitamin B6 in plasma and cerebrospinal fluid of children. PloS one. 2015;10:e0120972.

7. di Salvo ML, Safo MK, Contestabile R. Biomedical aspects of pyridoxal 5'-phosphate availability. Frontiers in bioscience. 2012;4:897-913.

8. Spinneker A, Sola R, Lemmen V, Castillo MJ, Pietrzik K, Gonzalez-Gross M. Vitamin B6 status, deficiency and its consequences--an overview. Nutricion hospitalaria. 2007;22:7-24.

9. Kashanian M, Mazinani R, Jalalmanesh S. Pyridoxine (vitamin B6) therapy for premenstrual syndrome. International journal of gynaecology and obstetrics: the official organ of the International Federation of Gynaecology and Obstetrics. 2007;96:43-4.

10. Wyatt KM, Dimmock PW, Jones PW, Shaughn O'Brien PM. Efficacy of vitamin B-6 in the treatment of premenstrual syndrome: systematic review. Bmj. 1999;318:1375-81.

11. Bendich A. The potential for dietary supplements to reduce premenstrual syndrome (PMS) symptoms. Journal of the American College of Nutrition. 2000;19:3-12.

12. Bailey RL, Gahche JJ, Lentino CV, Dwyer JT, Engel JS, Thomas PR, et al. Dietary supplement use in the United States, 2003-2006. The Journal of nutrition. 2011;141:261-6.

13. Morris MS, Picciano MF, Jacques PF, Selhub J. Plasma pyridoxal 5'-phosphate in the US population: the National Health and Nutrition Examination Survey, 2003-2004. The American journal of clinical nutrition. 2008;87:1446-54.

14. Simpson JL, Bailey LB, Pietrzik K, Shane B, Holzgreve W. Micronutrients and women of reproductive potential: required dietary intake and consequences of dietary deficiency or excess. Part Il--vitamin D, vitamin A, iron, zinc, iodine, essential fatty acids. The journal of maternal-fetal \& neonatal medicine : the official journal of the European Association of Perinatal Medicine, the Federation of Asia and Oceania Perinatal Societies, the International Society of Perinatal Obstet. 2011;24:1-24.

15. Schaumburg H, Kaplan J, Windebank A, Vick N, Rasmus S, Pleasure D, et al. Sensory neuropathy from pyridoxine abuse. A new megavitamin syndrome. The New England journal of medicine. 1983;309:445-8.

16. lareb Bc. Meldingen van bijwerkingen van warenwetmiddelen; 2015 Contract No.: Document Number|.

17. Morra M, Philipszoon HD, D'Andrea G, Cananzi AR, L'Erario R, Milone FF. Sensory and motor neuropathy caused by excessive ingestion of vitamin B6: a case report. Functional neurology. 1993;8:429-32.

18. Dalton K, Dalton MJ. Characteristics of pyridoxine overdose neuropathy syndrome. Acta neurologica Scandinavica. 1987;76:8-11. 
19. Ubbink JB, Serfontein WJ, Becker PJ, de Villiers LS. Effect of different levels of oral pyridoxine supplementation on plasma pyridoxal-5'-phosphate and pyridoxal levels and urinary vitamin B-6 excretion. The American journal of clinical nutrition. 1987;46:78-85.

20. Bisp MR, Bor MV, Heinsvig EM, Kall MA, Nexo E. Determination of vitamin B6 vitamers and pyridoxic acid in plasma: development and evaluation of a high-performance liquid chromatographic assay. Analytical biochemistry. 2002;305:82-9.

21. van der Ham $M$, Albersen $M$, de Koning TJ, Visser $G$, Middendorp A, Bosma $M$, et al. Quantification of vitamin B6 vitamers in human cerebrospinal fluid by ultra performance liquid chromatography-tandem mass spectrometry. Analytica chimica acta. 2012;712:108-14.

22. Vincent AM, Brownlee M, Russell JW. Oxidative stress and programmed cell death in diabetic neuropathy. Annals of the New York Academy of Sciences. 2002;959:368-83.

23. Schwarcz R. The kynurenine pathway of tryptophan degradation as a drug target. Current opinion in pharmacology. 2004;4:12-7.

24. Midttun O, Ulvik A, Ringdal Pedersen E, Ebbing M, Bleie O, Schartum-Hansen H, et al. Low plasma vitamin B-6 status affects metabolism through the kynurenine pathway in cardiovascular patients with systemic inflammation. The Journal of nutrition. 2011;141:611-7.

25. Schwarz MJ, Guillemin GJ, Teipel SJ, Buerger K, Hampel H. Increased 3-hydroxykynurenine serum concentrations differentiate Alzheimer's disease patients from controls. European archives of psychiatry and clinical neuroscience. 2013;263:345-52.

26. Stoy N, Mackay GM, Forrest CM, Christofides J, Egerton M, Stone TW, et al. Tryptophan metabolism and oxidative stress in patients with Huntington's disease. Journal of neurochemistry. 2005;93:611-23.

27. Bonda DJ, Mailankot M, Stone JG, Garrett MR, Staniszewska M, Castellani RJ, et al. Indoleamine 2,3-dioxygenase and 3-hydroxykynurenine modifications are found in the neuropathology of Alzheimer's disease. Redox report : communications in free radical research. 2010;15:161-8.

28. Jeong JH, Kim HJ, Lee TJ, Kim MK, Park ES, Choi BS. Epigallocatechin 3-gallate attenuates neuronal damage induced by 3-hydroxykynurenine. Toxicology. 2004;195:53-60.

29. Smith AJ, Stone TW, Smith RA. Neurotoxicity of tryptophan metabolites. Biochemical Society transactions. 2007;35:1287-9. 
Supplementary data

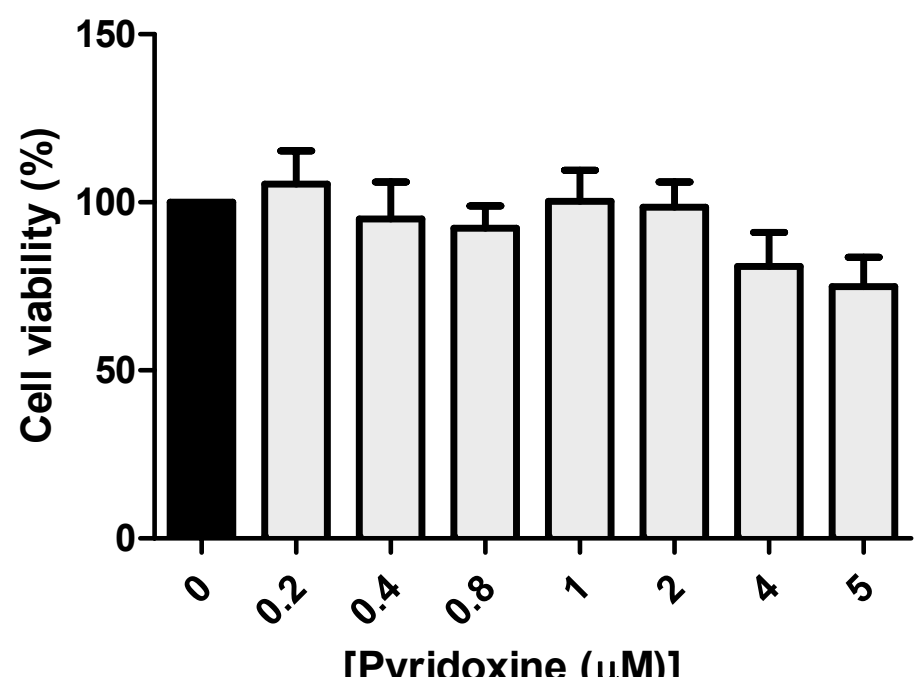

Figure 1| Cell viability assay in CaCo-2 cells after exposure to different concentrations of PN (0-5 $\mu \mathrm{M})$. 

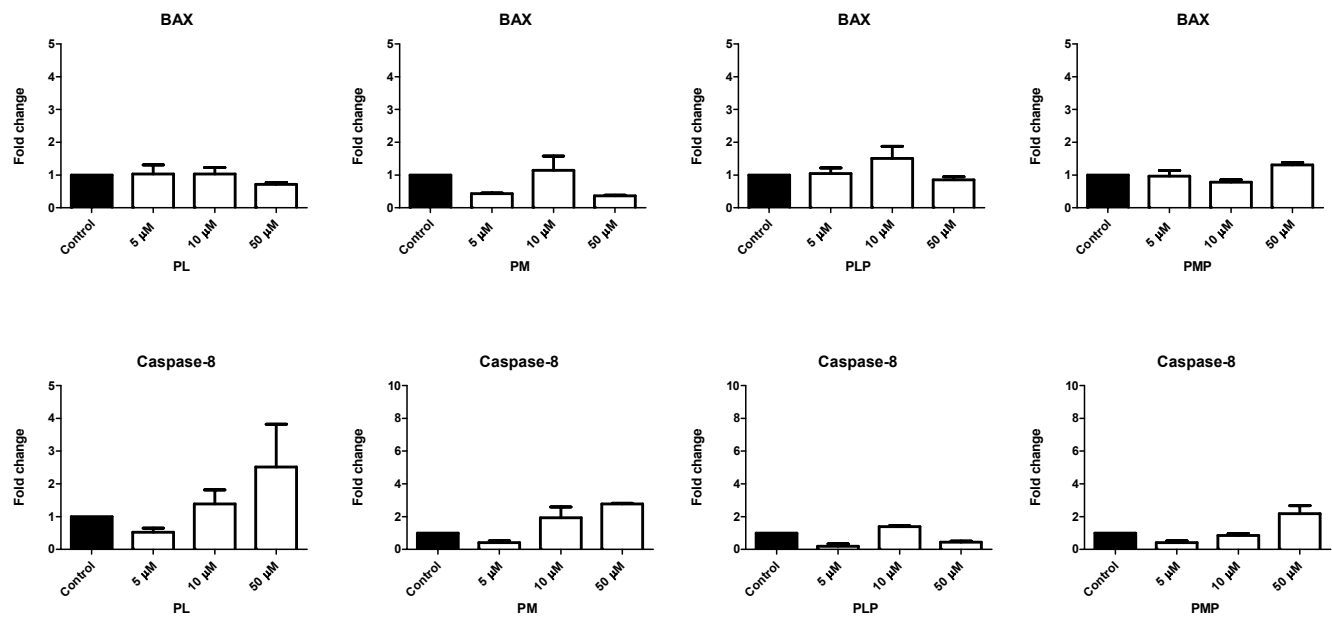

Figure 2| The effect of PL, PM, PLP and PM (0-50 $\mu \mathrm{M})$ on the expression of BAX and caspase-8 in SHSY5Y cells. 

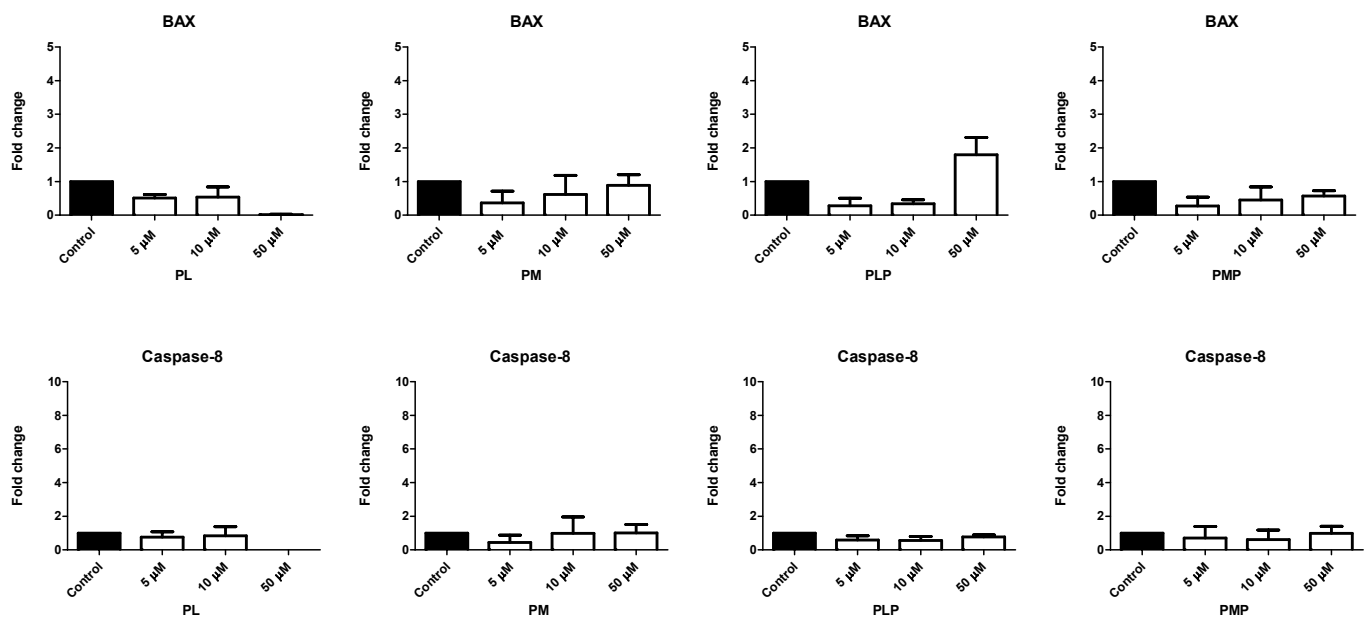

Figure $3 \mid$ The effect of PL, PM, PLP and PM (0-50 $\mu \mathrm{M})$ on the expression of BAX and caspase- 8 in CaCo-2 cells. 



\section{Chapter 7}

\section{General discussion}


The average age of the world population is rapidly increasing [1]. One of the consequences is an increased need for medical and social health care. The prevalence of diseases in elderly is much higher compared to the young population. Additionally, the prevalence of malnutrition is high among elderly [2]. Medicines and food products, such as food supplements, are frequently used by this population to stay healthy.

The effect of nutrition in maintaining a good health is recognized and nutrition is also more and more used to improve health and treat diseases. Bioactive compounds derived from food are being developed to promote health status. These so called nutraceuticals also comprise food supplements. The use of food supplements has exploded over the past years [3]. Thousands of food supplements are on the market, which all claim to improve health or battle diseases. People take food supplements with the idea that they only have benefits, while they are largely unaware of their potential risks. Although they can support health, food supplements may also induce harm. In conjunction with the increased use of food supplements, the number of adverse events, drug interactions and deaths involving these supplements has increased. In order to inform and protect consumers, an adequate benefit-risk assessment of the use of food supplements is mandatory. Since especially the risks are largely unknown, the aim of the present thesis was to investigate potential adverse effects of food supplements either combined with other food supplements or drugs, or alone in specific groups at risk. In this chapter the most important findings are summarized and discussed. Additionally, potential implications and suggestions for future research are discussed.

\section{Main findings}

\section{Antioxidant supplements}

In chapter 2 the changing perception on the health effects of antioxidants is discussed. Antioxidants are vital for human beings, since they protect against reactive oxygen species (ROS) $[4,5]$. In living organisms ROS can damage vital biomolecules such as proteins and this is known to play an important role in ageing and age-related diseases. Antioxidants are therefore considered as important agents in the protection against oxidative stress and ageing. Many food supplements are available that are rich in antioxidants. They are used on a large scale with the notion that antioxidants are healthy. Moreover, the use of all kinds of antioxidants in high doses has been recommended for supplementation. The perception was that all antioxidants are equal and that the higher the intake, the higher the beneficial health effects will be [6]. However, according to the theory of Paracelsus, in a high dose also antioxidants will be toxic, and indeed a too high intake of antioxidants has paradoxically been associated with increased mortality. The question arose if antioxidants in the end are healthy or toxic. This question was answered by focusing on two antioxidants with an opposite image, i.e. the 'healthy' vitamin $\mathrm{E}$ and the 'toxic' $\beta$-carotene. Apparently, the appreciation of an antioxidant is a reflection of the prevailing perception of the risks and benefits that also changes over time. In 1994 the ATBC study showed that $\beta$-carotene supplementation was associated with an increased incidence of lung cancer in smokers [7]. This was furthermore corroborated by other epidemiological studies. Since then, $\beta$ - 
carotene was considered as toxic, without paying any attention to its beneficial effect. In contrast to the toxic effects of $\beta$-carotene, numerous beneficial health effects have been proposed for vitamin $E$, which are mainly ascribed to its antioxidant activity. Based on these beneficial effects, vitamin E received a 'healthy' image. However, despite these different images, both antioxidants were shown in chapter 2 to have a similar toxicity in cells exposed to benzo(a)pyrene diolepoxide (BPDE), by inhibiting the protective enzyme GST $\pi$. An increased number of BPDE-DNA adducts in lung epithelial cells (BEAS-2B) and human keratinocytes ( $\mathrm{HaCaT}$ ) were found after treatment with both antioxidants. Based on these findings, it could be concluded that both vitamin $E$ and $\beta$-carotene could have toxic effects when combined with electrophilic compounds such as BPDE, which is for instance found in cigarette smoke or coal tar cream. In the perception of the health effect of an antioxidant, it is often considered that an antioxidant either only provides benefits or that it only poses risks. These opposing, one sided views are the main obstacles in the accurate perception of the health effect of antioxidants. A more balanced view is necessary as any bioactive, antioxidants included, have benefits as well as risks. It is therefore important to come to an accurate benefit-risk analysis. Ideally, such benefit-risk analysis should be performed for each individual. However, since this is impossible to do, the focus should first be on specific population groups. Identifying groups that would benefit of a certain antioxidant should have the priority when performing a benefit-risk analysis. But also groups at risk should be identified. Risk groups are often found by chance, as demonstrated by the ATBC study. The mechanism of both the benefits and risks should be elucidated. Apparently, the line between healthy and toxic is very thin. It is concluded that supplementation of antioxidants does not necessarily have to be beneficial and a natural origin is no guaranty for safety.

\section{Adverse interactions between food supplements and drugs}

Ageing is a process in which structural and functional changes in organs and organ systems occur [8]. This often leads to multiple diseases. In order to treat these diseases, elderly people often use multiple drugs. Polypharmacy is very common in the elderly population [9]. Next to prescription medicines, the use of self-medication, such as OTC drugs, is also on the rise. The use of multiple drugs simultaneously increases the risk of adverse effects and unwanted interactions, which can aggravate side effects instead of improving the quality of life of the elderly. On top of the medicines, elderly people also take numerous food supplements to improve health. Generally, food supplements are perceived as being healthy and to support (general) health, while they may also induce harm. In conjunction with the increased use of food supplements, the number of adverse events, drug interactions and deaths involving food supplements has been on the rise. Again, the elderly population is more vulnerable for adverse events associated with food supplement use. This is mainly due to the ageing-related changes, such as organ function decline and changes in pharmacokinetics and pharmacodynamics. A very common age-related change is the enlargement of the prostate gland, also known as benign prostatic hyperplasia (BPH). As men age, they are more likely to develop prostate problems, since it tends to grow larger as you age. Alpha-adrenergic receptor-blocking agents such as tamsulosin are used to treat $\mathrm{BPH}$. By blocking these receptors, the smooth muscle tension is decreased, allowing passage of the urine. Although tamsulosin is administered to block $\alpha_{1 A^{-}}$ 


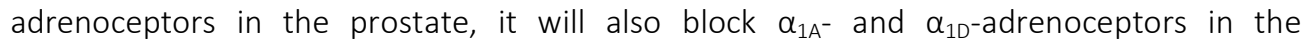
vasculature. This may lead to unwanted side effects, such as orthostatic hypotension. Orthostatic hypotension is caused by a drastic fall in blood pressure due to gravitational displacement of blood when standing up. Normally, the sympathetic system is able to compensate for this effect by increasing the sympathetic outflow, heart rate, vascular resistance, constriction of the veins and cardiac output via activation of $\alpha_{1 A}$-adrenoceptors in the vasculature. Consequently, the blood will be redistributed and blood pressure will be normalized. Blocking the $\alpha_{1}$-adrenoceptors in the arteries and veins will antagonize such a physiological vaso- and venoconstrictor reflex, which forms the molecular basis for orthostatic hypotension. In chapter 3 , we have evaluated a pharmacodynamic interaction of a food supplement, quercetin, and the drug, tamsulosin on isolated mesenteric arteries. The combination of tamsulosin with quercetin or quercetin metabolites proved to be far more potent than the compounds in isolation. It was shown that the food supplement quercetin strongly potentiates the $\alpha_{1}$-adrenoceptor antagonizing effects of the drug tamsulosin. The strong pharmacodynamic interaction between the food supplement quercetin and tamsulosin underlines the impact of supplement-drug interactions that warrant more research.

Another main effect of ageing is the deterioration of the blood-brain-barrier [10]. Consequently, the permeability of this barrier increases, making it easier for drugs and food supplements to enter the brain. Additionally, the number of cholinergic receptors decreases with ageing. Together, these changes make that anticholinergic accumulation is a common feature in elderly. Anticholinergic effects of drugs arise by blocking cholinergic neurotransmission, more specifically blocking the muscarinic receptors in the brains. These receptors play an important role in numerous processes, including cognition and movement. In 2008 the Anticholinergic Cognitive Burden (ACB) scale was developed, in which drugs are categorized based on their anticholinergic effect [11]. In chapter 4 it is shown that the affinity of the drugs for the muscarinic receptors correlated well with their ACB scores. Food supplements also appeared to bind to these muscarinic receptors. The anticholinergic side effect of a single compound, drug or food supplement, is often relatively mild. However, when several compounds are taken simultaneously, more of the receptors will be blocked, which aggravates the impact. It was shown that the combination of several drugs and supplements had an affinity that is higher than the affinity of the individual compounds. This explains the process of anticholinergic accumulation. Since elderly are the largest group of consumers of medicines and polypharmacy is very common among this population, they are susceptible to these effects. Cognitive impairment, which is a consequence of anticholinergic accumulation, may be detrimental for elderly. Cognitive impairment include brain injuries, neurological disorders and mental diseases. Signs of cognitive impairment are associated with an increased mortality risk for elderly, indicating the relevance of these findings.

Chapter 5 describes the hazardous interaction between iron supplements and magnesium peroxide. Ageing is accompanied by changes in the gastro-intestinal system, such as reduced absorption of nutrients and an increased risk for gastro-esophageal reflux disease. Because of the reduced absorption of nutrients, malnutrition is very common among 
elderly. Iron deficiency is the single most prevalent nutritional deficiency worldwide with elderly as a group with the highest prevalence. In order to maintain iron levels, iron supplements are often used. Numerous iron supplements are present, each containing relatively high doses of iron. The European Food and Safety Authority (EFSA) has not set an tolerable upper intake level (UL) for iron supplements because of insufficient data on adverse effects. However, already at doses of $30 \mathrm{mg} /$ day, supplemental intake of iron was associated with high saturation of the iron storage, which is a risk factor for several chronic diseases. The highest dose of iron supplements found was 50 and $100 \mathrm{mg} / \mathrm{day}$. In our study it was shown that iron supplements induced the formation of hydroxyl radicals. This was augmented by magnesium peroxide, an antacid that is available as OTC drugs. The increased formation of hydroxyl radicals might lead to adverse events in the intestines. This is an example of an interaction between a food supplement and an OTC, indicating that also the use of self-medication can lead to hazardous interactions.

In Chapter 6 the neuropathy observed after taking a relatively high dose of vitamin $B_{6}$ supplements is examined. In the Netherlands, the Netherlands Pharmacovigilance Centre Lareb collects and analyses reports of adverse reactions of food supplements, medicines and vaccines. Lareb receives this information by health care professionals, patients and manufacturers which report any adverse effect of these products. Recently, Lareb published a report concerning the side effects of vitamin $B_{6}$ supplements. Since 2014 , more than 50 cases of sensory neuronal pain were reported after taking vitamin B6 supplements. Vitamin $B_{6}$ functions as a coenzyme in many reactions that are involved in amino acid, carbohydrates and lipid metabolism and neurotransmitter synthesis. Vitamin $B_{6}$ supplementation is commonly recommended for the genetic disorders cystathioninuria and homocystinuria, as well as for other conditions including premenstrual tension, seizures, carpal tunnel syndrome, pregnancy and vitamin $B_{6}$ deficiency. Moreover, low levels of vitamin $B_{6}$ are most frequently found in elderly and in alcoholics. Vitamin $B_{6}$ deficiency is known to give symptoms as sensory neuropathy. These low levels have been related to increased risk of cardiovascular diseases and neuronal symptoms. In such cases, vitamin $\mathrm{B}_{6}$ supplements are advised $[12,13]$. In the last decades, various cases of vitamin $B_{6}$ induced polyneuropathy have been reported after the use of vitamin $B_{6}$ supplements. People chronically taking mega doses ( $>50 \mathrm{mg} /$ day) of vitamin $B_{6}$ reported complaints as pain in the extremities and muscle weakness [14-16]. However, even at lower doses, vitamin $B_{6}$ has been found to lead to the same complaints. This is exemplified by some of the reported cases to Lareb, in which doses of $2 \mathrm{mg}$ /day gave complaints. These complaints are similar to those observed in people with a vitamin $B_{6}$ deficiency. However, the molecular mechanism of vitamin B6 induced toxicity is unknown.

Vitamin $B_{6}$ supplements are used by a large number of people. Most of the vitamin $B_{6}$ supplements that are available on the market contain pyridoxine. In our body, pyridoxine will be converted into the biologically active form pyridoxal-5'-phosphate. Our results indicate that vitamin $B_{6}$ toxicity is caused by competition between the active pyridoxal- $5^{\prime}$ phosphate and the inactive pyridoxine. Pyridoxine induced cell death in human 
neuroblastoma cells, whereas pyridoxal-5'-phosphate prevented cell death induced by pyridoxine. On a molecular level, pyridoxine can inhibit pyridoxal-5'-phosphate dependent processes, which is shown by the inhibition of the enzyme activity of two pyridoxal- $5^{\prime}$ phosphate dependent enzymes by pyridoxine. As a consequence, the paradox arises that the symptoms of vitamin $B_{6}$ supplementation are similar to those of vitamin $B_{6}$ deficiency. The recommended daily intake of vitamin $B_{6}$ is debated and EFSA has recently lowered the upper limit for vitamin $B_{6}$ [17]. The question is whether lowering the safe dose for vitamin $B_{6}$ is the best solution. Since vitamin $B_{6}$ supplementation even at relatively low doses has given rise to complaints. Our study indicates that the toxicity of vitamin $B_{6}$ is not only determined by the dose, but especially by the vitamer used. Replacing pyridoxine by pyridoxal or pyridoxal-5'-phosphate in supplements is advised, since these are at least equally active and much less toxic.

\section{Perception on food supplements}

In the present thesis we have identified potential adverse effects of some food supplements. Moreover, some potential supplement-drug and supplement-supplement interactions have been identified, which may have serious adverse effects. Next to these potential interactions, numerous evidenced supplement-drug interactions are known, most of them between herbal supplements and drugs [18-20]. These potential adverse effects do not fit in the positive view that consumers have of food supplements. The idea is that food supplements maintain and improve overall health and might compensate for an unhealthy lifestyle. The enormous increase in food supplement use is based on the widespread believe that the products are healthy and that products of natural origin are safe [21]. Food supplements are therefore not only taken to supplement the diet, as what they are actually aimed for. This is shown by the low percentage $(22 \%)$ of the users that really used food supplements as a supplement to their diet. The general assumption is that the quality of prescription and over-the-counter supplements is high. Generally, efficacy and potency of these products are accepted without questioning. Especially for antioxidants the expectations are very high. In contrast to these high expectations, reports on the adverse events involving these supplements are increasing. These adverse events are often caused by over-consumption (due to too high doses) of food supplements and by interactions with other food supplements or drugs. In the literature numerous interactions between food supplements, especially herbal supplements, and drugs have been reported. These include pharmacokinetic and pharmacodynamic interactions, both leading to adverse effects. In the Netherlands, Lareb reported at least 55 reports on interactions between food supplements and drugs [20]. These included both herbal and non-herbal supplements. All these interactions lead to adverse effects in people. All the reported complaints and interactions of food supplements are collected into a database, which is used to write reports on adverse effects of drugs and food supplements. Lareb also informs the European Medicines Agency and the World Health Organization (WHO) about these reports, thereby helping monitoring the global food supplement and drug safety. 


\section{Risk assessment and risk management}

In the appreciation of food supplements, it is important to evaluate their benefits and risks in an accurate benefit-risk assessment. Food supplements are consumed to improve health. Often, a positive health effect of a food supplement has not been demonstrated. In order to recommend the application of food supplements, it is essential to obtain scientific proof for the actual benefits by focusing on the molecular mechanisms of these benefits. Food supplements should only be administered to people expected to benefit from them. For explicit health claims of food supplements, using a similar procedure to drug registration would be helpful, so that not only the activity of such particular food supplement has to be proven in a clinical study, but also safety issues, metabolism and biological effects have to be shown [22]. Regarding the risks, both the necessity and dose of dietary supplementation and the identification of vulnerable groups should be carefully evaluated.

Vitamins and minerals are essential for maintaining an optimal health. However, the estimation of optimal intakes of micronutrients for a given population is difficult. Different individuals not only have different needs and intakes of certain nutrients, but they also have differences in susceptibility to adverse effects of food supplements. For instance, elderly are at higher risk for adverse effects of food supplements, including the interactions with drugs. This can mainly be contributed to the physiological changes due to ageing. Especially the pharmacokinetic and pharmacodynamic changes make elderly at higher risk for adverse effects of food supplements. Pharmacokinetic changes during ageing include reduced absorption (of nutrients and drugs), distribution (resulting in higher serum levels of nutrients and drugs), metabolism (resulting in lowered metabolism of nutrients and drugs) and excretion (resulting in reduced clearance of nutrients and drugs). All these pharmacokinetic changes may lead to an accumulation of certain nutrients and/or drugs, which might lead to more adverse effects. Pharmacodynamic changes refer to changes in concentration of a particular drug at its receptor, the response it elicits on the receptor, post receptor events and homeostatic mechanisms. Together with the pharmacokinetic changes, these changes will increase the vulnerability of the elderly population for drugsupplement interactions, ultimately leading to adverse effects. Also the high number of medicine use among this population makes elderly a vulnerable group for adverse effects of food supplements. Moreover, elderly often use multiple drugs at the same time. This will not only lead to a higher risk of adverse effects, it will also increase the possibility of unwanted interactions with other drugs or food supplements, leading to adverse effects of both the drugs as the food supplements. The use of multiple drugs in combination with food supplements may therefore decrease the quality of life of elderly.

The most important challenge in an appropriate risk assessment is to balance the risk of deficiencies with the risk of overconsumption within the same population [23]. Adverse effects of (micro)nutrients may arise due to too low or too high intake, which is illustrated by some examples in table 1. 
Table 1|Adverse effects of nutrients arise due to a too low or too high intake

\begin{tabular}{lll}
\hline & Too low intake & Too high intake \\
\hline Iron & Anaemia & Gastrointestinal side effects \\
Vitamin A & Growth abnormalities & Liver damage, teratogenic \\
Vitamin C & Fatigue & Gastrointestinal side effects \\
Vitamin B6 & Anaemia, & Sensory neuropathy \\
& Sensory neuropathy & \\
Calcium & Osteoporosis & $\begin{array}{l}\text { Hypercalcaemia, } \\
\text { Kidney stones }\end{array}$ \\
& & \\
\hline
\end{tabular}

The increasing use of food supplements will lead to increased intake levels of (micro)nutrients for different population groups. In order to protect consumers, it becomes more and more important to determine safe levels of intake and to perform accurate riskbenefit analyses. As mentioned before, adverse health effects of food supplements mainly occur by excessive intakes or by interactions with other drugs or food supplements. In order to reduce the risk of excessive intake, EFSA has set ULS. Upper safe levels of vitamins and minerals, which are established by risk assessment, are based on scientific data and take into account the different sensitivity of different consumer groups. EFSA provides the EC with scientific opinions about the upper levels of vitamins and minerals. However, the available scientific data on the safety in use of vitamins and minerals is limited.

With regards to the risk assessment, the same concept applies to nutrients and minerals as to other food chemicals, as agreed upon by the FAO/WHO [17]. The first step is to identify known or potential adverse health effects of a particular nutrient (hazard identification). Collecting and evaluating all the information regarding adverse effects of this nutrient. The second step is the qualitative and quantitative evaluation of the nature of these adverse effects of the nutrient (hazard characterization). This step includes the assessment of doseresponse effects, in which no observed adverse effect levels (NOAEL) and lowest observed adverse effect levels (LOAEL) are determined. After these evaluations, ULs can be derived, which take into account uncertainties in the data. These ULs can be derived for different subpopulations. In the third step the usual total daily intake of a nutrient among the general population is evaluated (exposure assessment). The three different steps are finally concluded in the risk characterization step. Based on the findings of the first three steps, the risk is characterized. The risk will depend on the part of the population exceeding the UL and the magnitude and duration of the excessive intake. It should be specified whether there are distinct sensitivities to the adverse effects of a nutrient for sub-populations.

Remarkably, ULs do not function as limits for the doses of food supplements. Often food supplements are found to have doses much higher than the ULS. Therefore, it might be more important to set maximum safe levels (MLS) of nutrients in food supplements [24]. MLS can be set by using a risk management model, taking quantitative and qualitative risk 
assessments into account. When doing this, nutrients can be categorized into three groups, depending on the risks. Group 1 contains nutrients that do not represent any relevant risk to human health in the general population. When authoritative risk assessments do not show adverse effects of particular nutrients and when no UL can be set, these nutrients are placed into group 1. For these nutrients, no further risk management is necessary. Examples of nutrients that are categorized into group 1 are vitamin $B_{1}$, vitamin $B_{2}$, biotin and vitamin $B_{12}$. EFSA did not find any data on hazards related to high intakes of these nutrients in their risk assessment. Therefore, no MLS have to be set for these nutrients. In these cases, guidance levels (GL) for supplementation can be set.

Nutrients in group 2 exhibit a low risk of exceeding the UL and nutrients in group 3 have a potential risk at excessive intakes. When characterizing the risks for these nutrients, the Population Safety Index (PSI) may be used. By using the PSI, vitamins and minerals can be classified into two different categories of risks. When the PSI of a certain nutrient is over 1.5 , the chance of exceeding the upper limit is low (group 2).

Examples of nutrients present in this group are vitamin C, vitamin D, vitamin E, selenium, magnesium and folic acid.

Table 3|Proposed maximum safe levels (MLS) in food supplements for adults. to humans

\begin{tabular}{lll}
\hline $\begin{array}{l}\text { Group } 1 \\
\text { No evidence of adverse effects } \\
\text { to humans }\end{array}$ & No MLS necessary & \\
$\begin{array}{l}\text { Group 2 } \\
\text { Low risk of exceeding UL }\end{array}$ & Nutrient & MLS \\
& Vitamin C & $1700 \mathrm{mg}$ \\
& Vitamin D & $83 \mu \mathrm{g}$ \\
& Vitamin E & $270 \mathrm{mg}$ \\
\hline $\begin{array}{l}\text { Group 3 } \\
\text { Potential adverse } \\
\text { excessive intake }\end{array}$ & Magnesium & $250 \mathrm{mg}$ \\
& Folic acid & $600 \mu \mathrm{g}$ \\
& Nutrient & MLS \\
& & \\
\hline & Vitamin A & $1200 \mu \mathrm{mg}$ \\
\hline & Beta-carotene & $1000 \mathrm{mg}$ \\
\hline & Calcium & $20 \mathrm{mg}$ \\
\hline & Iron & $15 \mathrm{mg}$ \\
\hline & Zinc & \\
\hline
\end{tabular}

\section{Group 1}

No evidence of adverse effects

\section{No MLS necessary}

\begin{abstract}
Table 3/Proposed maximum safe levels (MLS) in food supplements for adults.
\end{abstract}


Nutrients with a PSI of 1.5 or lower have a potential risk of exceeding the UL with potentially adverse effects (group 3). Examples of nutrients in this group are vitamin A, beta-carotene, calcium, iron, and zinc. For the nutrients of both groups MLS have been proposed by the International Alliance of Dietary/Food Supplement Associations (IADSA). IADSA is an association that brings together over 50 associations of food supplement manufacturers and distributors from across the world. Its aim is to guarantee a greater exchange of knowledge about science and regulation of food supplements and ingredients among industry, scientists, regulators and consumers. The MLS can be used to minimize the chance of developing adverse events due to supplementation. Some examples of MLS for nutrients are shown in table 2.

\section{Education}

As the global use of food supplements as well as the number of food supplements is increasing, health issues and safety concerns are increasingly debated. Especially since evidence of quality, efficacy and safety is not required when putting food supplements on the market. Although food supplements have a promising potential, knowledge about adverse effects is often lacking. Adverse health effects of food supplements not only occur after excessive intakes, but also by interacting with drugs or other food supplements. People do not inform their physician about the use of their food supplements. Physicians therefore do not associate adverse events with supplement use. Moreover, there generally is a lack of knowledge among physicians about interactions of food supplements with other food supplements and medications. Such supplement-drug interactions go unrecognized by both consumers and health care professionals. As a consequence, the reported food supplement-related adverse events are expected to be a large underestimation. Nevertheless, it may have serious adverse effects, lead to ineffective therapy and to an increased chance for deficiencies or toxicities. In order to reduce the interactions between food supplements with drugs, it is important for consumers to be aware of potential supplement-drug interactions. It is essential to provide the general public and healthcare professionals, with scientific sound information so they become aware of the risks of using food supplements. Especially since there is an uncontrolled supply of food supplements via diverse sources. Health care professionals should encourage patients to report the use of all (self)-medications and food supplements to their general practitioner, so that they can screen a patient's medical history for potential supplement-drug interactions. A better education of the consumers and the healthcare professionals in the field of food supplements is vital to prevent serious side effects due to food supplements. 


\section{References}

1. Lutz W, Sanderson W, Scherbov S. The coming acceleration of global population ageing. Nature. 2008;451:716-9.

2. de Groot CP, van den Broek T, van Staveren W. Energy intake and micronutrient intake in elderly Europeans: seeking the minimum requirement in the SENECA study. Age and ageing. 1999;28:469-74.

3. van Rossum CTMF, H.P.; Verkaik-Kloosterman, J.; Buurma-Rethans, E.J.M.; Ocké, M.C. Dutch National Food Consumption Survey 2007-2010. In: RIVM, editor.; 2011.

4. Vrolijk MF, Opperhuizen A, Jansen EH, Godschalk RW, Van Schooten FJ, Bast A, et al. The shifting perception on antioxidants: the case of vitamin $E$ and beta-carotene. Redox biology. 2015;4:272-8.

5. Pisoschi AM, Pop A. The role of antioxidants in the chemistry of oxidative stress: A review. European journal of medicinal chemistry. 2015;97:55-74.

6. Bast A, Haenen GR. Ten misconceptions about antioxidants. Trends in pharmacological sciences. 2013;34:430-6.

7. The effect of vitamin $E$ and beta carotene on the incidence of lung cancer and other cancers in male smokers. The Alpha-Tocopherol, Beta Carotene Cancer Prevention Study Group. The New England journal of medicine. 1994;330:1029-35.

8. Mangoni AA, Jackson SH. Age-related changes in pharmacokinetics and pharmacodynamics: basic principles and practical applications. British journal of clinical pharmacology. 2004;57:6-14.

9. Hajjar ER, Cafiero AC, Hanlon JT. Polypharmacy in elderly patients. The American journal of geriatric pharmacotherapy. 2007;5:345-51.

10. Midlov P. Pharmacokinetics and pharmacodynamics in the elderly. OA Elderly Medicine. 2013;Aug.

11. Boustani M. Impact of anticholinergics on the aging brain: a review and practical application. Aging Health. 2008;4:311-20.

12. Kashanian M, Mazinani R, Jalalmanesh S. Pyridoxine (vitamin B6) therapy for premenstrual syndrome. International journal of gynaecology and obstetrics: the official organ of the International Federation of Gynaecology and Obstetrics. 2007;96:43-4.

13. Wyatt KM, Dimmock PW, Jones PW, Shaughn O'Brien PM. Efficacy of vitamin B-6 in the treatment of premenstrual syndrome: systematic review. Bmj. 1999;318:1375-81.

14. Schaumburg H, Kaplan J, Windebank A, Vick N, Rasmus S, Pleasure D, et al. Sensory neuropathy from pyridoxine abuse. A new megavitamin syndrome. The New England journal of medicine. 1983;309:445-8.

15. Morra M, Philipszoon HD, D'Andrea G, Cananzi AR, L'Erario R, Milone FF. Sensory and motor neuropathy caused by excessive ingestion of vitamin B6: a case report. Functional neurology. 1993;8:429-32.

16. Dalton K, Dalton MJ. Characteristics of pyridoxine overdose neuropathy syndrome. Acta neurologica Scandinavica. 1987;76:8-11.

17. Authority EFS. TOLERABLE UPPER INTAKE LEVELS FOR VITAMINS AND MINERALS. 2006.

18. Pirmohamed M. Drug-grapefruit juice interactions: two mechanisms are clear but individual responses vary. Bmj. 2013;346:f1.

19. Rosenblatt M, Mindel J. Spontaneous hyphema associated with ingestion of Ginkgo biloba extract. The New England journal of medicine. 1997;336:1108.

20. de Boer A, van Hunsel F, Bast A. Adverse food-drug interactions. Regulatory toxicology and pharmacology : RTP. 2015;73:859-65.

21. Blendon RJ, DesRoches CM, Benson JM, Brodie M, Altman DE. Americans' views on the use and regulation of dietary supplements. Archives of internal medicine. 2001;161:805-10. 
22. Haenen GR, Bast A. The use of vitamin supplements in self-medication. Therapie. 2002;57:119-22.

23. Renwick AG, Dragsted LO, Fletcher RJ, Flynn A, Scott JM, Tuijtelaars S, et al. Minimising the population risk of micronutrient deficiency and over-consumption: a new approach using selenium as an example. European journal of nutrition. 2008;47:17-25.

24. (IADSA) IAoDFSA. Nutritional risk analysis approaches for establishing maximum levels of vitamins and minerals in food (dietary) supplements, Contract No.: Document Number|. 




\title{
Chapter 8
}

\section{Summary}

Samenvatting

Valorisatie addendum

Dankwoord

\author{
Curriculum Vitae \\ List of publications
}




\section{Summary}

The aim of the present thesis was to investigate potential adverse effects of food supplements either combined with other food supplements or drugs or in isolation. The world population is rapidly ageing. This leads to increased needs in medical and social health care. Next to medicines, nutrition is becoming more important as a way of maintaining and promoting health and treating diseases. Nutraceuticals, which are bioactive compounds derived from food, are being developed to improve peoples' health status. These also comprise food supplements. The use of food supplements has exploded over the past years. The number of food supplement products that is offered by shops, supermarkets and online shops is massive. All these supplements claim to improve health or battle diseases. The enormous increase in food supplement use is based on the widespread believe that the products are healthy and that products of natural origin are safe. Peoples' perception on food supplements is that they only have benefits, while they are unaware of their potential risks. Remarkably, adverse effects by food supplements, which are for instance caused by interactions with drugs, are scarcely investigated. Our research identified potential adverse effects by food supplements and shows that the perception that food supplements only have beneficial effects is incorrect.

\section{Perception on antioxidants}

Especially for antioxidants the expectations are very high. Antioxidants are considered as being important agents in the protection against oxidative stress and ageing. Many food supplements are available that are rich in antioxidants. They are used on a large scale with this idea that antioxidants are healthy. Moreover, the use of all kinds of antioxidants in high doses was recommended for supplementation. In chapter 2 the changing perception on the health effects of antioxidants is discussed, using two examples, namely vitamin $E$ and $\beta$ carotene. Vitamin $E$ is an antioxidant that has been shown to have numerous beneficial health effects. In contrast, $\beta$-carotene was generally considered as being toxic, since the ATBC study was published in 1994. Remarkably, both antioxidants were shown to have a similar toxicity in cells exposed to BPDE by inhibiting the protective enzyme GST $\pi$. Based on these findings, it could be concluded that both vitamin $E$ and $\beta$-carotene have toxic effects when combined with electrophilic compounds, which can be found in cigarette smoke or coal tar cream. Supplementation of antioxidants does not necessarily have to be beneficial and a natural origin is no guaranty for safety. It is therefore important to come to an accurate benefit-risk analysis.

\section{Adverse interactions between food supplements and drugs}

Supplementation of food supplements may lead to adverse health effects. Especially elderly, in which a decline in structure and function of organs and organ systems occur, are more prone to adverse effects of food supplements. Moreover, the use of multiple drugs is also common in elderly, which increases the chance of drug-supplement interactions. The main types of interactions between drugs and dietary supplements are pharmacodynamic interactions and pharmacokinetic interactions. In chapter 3, we have evaluated a pharmacodynamic interaction of a food supplement, quercetin, and a drug, tamsulosin on 
isolated mesenteric arteries. A very common age-related disease is benign prostatic hyperplasia (BPH). As men age, they are more likely to develop prostate problems. Alphaadrenergic receptor-blocking agents such as tamsulosin are used to treat $\mathrm{BPH}$. Although the tamsulosin effect is aimed at $\alpha_{1 A^{-}}$adrenoceptors in the prostate, it will also block $\alpha_{1 A^{-}}$ and $\alpha_{1 D}$-adrenoceptors in the vasculature. Our results showed that the combination of tamsulosin with quercetin or quercetin metabolites was far more potent than the compounds in isolation. It was shown that the supplement quercetin strongly potentiates the $\alpha_{1}$-adrenoceptor antagonizing effects of the drug tamsulosin. The strong pharmacodynamic interaction between the food supplement quercetin and tamsulosin underlines the impact of supplement-drug interactions that warrant more research.

\section{Anticholinergic accumulation}

Anticholinergic effects of drugs arise by blocking cholinergic neurotransmission, more specifically by blocking the muscarinic receptors in the brains. These receptors play an important role in numerous processes, including cognition and movement. In 2008 the Anticholinergic Cognitive Burden (ACB) scale was developed, in which drugs are categorized based on their anticholinergic effect. In chapter 4 it is shown that the affinity of the drugs for the muscarinic receptors correlated well with their ACB scores. We found that food supplements also have the ability to bind to these receptors. It was shown that the combination of several drugs and supplements had an affinity that is higher than the affinity of the individual compounds. This explains the process of anticholinergic accumulation. It is concluded that the anticholinergic side effect of a single compound, for instance a drug or a food supplement, is often relatively mild. However, when several compounds are taken simultaneously, more of the receptors will be blocked, which aggravates the effect and hence the potential anticholinergic side effect.

\section{Iron supplements and magnesium peroxide}

Ageing is also accompanied by changes in the gastro-intestinal system, such as reduced absorption of nutrients and an increases risk for gastro-esophageal reflux disease. Because of the reduced absorption of nutrients, malnutrition is very common among elderly. Moreover, iron deficiency is the single most prevalent nutritional deficiency worldwide with elderly as a group with the highest prevalence. In order to maintain iron levels, iron supplements are often used. Numerous iron supplements are present, each containing relatively high doses of iron. In chapter 5, we focused on the hazardous interaction between iron supplements and magnesium peroxide. In our study it was shown that iron supplements induced the formation of hydroxyl radicals. This was augmented by magnesium peroxide, an antacid that is available as OTC drugs. This is an example of an interaction between a food supplement and an OTC, indicating that also the use of selfmedication can lead to hazardous interactions.

\section{Vitamin $\mathrm{B}_{6}$}

Vitamin $B_{6}$ is important for many physiological functions, being a coenzyme in reactions that are involved in amino acid, carbohydrates and lipid metabolism and neurotransmitter 
synthesis. Vitamin $B_{6}$ supplements are one of the most used supplements. Recently, Lareb published a report concerning the side effects of vitamin $B_{6}$ supplements. Since 2014, more than 50 cases of sensory neuronal pain were reported after taking vitamin $B_{6}$ supplements in the Netherlands. These complaints are similar to those observed in people with a vitamin $\mathrm{B}_{6}$ deficiency. However, the molecular mechanism of vitamin $\mathrm{B}_{6}$ induced toxicity is unknown. In Chapter 6 the neuropathy observed after taking a relatively high dose of vitamin $B_{6}$ supplements is examined. Our results indicate that vitamin $B_{6}$ toxicity is caused by competition between the active pyridoxal- $5^{\prime}$-phosphate and the inactive pyridoxine. Pyridoxine induced cell death in human neuroblastoma cells, whereas pyridoxal-5'phosphate prevented cell death induced by pyridoxine. On a molecular level, pyridoxine can inhibit pyridoxal-5'-phosphate dependent processes, since we found that pyridoxine inhibited the enzyme activity of two pyridoxal-5'-phosphate dependent enzymes. As a consequence, the paradox arises that the symptoms of vitamin $B_{6}$ supplementation are similar to those of vitamin $B_{6}$ deficiency.

\section{Overall conclusion}

Although the expectations of food supplements are very high, the number of adverse events involving these supplements is increasing. These adverse events are often caused by over-consumption of food supplements and by interactions with other food supplements or drugs. It is therefore important to evaluate their benefits and risks in an accurate benefit-risk assessment. In the future, more attention should be paid to the adverse effects of food supplements, including supplement-drug interactions, which could lead to serious adverse events. Additionally, a good education of consumers and healthcare professionals in the field of food supplements is essential to provide them with the right information and to prevent serious side effects due to food supplements. 




\title{
Chapter 8
}

\author{
Summary
}

Samenvatting

Valorisatie addendum

Dankwoord

\author{
Curriculum Vitae \\ List of publications
}




\section{Samenvatting}

Het doel van dit proefschrift is om mogelijke negatieve effecten van voedingssupplementen te identificeren, al dan niet gecombineerd met medicijnen of andere supplementen. De wereldbevolking is snel aan het vergrijzen. Dit leidt tot een toename in behoeftes in de medische en sociale zorg. Naast medicatie, wordt voeding meer en meer gebruikt als een middel voor het behoud en de bevordering van de gezondheid en de behandeling van ziekten. Nutraceuticals, welke bioactieve stoffen zijn die uit voeding worden afgeleid, worden ontwikkeld om de gezondheidstoestand van mensen verbeteren. Onder nutraceuticals vallen ook de voedingssupplementen. $\mathrm{Er}$ heeft een enorme toename plaatsgevonden in het gebruik van voedingssupplementen over de afgelopen jaren. Het aantal voedingssupplementen, dat wordt aangeboden door winkels, supermarkten en online winkels is enorm. Van al deze supplementen wordt beweerd dat ze de verbetering van de gezondheid stimuleren of helpen bij ziektebestrijding. De enorme toename in het gebruik van voedingssupplementen is gebaseerd op de algemene opinie dat deze producten gezond zijn en dat producten van natuurlijke oorsprong per sé veilig zijn. De algemene perceptie van mensen over voedingssupplementen is dat ze alleen maar voordelen hebben, terwijl zij zich niet bewust zijn van potentiële risico's. Nadelige effecten van voedingssupplementen, die bijvoorbeeld worden veroorzaakt door interacties met geneesmiddelen, worden nauwelijks onderzocht. Ons onderzoek identificeert potentiële nadelige gevolgen van voedingssupplementen en toont aan dat de perceptie dat voedingssupplementen alleen gunstige effecten hebben, onjuist is.

\section{Perceptie van antioxidanten}

Voornamelijk voor antioxidanten zijn de verwachtingen zeer hoog. Antioxidanten worden beschouwd als belangrijk middelen in de bescherming tegen oxidatieve stress en veroudering. Veel voedingssupplementen zijn beschikbaar die rijk zijn aan antioxidanten. Deze worden op grote schaal gebruikt met het idee dat antioxidanten alleen maar gezond zijn. Bovendien wordt het gebruik van alle soorten van antioxidanten in hoge dosering aanbevolen voor suppletie. In hoofdstuk 2 wordt de veranderende perceptie over de gezondheidseffecten van antioxidanten besproken, aan de hand van twee voorbeelden, namelijk vitamine $E$ en $\beta$-caroteen. Vitamine $E$ is een antioxidant dat is aangetoond vele gunstige gezondheidseffecten te hebben. $\beta$-caroteen daarentegen wordt over het algemeen beschouwd als toxisch, sinds de ATBC studie in 1994 werd gepubliceerd. In onze studie werd opmerkelijk gevonden dat beide antioxidanten een soortgelijke toxiciteit vertoonden in cellen die blootgesteld werden aan BPDE. Dit wordt verklaard door de remming van het beschermende enzym GST $\pi$. Op basis van deze bevindingen kan worden geconcludeerd dat zowel vitamine $E$ en $\beta$-caroteen toxische effecten hebben in combinatie met elektrofiele verbindingen, die aanwezig zijn in sigarettenrook of koolteer crème. Suppletie van antioxidanten hoeft niet noodzakelijk gunstig te zijn en natuurlijke oorsprong is geen garantie voor veiligheid. Het is daarom belangrijk om een nauwkeurige baten-risicoanalyse te maken. 


\section{Nadelige interacties tussen voedingssupplementen en geneesmiddelen}

Suppletie van voedingssupplementen kan leiden tot nadelige effecten op de gezondheid. Voornamelijk ouderen zijn meer vatbaar voor de nadelige effecten van voedingssupplementen, aangezien er zich in ouderen een afname van de structuur en functie van organen en orgaansystemen voordoen. Bovendien komt het gelijktijdige gebruik van meerdere medicijnen ook voor bij ouderen, wat de kans op geneesmiddelinteracties met supplementen verhoogt. De belangrijkste soorten interacties tussen geneesmiddelen en voedingssupplementen zijn farmacodynamische interacties en farmacokinetische interacties. In hoofdstuk 3 hebben we een farmacodynamische interactie tussen het voedingssupplement, quercetine, en een medicijn, tamsuolosine, op geïsoleerde mesenteriale slagaders besproken. Een veel voorkomende leeftijd gerelateerde ziekte is benigne prostaathyperplasie (BPH). Naarmate mannen ouder worden, zijn ze meer kans om prostaat problemen te ontwikkelen. Alfa-adrenergische receptor blokkerende middelen zoals tamsulosine worden gebruikt voor de behandeling van BPH. Hoewel het tamsulosine effect gercith is op $\alpha 1 \mathrm{~A}$-adrenoceptoren in de prostaat, zal het ook de $\alpha_{1 A^{-}}$en $\alpha_{1 D^{-}}$ adrenoceptoren in de vasculatuur blokkeren. Onze resultaten laten zien dat de combinatie van tamsulosine met quercetine of quercetine metabolieten veel sterkere effecten hadden dan de verbindingen afzonderlijk. Er werd aangetoond dat het supplement quercetine de antagoniserende effecten van het geneesmiddel tamsulosine op de $\alpha 1$-adrenoceptor sterk versterkt. De sterke farmacodynamische interactie tussen het voedingssupplement quercetine en tamsulosine onderstreept de impact van supplement-interacties met andere geneesmiddelen die meer onderzoek rechtvaardigen.

\section{Anticholinergische stapeling}

Anticholinerge effecten van geneesmiddelen ontstaan door het blokkeren van cholinerge neurotransmissie, in het bijzonder door blokkeren van de muscarine receptoren in de hersenen. Deze receptoren spelen een belangrijke rol bij talrijke processen, waaronder cognitie en beweging. In 2008 werd de Anticholinergica Cognitive Burden (ACB) schaal ontwikkeld, waarin drugs worden gecategoriseerd op basis van hun anticholinerge werking. In hoofdstuk 4 wordt aangetoond dat de affiniteit van de geneesmiddelen voor de muscarine receptoren goed correleerden met hun ACB scores. Wij laten zien dat voedingssupplementen ook het vermogen hebben om aan deze receptoren te binden. $\mathrm{Er}$ werd aangetoond dat de combinatie van verschillende geneesmiddelen en supplementen een affiniteit had die hoger is dan de affiniteit van de afzonderlijke verbindingen. Dit verklaart het proces van anticholinergische stapeling. Geconcludeerd wordt dat de anticholinergische bijwerking van een enkele verbinding, bijvoorbeeld een geneesmiddel of een voedingssupplement, vaak relatief mild. Echter, wanneer meerdere verbindingen tegelijkertijd worden ingenomen, zullen meer van de receptoren worden geblokkeerd, waardoor het effect en daarmee de potentiële anticholinergische bijwerking verergerd wordt. 


\section{IJzer supplementen en magnesium peroxide}

Veroudering gaat ook gepaard met veranderingen in het maag-darmkanaal, zoals een verminderde opname van voedingsstoffen en een stijging van het risico op gastrooesofageale refluxziekte. Vanwege de verminderde opname van voedingsstoffen, komt ondervoeding veel voor bij bejaarden. Bovendien is ijzertekort de meest voorkomende voedingstekorten wereldwijd, met ouderen als groep met de hoogste prevalentie van dit tekort. Om het ijzer niveau op peil te houden, worden ijzersupplementen vaak gebruikt. Talrijke hoeveelheden van ijzersupplementen zijn beschikbaar op de markt, elk met relatief hoge doseringen ijzer. In hoofdstuk 5 hebben we ons gericht op de potentieel gevaarlijke interactie tussen ijzersupplementen en magnesium peroxide. In onze studie is aangetoond dat ijzersupplementen de vorming van hydroxyl radicalen induceert. Dit effect werd vergroot door magnesium peroxide, een antacidum dat beschikbaar is als zelfzorgmedicijn. Dit is een voorbeeld van een interactie tussen een voedingssupplement en een zelfzorgmedicijn, wat aangeeft dat ook het gebruik van zelfmedicatie kan leiden tot gevaarlijke interacties.

\section{Vitamine B6}

Vitamine B6 speelt een belangrijke rol in veel fysiologische processen, aangezien het een co-enzym is dat in veel reacties betrokken is, zoals in het metabolisme van aminozuren, koolhydraten en vetmetabolisme en neurotransmitter synthese. Vitamine B6 supplementen zijn een van de meest gebruikte supplementen. Onlangs heeft Lareb een rapport gepubliceerd over de bijwerkingen van vitamine B6 supplementen. Sinds 2014 werden meer dan 50 gevallen van sensorische neuronale pijn gemeld na het nemen van vitamine B6 supplementen. Deze aandoeningen komen overeen met die waargenomen bij mensen met een tekort aan vitamine B6. Het moleculaire mechanisme van vitamine B6 geïnduceerde toxiciteit is echter niet bekend. In hoofdstuk 6 wordt de vitamine B6geinduceerd neuropathie onderzocht. Onze resultaten geven aan dat vitamine B6 toxiciteit wordt veroorzaakt door competitie tussen de actieve pyridoxal-5'-fosfaat en inactieve pyridoxine. Toevoeging van pyridoxine leidde tot celdood van humane neuroblastoma cellen, terwijl pyridoxal-5'-fosfaat deze door pyridoxine geïnduceerde celdood kon voorkomen. Op moleculair niveau kan pyridoxine pyridoxal-5'-fosfaat-afhankelijke processen remmen, wat bevestigd wordt door onze bevinding dat pyridoxine de enzymactiviteit van twee pyridoxal-5'-fosfaat-afhankelijke enzymen remde. Hierdoor ontstaat de paradox dat de symptomen veroorzaakt door vitamine B6 supplementen vergelijkbaar zijn met die van vitamine B6-deficiëntie.

\section{Algemene conclusie}

Hoewel de verwachtingen van voedingssupplementen erg hoog zijn, is het aantal ongewenste voorvallen waarvan deze supplementen de oorzaak zijn, toegenomen. Deze bijwerkingen worden vaak veroorzaakt door overconsumptie van voedingssupplementen en door interacties met andere voedingssupplementen of geneesmiddelen. Daarom is het belangrijk om de voordelen en risico's in een nauwkeurige baten-risico analyse te evalueren. In de toekomst moet er meer onderzoek worden gedaan naar de negatieve 
effecten van voedingssupplementen, inclusief supplement-medicijn interacties, wat kan leiden tot ernstige bijwerkingen. Daarnaast is een goede informatievoorziening aan de consumenten en beroepsbeoefenaren in de gezondheidszorg op het gebied van voedingssupplementen essentieel om hen te voorzien van de juiste informatie en zo ernstige bijwerkingen als gevolg van voedingssupplementen te voorkomen. 



\title{
Chapter 8
}

\author{
Summary
}

\section{Samenvatting}

\section{Valorisatie addendum}

Dankwoord

\author{
Curriculum Vitae \\ List of publications
}




\section{Valorisatie addendum}

De Nederlandse bevolking vergrijst. Dit leidt tot een toename in behoeftes in de medische en sociale zorg. Naast de grote hoeveelheden medicijnen die ouderen slikken, worden voedingssupplementen ook steeds meer gebruikt om de gezond te worden en te blijven. Dit heeft geleid tot een zeer groot aanbod van vitaminesupplementen en kruidenpreparaten die gericht zijn op het verbeteren van de gezondheid. Voedingssupplementen zijn oorspronkelijk bedoeld als aanvulling op het dagelijkse dieet wanneer er een tekort was. Echter, ze worden nu ook steeds vaker gebruikt om gezond te blijven, waarmee het supplement eigenlijk meer een medicijn wordt.

Van voedingssupplementen wordt vaak gedacht dat ze altijd gezond en veilig zijn, vooral als het natuurlijke producten zijn. De consumenten denken dat voedingssupplementen alleen maar voordelen hebben, en zijn zich niet bewust van potentiële risico's. Dit strookt niet met de praktijk. Ook supplementen hebben bijwerkingen. Het aantal bijwerkingen door supplementen neemt ook toe. Vanaf 2004 tot 2013, gingen er in de Verenigde Staten jaarlijks 23.000 mensen naar het ziekenhuis door het gebruik van voedingssupplementen. Meer dan 2000 mensen werden er jaarlijks opgenomen in het ziekenhuis na het gebruik van voedingssupplementen. Vaak ging het om mensen boven de 65 jaar. Meestal kwam het omdat er teveel supplementen werden gebruikt. Ook combinatie met medicijnen leidde vaak tot opnames in het ziekenhuis. Dergelijke Interacties tussen geneesmiddelen en voedingssupplementen kunnen ernstige gevolgen hebben. Tot op heden wordt er nauwelijks naar interacties gekeken. Dit komt omdat er onvoldoende naar dergelijke interacties wordt gekeken. Mede daarom kan er geen goede afweging gemaakt worden tussen het voordeel en het nadeel van het gebruik van voedingssupplementen en is het belangrijk om een goede baten-risico beoordeling te maken.

Het onderzoek beschreven in dit proefschrift is gericht op de bijwerkingen voedingssupplementen, waaronder mogelijke interacties met medicijnen. Dit is gedaan in opdracht van de Nederlandse Voedsel- en Warenautoriteit (NVWA). De resultaten zijn van belang voor zowel consumenten, de gezondheidzorg als overheidsinstellingen die op de veiligheid van voedingssupplementen toezien. Het onderzoek toont aan dat het combineren van voedingssupplementen met medicijnen bijwerkingen kan geven. Door met een moleculaire benadering naar de overlap tussen voedingssupplementen en geneesmiddelen te kijken, kunnen interacties worden ontrafeld. Deze interactie tussen een geneesmiddel en een supplement werd onder andere onderzocht op de relaxatie van geïsoleerde bloedvaten en de binding op receptoren. Hiermee werd het mechanisme van de interactie in kaart gebracht. Hierdoor is het mogelijk om ook een onderbouwing van het risico van voedingssupplementen te krijgen. Naast de consumenten, is het ook belangrijk om werkers in de gezondheidszorg goed te informeren over de bijwerkingen van voedingssupplementen.

Meestal vertellen patiënten hun huisarts niet dat ze voedingssupplementen gebruiken. Hierdoor kan een mogelijke interactie tussen voedingssupplementen en het medicijn dat de arts voorschrijft niet worden voorkomen. Bovendien weten artsen te weinig over de 
interacties tussen geneesmiddelen en voedingssupplementen. Door zowel consumenten als werkers in de gezondheidszorg (met name artsen) goed voor te lichten over interacties tussen geneesmiddelen en voedingssupplementen, kunnen de risico's op bijwerkingen verkleind worden. $\mathrm{Er}$ is dus nog veel verbetering mogelijk bij de communicatie van mogelijke risico's naar consumenten en professionals in de gezondheidszorg.

Het onderzoek is ook relevant voor de voedingsindustrie en de overheid. Veel bijwerkingen van voedingssupplementen treden vooral op als gevolg de dosis te hoog is. Het is daarom belangrijk om goed toe te zien op de doseringen van voedingssupplementen. Dit wordt in het proefschrift geïllustreerd met vitamine B6. De Aanbevolen Dagelijkse Hoeveelheid $(A D H)$ van vitamine B6 voor volwassen mannen en vrouwen is 1,5-1,7 mg per dag. De veilige bovengrens is gesteld op $25 \mathrm{mg}$ per dag door EFSA. De voedingssupplementen op de markt hebben een dosering tot $250 \mathrm{mg}$. Bij het Lareb zijn de afgelopen jaren steeds meer klachten binnen gekomen bij het (langdurig) gebruik van deze supplementen. Na aanleiding hiervan en ondersteund door het onderzoek in het huidige proefschrift, heeft het NVWA recent besloten om de maximale hoeveelheid van vitamine B6 in voedingssupplementen te verlagen tot $21 \mathrm{mg}$.

Het proefschrift beschrijft enkele mogelijke nadelige effecten van voedingssupplementen, gebaseerd op de moleculaire werking. Het toont dat voedingssupplementen niet per sé goed zijn voor de gezondheid. Er is een noodzaak om voor voedingssupplementen een goede baten-risico analyse te maken. Hiervoor is in de toekomst meer onderzoek nodig om consumenten zo goed mogelijk te kunnen informeren en beschermen. 



\title{
Chapter 8
}

\author{
Summary
}

Samenvatting

Valorisatie addendum

Dankwoord

\author{
Curriculum Vitae \\ List of publications
}




\section{Dankwoord}

In 2013 begon ik aan mijn promotieonderzoek. Nu, bijna 4 jaar later begin ik met het schrijven van het laatste, maar meest gelezen deel van het boekje, het dankwoord. Dit proefschrift zou er niet zijn geweest zonder de hulp van een heleboel mensen, die ik dan ook graag persoonlijk wil bedanken.

Allereerst wil ik mijn dank en waardering uitspreken voor het promotieteam: Aalt, Antoon, Guido en Eugène. Bedankt voor de kans die jullie mij geboden hebben om dit promotietraject te volgen. Vanaf de eerste dag was het fijn om met jullie samen te werken en heeft jullie enthousiasme me altijd goed weten te motiveren. Zonder jullie hulp was dit boekje er nooit geweest!

Aalt, als promotor heb ik ontzettend veel van je geleerd. Niet alleen op wetenschappelijk gebied, maar ook op persoonlijk gebied. Jouw ontzettende enthousiasme en hoeveelheid kennis tijdens de wekelijkse besprekingen hebben me altijd enorm gemotiveerd. Problemen en stress bestaan voor jou niet, iets waar ik toch wel jaloers op ben. Als er ook maar iets tegenzat of niet ging zoals verwacht, kwam jij altijd heel rustig met een oplossing, waarmee je de situatie zo draaide dat er toch nog iets positiefs uitkwam. Naast wetenschappelijke onderwerpen tijdens de besprekingen, werd er ook over van alles en nog wat gesproken. Zo heb je mij ook nog veel bijgeleerd over literatuur, geschiedenis, films en noem maar op. Bedankt!

Antoon, bedankt voor de kans en het vertrouwen die je mij hebt gegeven tijdens het onderzoek. Ondanks je drukke agenda, was je altijd beschikbaar en geïnteresseerd in niet alleen het onderzoek, maar ook in mij persoonlijk. Jouw begeleiding, adviezen en enthousiasme hebben me enorm geïnspireerd. Ik heb waardering voor de grote hoeveelheid kennis die je hebt en de manier waarop je die kennis overdraagt. Ontzettend bedankt voor de kans die jullie me geven om mezelf verder te gaan ontwikkelen in het onderzoek!

Guido, jouw deur staat altijd open voor je aio's. Altijd had je antwoorden op mijn vragen, altijd had je weer nieuwe ideeën. Daarnaast had je altijd advies en suggesties bij het schrijven van de artikelen, dank daarvoor! Ook de gesprekken over andere dingen naast het werk waren vaak erg interessant.

Eugène, heel erg bedankt voor de hulp tijdens mijn onderzoek. Ook al hebben we niet heel vaak samengezeten, je vragen en suggesties hebben mij altijd goed geholpen tijdens het onderzoek en het schrijven van de artikelen.

Ik wil ook graag de leden van de beoordelingscommissie, Prof. dr. T.M. Hackeng, Prof.dr.ir. I.C.W. Arts, Prof. dr. P.W. de Leeuw, Dr. H. Deluyker en Prof. dr. R. Witkamp bedanken voor het beoordelen van mijn proefschrift.

Dan zijn er natuurlijk een heleboel (oud) collega's die ik graag zou willen bedanken. Dit zijn er nogal een aantal geweest in de afgelopen vier jaren, dus ik hoop dat ik niemand vergeet. 
Om te beginnen mijn kamergenoten vanaf het moment dat ik begonnen ben: Roger $\mathbf{B}$. en Leonie. Ze zeggen wel eens dat het belangrijk is dat je kamergenoten hebt met wie je goed overweg kunt. Dit was bij ons totaal geen probleem. Vanaf de eerste dag dat ik begonnen ben, voelde het alsof ik al jaren op de kamer zat. ledere ochtend begonnen we met een 'Feel good' liedje, die we om en om mochten uitkiezen. Het liedje wat me toch wel het meeste bijgebleven is: 'Romeo - I'm coming home', welke jullie (en vooral Leonie) uit volle borst meezongen. Het samen organiseren van verschillende uitjes, zoals de dagjes uit, de darttoernooien, het pooltoernooi, het badmintontoernooi, de Thembi-avonden, een middagje Snowworld en de kerstdiners zorgden altijd voor veel gezelligheid en een goede sfeer op de afdeling. Mede dankzij jullie kwam ik altijd met ontzettend veel plezier naar mijn werk.

Leonie, vanaf het beginnen hadden we een goede klik. Jij begon meestal al tussen 7.00 8.00, dus als ik 's ochtends aankwam, was het meteen gezellig beginnen. De fijne gesprekken (over van alles en nog wat), lunches, koffie-pauzes, grappige filmpjes etc hebben me altijd goed gedaan. Ik wacht trouwens nog steeds op een re-match van de volleybal wedstrijd, die Roger en ik onterecht verloren hebben (omdat jullie last-minute de regels aanpasten van de wedstrijd) van jullie team (wat overigens een oneerlijke strijd was aangezien jullie 30 ervaringsjaren aan volleybalwedstrijden en trainingen hadden en Roger en ik welgeteld.. 0).Ook de vrijdagen dat Roger er niet was, waren altijd erg gezellig. Ik wil je hiervoor heel graag bedanken en jou en Mark heel veel geluk toewensen voor de toekomst!

Roger, sinds de eerste dag dat we kamergenoten waren, waren we niet alleen collega's, maar ook vrienden. Of zoals de Smos zou zeggen, was het een echte: 'Friendship'! Ik ben ontzettend vereerd dat je mijn paranimf wilt zijn. De vele momenten van ontspanning, zoals de lunches bij Van der Valk en Kwizzenjèr, hebben me altijd goed geholpen om er weer met volle energie tegenaan te kunnen gaan. Ook het bespreken en bekijken van alle onzin die op het internet stond, was altijd erg grappig. Daarnaast was het altijd fijn om na het werk even de werkstress van ons af te slaan op de tennisbaan of een drankje te doen bij Thembi. Onze competitiviteit, die niet alleen op de tennisbaan te zien was, was ook terug te zien in onze voorbereidingen op de darttoernooien en volleybalwedstrijden, waarbij we vaak in de pauzes nog even snel gingen trainen op kantoor. Ook de 'bier-omhalf vier', vaker wel iets later dan 'half vier' waren erg gezellig. Ja, zoals wel eens gezegd wordt: 'sommigen nemen het er van';-). Ook buiten het werk spraken we regelmatig af (met Els en Wendy) voor een etentje, een bioscoopje of een Mossel-avondje bij Ronnie. Bedankt voor alle hulp en adviezen die je mij als routinier op het gebied van paranimf hebt gegeven. Ik hoop dat we nog veel leuke momenten kunnen beleven!

Dan mijn tweede paranimf, Kevin. Toen ik in 2012 mijn stage liep op de afdeling Farmacologie, liep jij daar al rond als aio. Na de fusie tussen farmacologie en toxicologie, verhuisde je naar onze kant van de gang en raakte je meer betrokken bij onze aio-groep. Je hebt het zelfs geschopt tot 'Prins Kevin d'n ierste' met carnaval, wat een gedenkwaardige avond was (vooral voor jou). Vorig jaar was ik vereerd dat ik jou mocht bijstaan als paranimf op jouw promotie en nu ben ik heel blij dat jij mijn paranimf wilt zijn. Ook al ben je niet 
meer werkzaam op de afdeling, ik ben blij dat we nog steeds koffie- en lunchafspraken hebben. Bedankt voor alle hulp en adviezen bij de voorbereidingen van mijn promotie!

Ook belangrijk tijdens het promotietraject zijn de andere aio's. Toen ik in 2013 begon, kwam ik binnen in een warme aio-groep. Hiervoor wil de oud-aio's Kristien (bedankt voor de leuke gesprekken, de adviezen die je me altijd gegeven hebt en het beantwoorden van mijn vragen tijdens mijn aio periode), Danielle (bedankt voor je adviezen over het bezoeken van congressen), Erik (oftewel Partyboy, bedankt voor de gezellige periode in het lab), Matt (oftewel Kuusj, thanks for the entertainment and fun times at the department), Alie (bedankt voor de bijgewerkte klapper met 'things to do' voor de promotie en bedankt voor je adviezen en hulp betreffende BKO), Bregje, Agnieszka, en Max graag ontzettend voor bedanken. Jullie zorgden ervoor dat ik goed kon beginnen op de afdeling en met de lunches, koffie breaks en andere aio-uitjes was er altijd genoeg afleiding en ontspanning.

Daarnaast zijn er tijdens mijn aio-periode een hoop nieuwe aio's begonnen. Rianne en Mireille, jullie zijn beide ongeveer gelijktijdig begonnen aan jullie PhD als ik en zitten nu ook in de afrondende fase. Bedankt voor de gezellige tijd en heel veel succes met jullie eigen boekje en verdediging. Quan, thank you for all the amazing conversations we had. You always brought a big smile on my face with your funny jokes and amazing stories. I'm really happy to have met you. I'd like to wish you good luck with finishing your own thesis. Lots of luck and love also for your wife and your little girl! Carmen, na het vertrek van Roger en Leonie kwam jij bij op de kamer zitten. Ook al vertrok je vrij snel hierna naar 'the States', toch wil ik je bedanken voor de gezellige tijd! Jouw enthousiasme en enorm goede werkmentaliteit zijn een voorbeeld voor iedereen! Verder wil ik ook de andere aio's Gesiele, Charlotte, Timme, Sven, Philippe en Ming bedanken voor alle gezelligheid en ontspanning op de afdeling en tijdens de verschillende borrels. Jullie ook allemaal heel veel succes gewenst met jullie PhD.

Daarnaast wil ik ook de stagiaires die ik heb mogen begeleiden bedanken: Gerly, Nina, Aktar, Diana, Lukas en Ankie. Ik heb jullie allemaal met veel plezier begeleid. Jullie hebben mij goed geholpen en een goede bijdrage gehad aan mijn onderzoek!

Frederik-Jan en Roger G, bedankt voor jullie bijdrage en kritische blik op ons gezamenlijke artikel over vitamine E en beta-caroteen! Geja, bedankt voor je bijdrage aan ons vitamine B6 stuk.

Een speciaal bedankje voor Lou: Bedankt voor de DNA adduct metingen die je voor ons hebt uitgevoerd. Dit heeft bijgedragen aan een mooie publicatie. Daarnaast wil ik je graag bedanken voor de erg leuke gesprekken die we altijd hadden en voor de gezellige vrijdagmiddag borrels.

Verder wil ik alle andere collega's van de afdeling bedanken voor de samenwerking en voor de leuke periode: Antje, Gertjan, Alex, Sébastien, Caroline, Pieter, Jan, Agnes, Matthijs, Harry, Ben, Paul, Josephina, Agnieszka S, Khrystyna, Agnieszka B, Edwin, Marie-José, Ger, Jacques, Peter, Danielle en Lily. 
Dan wil ik graag nog Marie-Claire in het speciaal bedanken. In de afgelopen 4 jaar heeft $u$ ontzettend veel geregeld. Zonder $u$ zou de afdeling niet draaiende blijven. Naast het regelen van afspraken en administratieve zaken, hebben wij ook heel vaak leuke gesprekken over allerlei andere zaken gehad. $U$ had altijd goede adviezen voor mij en als ik ergens wat stress voor had, nam u die stress snel weg. Een hele grote merci voor alle hulp!

Verder zijn er nog een paar mensen van buiten de afdeling bedanken die het mogelijk maken om op de universiteit goed onderzoek te doen. Allereerst de mensen van het magazijn, in het speciaal Eddy de Haan. Bedankt voor de bezorging van alle stoffen en materialen die nodig waren voor de uitvoering van het onderzoek. Ook bedankt voor de altijd korte maar gezellige praatjes die we maakten. Daarnaast een grote dank voor de mannen van de spoelkeuken: Wil, Lei en Alex. Jullie zorgen er altijd voor dat wij als onderzoekers heel makkelijk ons werk kunnen doen, zonder om te hoeven kijken naar de schoonmaak en de sterilisatie van het glaswerk en andere lab benodigdheden. Als wij in het lab iets snel gesteriliseerd nodig hebben, zorgen jullie daarvoor. Chapeau hiervoor! Daarnaast wil ik jullie bedanken voor de erg leuke en gezellige vrijdagmiddag borrels, wat altijd een heel leuk begin van het weekend was. Bedankt voor de goede zorg! Als laatste Geraldine en Elly die er altijd voor zorgden dat we op goed opgeruimde en schoongemaakte kantoren en labs konden werken.

Naast de mensen binnen de universiteit, is het heel erg belangrijk om mensen om me heen te hebben buiten mijn werk om afleiding en ontspanning te hebben. Hiervoor wil ik graag een heel grote dankjewel zeggen tegen mijn vrienden, waarmee we al jaren een hechte groep vormen. Bedankt voor alle dagen (en vooral avonden) van ontspanning die we samen hebben meegemaakt (en nog mee zullen maken). Ik kan pagina's volschrijven om jullie te bedanken voor alles wat we samen gedaan hebben ter ontspanning en afleiding, maar daar ga ik dit wetenschappelijk boekje niet mee vullen. Nogmaals dank voor alles!

Uiteraard wil ik ook mijn familie heel erg bedanken. Mam en pap, Desi en Birgit, Chiron en Vera, bedankt dat jullie er altijd zijn. Ik ben dankbaar dat jullie me altijd steunen en geïnteresseerd zijn in wat ik nou toch allemaal onderzoek. Daarnaast wil ik graag mijn schoonouders, Frans en Regina, bedanken dat ik ook daar altijd terecht kan.

Mijn allerlaatste dank gaat uit naar mijn lieve vrouw, Wendy. Al bijna 10 jaar zijn wij samen en als ik terugkijk op wat wij allemaal bereikt hebben en gedaan hebben, voel ik alleen maar liefde, blijdschap en trots. Ik zou een heel boek kunnen schrijven over hoe dankbaar ik jou ben. Jij bent voor mij de afgelopen jaren de grootste steun en toeverlaat geweest. Het is niet altijd even makkelijk voor jou geweest als ik weer stress had over van alles en nog wat. Ik ben je eeuwig dankbaar voor al je steun, adviezen, goede zorg en dat je er altijd alles aan deed om de stress bij mij weg te nemen. Als ik het vertrouwen even helemaal kwijt was, was jij daar om ervoor te zorgen dat ik het vertrouwen toch weer terug kreeg. Je wist me altijd weer gerust te stellen. Dankzij jou heb ik dit boekje kunnen schrijven. Ik ben enorm trots op jou. Ik heb je lief! 



\section{Chapter 8}

Summary

Samenvatting

Valorisatie addendum

Dankwoord

Curriculum Vitae

List of publications 
Misha Francois Vrolijk was born on October 10th, 1989 in Maastricht, the Netherlands. After finishing secondary school at 'Porta Mosana College' in Maastricht, he enrolled in the bachelors program Molecular Life Sciences" at Maastricht University. Following his Bachelor Degree in 2011, he started with his master program Molecular Life Sciences. In 2013 he completed his Master Degree with an internship at the department of Pharmacology, Maastricht University. In 2013 he started his PhD project at the department of Toxicology, Maastricht University. During his PhD trajectory, he presented his work as a poster at several national and international conferences. The research performed during this project, under the supervision of prof. dr. A. Bast, prof. dr. A. Opperhuizen and prof. dr. G.R.M.M. Haenen, is described in this thesis. 




\section{Chapter 8}

Summary

Samenvatting

Valorisatie addendum

Dankwoord

Curriculum Vitae

List of publications 
1. Vrolijk MF, Opperhuizen A, Jansen EH, Bast A, Haenen GR. Iron Supplements and Magnesium Peroxide: An Example of a Hazardous Combination in Self-Medication. Basic Clin Pharmacol Toxicol. 2016 Oct;119(4):412-7.

2. Vrolijk MF, Opperhuizen A, Jansen EH, Godschalk RW, Van Schooten FJ, Bast A, Haenen GR. The shifting perception on antioxidants: the case of vitamin $E$ and $\beta$ carotene. Redox Biol. 2015;4:272-8.

3. Vrolijk MF, Haenen GR, Opperhuizen A, Jansen EH, Schiffers PM, Bast A. The supplement-drug interaction of quercetin with tamsulosin on vasorelaxation. Eur J Pharmacol. 2015 Jan 5;746:132-7.

4. Vrolijk MF, Opperhuizen A, Jansen EH, Bast A, Haenen GR. Anticholinergic Accumulation: A Slumbering Interaction between Drugs and Food Supplements. Basic Clin Pharmacol Toxicol. 2015 Dec;117(6):427-32.

5. Vrolijk MF, Opperhuizen A, Jansen EH, Hageman GJ, Bast A, Haenen GR. The Vitamin B6 Paradox: Supplementation of high concentrations of Pyridoxine leads to decreased vitamin B6 function. (Submitted)

6. Eugène Jansen, Piet Beekhof, Misha Vrolijk, Abdonas Tamosiunas, Dalia Luksiene and Migle Baceviciene. The effect on biomarkers of tissue toxicity of a low-dosed multivitamin and mineral supplement in human volunteers. (Submitted).

7. Lemmens KJ, Vrolijk MF, Bouwman FG, van der Vijgh WJ, Bast A, Haenen GR. The minor structural difference between the antioxidants quercetin and 4'Omethylquercetin has a major impact on their selective thiol toxicity. Int J Mol Sci. 2014 Apr 30;15(5):7475-84.

8. Bartholomé R, Salden B, Vrolijk MF, Troost FJ, Masclee A, Bast A, Haenen GR. Paracetamol as a Post Prandial Marker for Gastric Emptying, A Food-Drug Interaction on Absorption. PLoS One. 2015 Sep 9;10(9):e0136618.

9. Vrolijk, M.F., Haenen, Dr. G.R.M.M., Bast, Prof. dr. A., Opperhuizen, Prof. dr. A. en Jansen, Dr. E.H.J.M. Een voorbeeld van onderbelichte geneesmiddelvoedingssupplement interactie: Orthostatische hypotensie door tamsulosine en quercetine. Medisch Farmaceutische Mededelingen. 2015, editie 3. 

